\title{
ELECTROPHYSIOLOGICAL INTERACTIONS BETWEEN DISOPYRAMIDE AND ITS MAJOR METABOLITE, MONO-N-DEALKYLDISOPYRAMIDE, IN CANINE VENTRICULAR TISSUE
}

by

William Toy

\begin{abstract}
Department of Pharmacology \& Experimental Therapeutics McGill University, Montreal
\end{abstract}

May, 1990

A thesis submitted to the Faculty of Graduate Studies and Research in partial fulfillment of the requirements for the degree of Master of Science.

Copyright (c) William Toy, 1990

AFN 3297 
This thesis is dedicated to

my parents

for their tremendous love and support. 


\section{Organization of Thesis}

The core of this thesis is composed of a general introduction, two manuscripts, and a general summary and conclusions. The first manuscript which constitutes chapter 2 of the thesis is in press in the Journal of Pharmacology and Experimental Therapeutics. However, in order to be appropriately incorporated into the thesis this article has been modified. The second manuscript presented in chapter 3 , is in preparation for publication. For these two studies: the proposal; study design; experimentation; data analysis and interpretation; and dissertation of the two manuscripts and the thesis was principally the work of the author. 


\section{Acknowledgments}

I would express my gratitude and appreciation to all who have contributed to this thesis and who have made this work an enjoyable and enlightening experience. In particular, I would like to thank:

Dr. B.I. Sasyniuk, my thesis supervisor, for the opportunity of working in her laboratory and for her guidance, inspiration, and support throughout my studies.

Dr. A.C. Cue11o, chairman of the Department of Pharmacology and Experimental Therapeutics at McGill University, for tremendous support and interest in my scientific progress.

Dr. B. Collier, for his advice and opinions of the scientific field and on inany other topics.

Miss Maria Valois, for her many helpful insights on the subject of cardiac electrophysiology.

Mr. Richard T. Baker III, Mr. John Lewis and Miss Nancy Salbach for invaluable technical assistance.

The Fonds de la Recherche en Santé du Québec for providing financial support during my studies.

Finally, a special thanks to Miss Golda Tradounsky, my dearest friend, for her continuing love and friendship. 
Table of Contents

Organization of Thesis . . . . . . . . . . . . . . . . . . . . 1

Acknowledgments , . . . . . . . . . . . . . . . . . 2

Table of Contents . . . . . . . . . . . . . . . . . . 3

List of Tables... . . . . . . . . . . . . . . . . . 7

List of figures . . . . . . . . . . . . . . . . . . 8

General Abstract. . . . . . . . . . . . . . . . . . . 10

Résumé Général . . . . . . . . . . . . . . . . . . . . 12

Chapter 1 - Introduction . . . . . . . . . . . . . . . . . . . . . 14

1. Metabolites of Class I Antiarrhythmic Drugs . . . . . . . 15

1.1 Lidocaine, Quinidine and Flecainide . . . . . . . . 16

1.2 Procainamide, Encainide and Propafenone . . . . . . . . 19

1.3 Disopyramide . . . . . . . . . . . . . . 22

2. Class I Antiarrhythmic Drug Interactions . . . . . . . . 22

2.1 Theoretical Considerations

2.1.1 Therapeutic Synergism . . . . . . . . . . . 23

2.1.2 Competitive Displacement Interactions . . . . . . . . 24

2.1.3 Action Potential Duration . . . . . . . . . . 25

2.2 Experimental Investigations

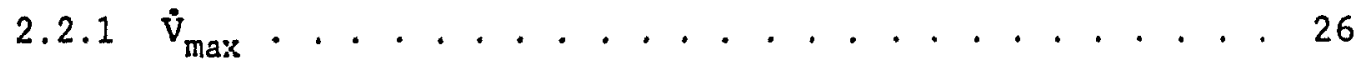

2.2.2 Action Potential Duration . . . . . . . . . . . . 30

2.3 Clinical Investigations . . . . . . . . . . . . 31

2.4 Interactions with Metabolites . . . . . . . . . . . . . 34

2.5 Proarrhythmic Antiarrhythmic Drug Interactions 
2.5.1 Ventricular Tachycardia and Slow Conduction .... . 35

2.5.2 Torsade de Pointex and Triggered Arrhythmias

2.5.2.1 Torsade de Pointes Arrhythmias in Patients ... . 35

2.5.2.2 Early Afterdepolarizations and Triggered Activity

In Vitro................... . 36

3. Objectives . . . . . . . . . . . . . . . . . 39

Chapter 2 - Frequency and Voltage Dependent Effects of

Mono-N-dealkyldisopyramide, the Major Metabolite of Disopyramide, in

Canine Ventricular Tissue . . . . . . . . . . . . . . . . 41

1. Abstract . . . . . . . . . . . . . . . . . . 42

2. Introduction . . . . . . . . . . . . . . . 44

3. Methods

3.1 Experimental Preparation ............... 45

3.2 Protocols . . . . . . . . . . . . . . 47

3.3 Drug . . . . . . . . . . . . . . . . 49

3.4 Data Analysis . . . . . . . . . . . . . 50

4. Results

4.1 Concentration dependent effects on action potential characteristics in Purkinje fibers... . . . . . . . 51

4.2 Effects of MND on action potential duration and effective refractory period during steady-state changes in basic cycle length

4.2.1 Purkinje fibers . . . . . . . . . . . . . . . . 51

4.2.2 Ventricular muscle . . . . . . . . . . . . 54

4.3 Effects on the kinetics of onset and magnitude of 
rate-dependent $\dot{\mathrm{V}}_{\max }$ depression . . . . . . . . . . 54

4.4 Characteristics of recovery from rate-dependent block . 57

4.5 Voltage-dependent effects ............. 61

5. Discussion . . . . . . . . . . . . . . . . . 65

Chapter 3 - Electrophysiological Interactions between Disopyramide and its Major Metabolite, Mono-N-dealkyldisopyramide, in Canine Ventricular Tissue . . . . . . . . . . . . . . . . . . 72

1. Abstract . . . . . . . . . . . . . . . 73

2. Introduction . . . . . . . . . . . . . . . 75

3. Methods

3.1 Experimental Preparation . . . . . . . . . . . . 77

3.2 Protocols . . . . . . . . . . . . . . . . . 78

3.3 Drugs . . . . . . . . . . . . . . . . . . . . 81

3.4 Data Analysis . . . . . . . . . . . . . . . . 81

3.5 Definitions . . . . . . . . . . . . . . . . . 82

4. Results

4.1 Effects at rapid stimulation rates

4.1.1 Effects on action potential characteristics in Purkinje fibers . . . . . . . . . . . . . . . 84

4.1.2 Drug-induced tonic and rate-dependent block . . . . . 84

4.1.3 Effects on action potential duration during abrupt decreases in cycle length . . . . . . . . . . 87

4.1.4 Characteristics of recovery from rate-dependent block 91 4.1.5 Effects on effective refractory period........ . 91 
4.2 Effects at slow stimulation rates

4.2.1 Action Potential Duration in the Absence of Triggered Activity . . . . . . . . . . . . . . 94

4.2.2 Early Afterdepolarizations (EADs) and Triggered Activity . . . . . . . . . . . . . . 96

4.2.3 Prevention and Abolition of Triggered Activity

4.2.3.1 MND . . . . . . . . . . . . . . 100

4.2.3.2 Mexiletine. . . . . . . . . . . . . 100

4.2.3.3 Pacing . . . . . . . . . . . . . . . 103

5. Discussion . . . . . . . . . . . . . . . . . 103

Chapter 4 - General Summary and Conclusions . . . . . . . . . . . . 112

Chapter 5 - References . . . . . . . . . . . . . . . 120 
List of Tables

Chapter 2

Table 1: Concentration dependent effects of MND on action potential characteristics in canine Purkinje fibers . 52

Table 2: Effects of interstimulus interval on the kinetics of onset and magnitude of rate-dependent $\dot{V}_{\text {max }}$ depression produced by MND . . . . . . . . . . . . . . 59

Chapter 3

Table 1: Effects of disopyramide, MND and their combination on action potential characteristics in canine Purkinje fibers ...................... 85

Table 2: Effects of the interaction between disopyramide and MND on action potential characteristics in canine Purkinjo fibers .................... . 86

Table 3: Effects of disopyramide, MND and their combination on the rate constant and magnitude of rate-dependent block 88 
List of Figures

Chapter 2

Figure 1: Effects of MND on rate dependent shortening of action potential duration in Purkinje fibers and ventricular muscle .................. 53

Figure 2: Cycle length dependent effects of MND on action potential duration and effective refractory period in Purkinje fibers and ventricular muscle... . . . . 55

Figure 3: Concentration dependent effects of MND on the kinetics of onset and magnitude of rate-dependent block. . . 56

Figure 4: Concentration dependent effects of MND on depression of $\dot{\mathrm{v}}_{\max }$. . . . . . . . . . . . . . . . . 58

Figure 5: Recovery of $\dot{\mathrm{v}}_{\max }$ and activation time with MND . . . 60

Figure 6. Concentration dependent effects of MND on the magnitude and time course of $\dot{\mathrm{V}}_{\max }$ recovery . . . . . . 62

Figure 7: Effects of MND on the relationship between $\dot{V}_{\max }$ and membrane potential ............... . . 64

Chapter 3

Figure 1: Effects of disopyramide and the combination of disopyranide and MND on tonic and rate-dependent block in Purkinje fibers................. . 89

Figure 2: Effects of disopyramide and the combination of disopyramide and MND on rate dependent changes in action potential duration in Purkinje fibers . . . . . 90 
Figure 3: Effects of disopyramide and the combination of disopyramide and MND on recovery of $\dot{V}_{\max }$. . . . . . . 92

Figure 4: Effects of disopyramide and the combination of disopyramide and MND on the effective refractory period in Purkinje fibers versus ventricular muscle . 93

Figure 5: Effects of disopyramide on the action potential duration-rate relationship in Purkinje fibers . . . . 95

Figure 6: Effects of cycle length on EADs and triggered activity induced by disopyramide . . . . . . . . . . . . 97

Figure 7: Differential effects by disopyramide on induction of triggered activity in Purkinje fibers versus ventricular muscle . . . . . . . . . . . . . 99

Figure 8: Effects of MND on EADs and triggered activity induced by disopyramide in Purkinje fibers . . . . . . . . . . 101

Figure 9: Effects of mexiletine on EADs and triggered activity induced by disopyramide in Purkinje fibers . . . . . . 102 
General Abstract

Mono-N-dealkyldisopyramide (MND), the major metabolite of disopyramide, reaches significant concentrations in patients; however, little is known about its electrophysiological effects. We therefore assessed its activity in canine ventricular tissue superfused in vitro. MND produced a concentration and rate dependent increase in the magnitude of $\dot{V}_{\max }$ depression. MND shortened all phases of repolarization in Purkinje fibers but prolonged action potential duration and effective refractory period in ventricular muscle.

We then assessed the effects of the combination of disopyramide and MND at clinically relevant concentrations. The combination produced additive effects on depression of $\dot{V}_{\max }$. MND accentuated the shortening of action potential duration in Purkinje fibers and the prolongation of refractory periods in both Purkinje fibers and ventricular muscle produced by disopyramide at normal heart rates.

In contrast, at slow stimulation rates and under predisposing electrolyte conditions, disopyramide produced a reverse use-dependent prolongation of action potential duration which led to the development of early afterdepolarizations and triggered activity in Purkinje fibers. Mexiletine and pacing abolished triggered activity, while MND shifted the incidence of triggered activity to longer cycle lengths.

The results suggest that MND, by depressing $\dot{\mathrm{V}}_{\max }$ and conduction velocity and prolonging refractory periods, enhances the effects of disopyramide and may have antiarrhythmic properties of its own. Its 
effects on disopyramide-induced triggered activity suggest that it may also reduce the arrhythmogenic potential of disopyramide. Therefore MND may contribute to either the antiarrhythmic or toxic actions of disopyramide. 
Résumé Général

Mono-N-déalkyldisopyramide (MND), le métabolite principal du disopyramide, atteint des concentrations significatives chez les patients; toutefois, ses effets électrophysiologiques sont peu connus. Nous avons par conséquent évalué ses effets dans les tissus ventriculaires canins superfusés in vitro. Le MND a provoqué une diminution de $\dot{V}_{\max }$ dont l'intensité était fonction de la concentration et de la fréquence d'entrainement. Le MND a raccourci toutes les phases de la repolarisation dans des fibres de Purkinje mais a prolongé la durée du potentiel d'action et la période réfractaire effective du muscle ventriculaire.

Nous avons ensuite évalué les effets de la combinaison du disopyramide et du MND $a$ des concentrations cliniquement pertinentes. La combinaison a provoqué des effets additifs sur la diminution de $\dot{\mathrm{V}}_{\max }$. Le MND a accentué le raccourcissement de la durée du potentiel d'action des fibres de Purkinje ainsi que la prolongation des périodes réfractaires des fibres de Purkinje et du muscle ventriculaire provoqués par le disopyramide à des fréquences cardiaques normales.

A l'opposé, à des basses fréquences de stimulation et sous des conditions d'électrolyte prédisposantes le disopyramide a provoqué une prolongation de la durée du potentiel d'action, en fonction inverse de la fréquence, qui a mené au développement de post-dépolarisations prématurées et d'activité déclenchée dans les fibres de Purkinje. La 
mexilétine et l'entrainement ont aboli l'activité déclenchée, tandis que le MND a déplacé l'apparition de l'activité déclenchée à des durées de cycle plus longues.

Les résultats suggèrent que le MND, en diminuant la $\dot{V}_{\text {max }}$ et $1 a$ vélocité de la conduction et en prolongeant les périodes réfractaires, accroit les effets du disopyramide et pourrait avoir ses propre propriétés antiarythmiques. Ses effets sur l'activité déclenchée induite par le disopyramide suggèrent qu'il pourrait aussi réduire le potentiel arythmogène du disopyramide. Par conséquent, le MND pourrait contribuer soit aux actions antiarythmiques ou toxiques du disopyramide. 
Chapter 1

Introduction 


\section{Metabolites of Class I Antiarrhythmic Drugs}

Many antiarrhythmic agents are extensively metabolized following administration to patients (Kates, 1984). These antiarrhythmic drugs, used in the treatment and prevention of life-threathening cardiac arrhythmias, also have low therapeutic indices. Therefore in those cases where significant metabolites are produced, it is essential to determine the pharmacological properties and disposition characteristics of both the parent drug and metabolite(s) for safe and optimal therapy. The presence of an active metabolite may, unpredictably, either potentiate the antiarrhythmic effects of the parent drug or alternatively increase the possibility of drug toxicity. These interactions complicate determination of the clinical efficacy of the parent antiarrhythmic agents.

Two important considerations which determine the significance of metabolites in the action of antiarrhythmic drugs are: i) the amount of accumulation and 2) intrinsic pharmacodynamic activities of the metabolites. Metabolites must be present in sufficient plasma concentrations and be pharmacologically active in order to produce any significant effects. With Class I antiarrhythmic agents (sodium channel blockers), while the pharmacologic properties of most drugs have not been fully determined, the extent of metabolism and plasma concentrations of metabolites during therapy have been measured for most. The plasma metabolite levels of most of these agents can reach or even exceed those of the parent drugs (Kates, 1984 and 1986). In 
addition, the concentration of metabolites may further increase in diseased states such as renal failure if renal excretion is a major elimination pathway. Such increases occur with the metabolites of procainamide (Drayer et al., 1977) and disopyramide (Aitio, 1981).

In this section, we review the pharmacological actions produced by the metabolites of various Class I antiarrhythmic agents. Most of these studies have evaluated the effects and relative potency of the metabolites compared to the parent drugs in in vivo and in vitro experinental models. The metabolism of the clinically available class I agents produce compounds which vary in their pharmacological profiles and thus their clinical significance in the therapeutic or toxic effects of antiarrhythmic drug therapy. One possible outcome of metabolism is the production of inactive metabolites. Both mexiletine and tocainide are examples of drugs which have no active metabolites (Pentikainen et al., 1982; Ronfeld et al., 1982).

\subsection{Lidocaine, Quinidine and Flecainide}

Other antiarrhythmic agents are metabolized into compounds which are active and may therefore contribute to the clinical efficacy or toxicity produced by the parent drug. The antiarrhythmic agents in this group include lidocaine, quinidine and flecainide (Kates, 1986). Significant plasma concentrations of metabolites with these agents may occur in subgroups of patients (because of large interindividual variability) or under certain conditions such as renal failure (for drugs in which renal excretion is a major elimination pathway). 
Lidocaine is metabolized to two important metabolites in man: monoethylglycylxylidide (MEGX) and glycylxylidide (GX) (Narang et al., 1978). MEGX has been shown to be equally or slightly less potent than lidocaine in suppressing experimentaily-induced ventricular arrhythmias in mice and dogs (Smith and Duce, 1971; Strong et al., 1975; Freedman et al., 1982) and arrhythmias in isolated guinea-pig atrium (Burney et al., 1974). GX also produced antiarrhythmic effects but was much less potent than lidocaine in the same studies by Strong et al. (1975) and Burney et al. (1974).

The effects produced by GX in vitro in the study of Bennett et al. (1988), however, suggest a possible mechanism by which it may reduce the clinical efficacy of lidocaine. The metabolite competitively displaced lidocaine in isolated guinea-pig ventricular myocytes at potentials between -80 and $-100 \mathrm{mV}$. This interaction could be explained by a modulated receptor model with two drugs competing for the same sodium channel receptor. In the presence of the combination, GX competitively displaced lidocaine from sodium channels due to its faster binding kinetics. Subsequent dissociation of GX from channels resulted in an increased in the sodium current compared to that with lidocaine alone. Thus under appropriate conditions, accumulation of the metabolite could prevent the sodium channel blocking effects (Class I action) of the parent drug.

Quinidine also has two important cardioactive metabolites in man: 3-hydroxy-quinidine (3-OH-Q) and $2^{\prime}$-oxo-quinidine (2'-oxo-Q) (Drayer et a1., 1978). The electrophysiologic effects of both metabolites are 
qualitatively similar to effects produced by quinidine (Thompson et al., 1987). All three compounds produced a use-dependent depression of $\dot{V}_{\max }$ and a reverse use-dependent prolongation of action potential duration (ie. action potential prolongation was greatar at slower stimulation rates) in canine Purkinje fibers. Like the parent drug, 3-OH-Q also induced early afterdepolarizations at very long cycle lengths. In experimental arrhythmia models, both metabolites were equipotent to quinidine in their antiarrhythmic efficacy against ventricular arrhythmias in mice, however, 3-OH-Q was less potent than quinidine or $2^{\prime}$-oxo-Q in rabbits (Drayer et a1., 1978). Vozeh et al. (1987) also showed that $3-\mathrm{OH}-\mathrm{Q}$ was less potent than quinidine against ventricular arrhythmias in isolated rat heart, but determined that the interaction between quinidine and $3-\mathrm{OH}-\mathrm{Q}$ produced additive effects.

The two major metabolites of flecainide in man are meta-0-dealkylated flecainide and the meta-0-dealkylated lactam of flecainide (Conard and Ober, 1984). Meta-0-dealkylated flecainide produced electrophysiological effects on conduction, refractoriness and experimental arrhythmias in anesthetized dogs and was approximately one-half as potent as flecainide (Guehler et al., 1985). The meta-0-dealkylated lactam of flecainide exhibited qualitatively similar but much weaker electrophysiological actions. 


\subsection{Procainamide. Encainide and Propafenone}

Lastly, there are examples of antiarrhythmics agents with which metabolites may be very important for clinical efficacy or toxicity during therapy. Procainamide is metabolized to the highly cardioactive compound $\mathrm{N}$-acetyl procainamide (NAPA) (Drayer et al., 1977). NAPA was effective against chronic high frequency ventricular ectopic depolarizations in a subset of patients resistant to procainamide (Roden et al., 1980). Atkinson et al. (1983) also showed that NAPA effectively suppressed ventricular ectopy during long-term treatment. The pharmacological actions of the metabolites of encainide: 0-demethyl encainide (ODE) and 3-methoxy-0-demethyl encainide (3MODE) (Kates et al., 1982), have also been evaluated directly in clinical trials. Both ODE and 3MODE suppressed chronic ventricular arrhythmias in patients (Barbey et al., 1988a).

The metabolism of procainamide to NAPA results in the loss of the Class I actions produced by procainamide while the Class III effects (action potential prolongation) are preserved (Singh et al., 1988). In canine Purkinje fibers and muscle, NAPA had no effects on $\dot{V}_{\max }$ and action potential amplitude but lengthened the action potential duration and effective refractory period (Bagwell et al., 1976; Dangman and Hoffman, 1981). Consistent with the in vitro finding that NAPA does not depress $\dot{V}_{\max }$, the QRS interval was not affected, while atrial and ventricular refractory periods and the $\mathrm{QT}_{\mathrm{c}}$ int 'rval were increased in vivo in anesthetized dogs (Amlie et al., 1978; Jaillon and Winkle, 1979; Boucher et al., 1987). 
The antiarrhythmic efficacy of NAPA is also demonstrated in animal arrhythmia models. NAPA provided protection against ventricular arrhythmias in mice (Drayer et al., 1974; Elson et al., 1975), dogs (Bagwell et al., 1976; Reynolds and Kamath, 1979) and rabbits (Minchin et al., 1978), and atrial arrhythmias in dogs (Drayer et al., 1974). The metabolism of procainamide to NAPA produces an effective antiarrhythmic agent with only Class III electrophysiological effects and a different clinical antiarrhythmic spectra compared to procainamide (Roden et al., 1980).

Several studies suggest that the metabolites of encainide may be responsible for the clinical efficacy or toxicity of encainide in most patients (Roden et al., 198?; Duff et al., 1983a; Barbey et al., 1988a). The electrophysiologic actions of $O D E$ and $3 M O D E$ are qualitatively similar to those produced by encainide. ODE was more potent than encainide in depressing $\dot{\mathrm{V}}_{\max }$ (Elharrar and Zipes, 1982), slowing conduction velocity (Dresel, 1984; Davy et al., 1986) and suppressing experimental animal arrhythmias (Roden et al., 1982; Kerr et al., 1985). 3MODE was either of similar or greater potency than encainide in the same studies. In patients, during long term oxal therapy with encainide, the ievels of the metabolites greatly exceed that of the parent drug (Kates et al., 1982). In addition, arrhythmia suppression in patients correlate better with concentrations of ODE than encainide (Carey et al., 1981). Thus, the available data suggest that ODE and 3MODE are of clinical importance. The efficacy or toxicity of encainide may be due to or greatly modulated by its metabolites. 
Finally, propafenone undergoes extensive metabolism (Siddoway et al., 1984) to produce two metabolites found in the plasma of patients during chronic therapy: 5-hydroxy-(5-OH-) propafenone and $\mathrm{N}$-depropyl(N-DP-) propafenone (Kates et al., 1985). The plasma ratio of propafenone : 5-OH-propafenone : $\mathrm{N}-\mathrm{DP}-\mathrm{propafenone}$ is approximately $10: 2: 2$. However, Latini et al. (1987) showed that the myocardium/plasma partition ratio for 5-OH-propafenone is five time greater than for propafenone. Thus this metabolite is concentrated in the heart to a similar extent as the parent drug.

Like the parent drug, the primary electrophysiological effect of the metabolites in vitro is a rate-dependent depression of $\dot{\mathrm{v}}_{\mathrm{max}}$ (Thompson et al., 1988; Malfatto et al., 1988; Rouet et al., 1989). Both metabolites suppressed experimentally-induced ventricular arrhythmias in vivo in rats and dogs (Philipsborn et al., 1984; Malfatto et al., 1988; Oti-Amoako et al., 1990). In both in vitro and in vivo experimental models, 5-OH-propafenone has a similar potency compared to the parent drug while that of the N-DP metabolite is much smaller than propafenone. In addition to Class I activity, propafenone also displays Class II (beta-adrenoceptor blocking) and Class IV ( $\mathrm{Ca}^{2+}$ antagonist) antiarrhythmic actions at higher concentrations (Ledda et al., 1981; Dukes and Vaughan Williams, 1984). 5-OH-propafenone also displays beta-adrenoceptor blocking and $\mathrm{Ca}^{2+}$ antagonist effects at higher concentrations (Philipsborn et al., 1984; Delgado et a1., 1987). Thus the metabolites of propafenone also exhibit Class I, II and IV 
antiarrhythmic actions and may be responsible for some of the antiarrhythmic or arrhythmogenic effects previously ascribed to propafenone.

\subsection{Disopyramide}

The Class Ia agent disopyramide is primarily metabolized in man by hepatic N-dealkylation to mono-N-dealkyldisopyramide (MND) (Karim, 1975). MND decreased the maximum atrial driving frequency suggesting that it lengthened refractory periods in vitro (Grant et al., 1978) and in vivo (Dubray et al., 1986), and prevented atrial arrhythmias in a canine model (Baines et al., 1976). However, more precise definition of the pharmacological activities of this metabolite have not been previously undertaken.

\section{Class I Antiarrhythmic Drug Interactions}

The electrophysiological interactions which occur between Class I antiarrhythmic drugs and cardiac cells or other Class I agents have been previously investigated in experimental and clinical studies. Some theoretical principles useful in understanding and predicting the outcome of these interactions have been piesented by Hondeghem (1987). In this section, we review these principles, and experimental and clinical investigations within the framework of antiarrhythmic drug interactions. 


\subsection{Theoretical Considerations}

\subsubsection{Therapeutic Synergism}

Class I antiarrhythmic drugs have characteristic time constants of recovery from depression of $\dot{V}_{\max }$ or reduction of the sodium current (Courtney, 1980 and 1987). These time constants range from very fast for Class Ib agents (hundreds of msec) to very slow for Class Ic agents (tens of $\mathrm{sec}$ ). Hondeghem and Katzung (1980) predicted that the combination of drugs with different kinetics of interaction with the sodium channel could provide a diastolic block that was not attainable by either agent alone. The combination of a slow with a fast drug could provide a more effective depression of early extrasystoles or tachycardias, while depression of impulses at normal heart rates would not be much greater than that produced by the slower agent alone. In the presence of the combination, both drugs would contribute to the block of sodium channels at the beginning of diastole. Block produced by the fast drug, however, would subsequently recover during diastole. Also, since such drug combinations may increase the magnitude of depression, lower concentrations of the individual agents would be required for antiarrhythmic efficacy thereby reducing the likelihood of potential adverse side effects. The combination of two drugs with very similar recovery kinetics, however, would not be of any great benefit beyond that of an increase in the total drug concentration. In fact, in the case of two slow agents, excessive depression of normal beats inay 
lead to drug toxicity. These concepts have provided a rational basis for the use of antiarrhythmic drug combinations to produce therapeutic synergy.

\subsubsection{Competitive Displacement Interactions}

Class I antiarrhythmic drugs have been postulated to bind to a specific receptor site on or very close to the transmembrane sodium channel (Hondeghem and Katzung, 1984). If the interaction of agents with the sodium channel is specific, then competition between two drugs should be possible at certain stimulation rates. The addition of a drug with a shorter time constant of recovery to a drug with a longer time constant could reduce the block of sodium channels and increase the sodium current through competitive displacement interactions. The slower agent must be present at a high enough concentration to block a significant fraction of sodium channels per action potential and a have a time contant short enough to result in significant unblocking during diastole. Under these conditions, addition of a faster drug may displace the slower agent from sodium channel receptors, recover more quickly and reduce the magnitude of block during diastole. Such interactions would argue against a nonspecific membrane disturbance model in which addition of a second drug would always increase the block of sodium channels. 
If the recovery time constant of the slower agent is too long, however, then the fraction of blocked channels which could be competitively displaced with each action potential would be very small. In this situation, block would not be reduced.

State-dependent binding of the individual drugs to the sodium channel can also be an important consideration with these competitive interactions. Clinically useful class I drugs have a low affinity for sodium channels in the resting state and a high affinity for those in the activated and/or inactivated states (Hondeghem and Katzung, 1984). Consequently, block develops with each action potential and recovery from block occurs during diastole. Since the activated state occurs before the inactivated state, open channel blockers will sequester channels first and have an advantage over inactivated channel blockers. Similarly, for two drugs which have a large affinity for the same channel state, the faster blocker will have an advantage over the slower one.

\subsubsection{Action Potential Duration}

The effects of Class I antiarrhythmic drugs on action potential duration may also have an influence on their effectiveness in blocking sodium channels. Drugs which preferentially block open channels will not be affected by changes in action potential duration. However, since changes in repolarization alters the amount of time the sodium channel remains in the inactivated state, the action of inactivation blockers may be modified by drug effects on action potential repolarization. 


\subsection{Experimental Investigations}

\section{$2.2 .1 \dot{v}_{\max }$}

The mechanism by which Class I antiarrhythmic drug combinations produce therapeutic synergy has been demonstrated in vitro. Hondeghem and Katzung (1980), using $\dot{\mathrm{V}}_{\max }$ as an index of sodium channel block, demonstrated that the combination of a faster and a slower agent (lidocaine and quinidine, respectively) produced a large depression of early extrasystoles while smaller effects were observed on impulses at a normal steady-state rate of $1 \mathrm{~Hz}$. Other combinations of kinetically different drugs investigated in vitro include: quinidine plus tocainide (Valois and Sasyniuk, 1987) or mexiletine (Roden et a1., 1987), and propafenone plus mexiletine (Valenzuela et al., 1989). All these studies demonstrate that such drug combinations can produce a more effective depression of early premature impulses or those elicited at rapid heart rates compared to effects with single agents, while depression of $\dot{V}_{\max }$ at normal heart rates is smaller.

Frequency dependent interactions have also been observed on steady-state conduction in vivo in the presence of the combinations of mexiletine plus quinidine (Bajaj et al., 1987) or lidocaine plus quinidine or flecainide (Pallandi and Campbell, 1988). Myocardial conduction with the combinations at normal heart rates were similar to effects with the slower agents alone, but very rapid pacing further slowed conduction. Enhanced antiarrhythmic efficacy has also been demonstrated experimentally with drug combinations in vivo in dogs 
following ischemic injury. The combination of quinidine and mexiletine was significantly more effective than monotherapy against induction of ventricular tachycardia (Duff, 1989).

Although the combination of drugs with different kinetics of interaction with the sodium channel can produce a therapeutic synergy (eg. selective depression of premature beats or tachycardias and/or reduced drug toxicity), the pharmacological interactions between these agents when present in low to moderate concentrations generally produced additive effects. That is, when the cycle length dependencies of individual drug actions are considered, the effects of the combinations on depression of $\dot{V}_{\max }$ in vitro or slowing of conduction in vivo can be accounted for by the sum of the individual drug effects (Fransen et al., 1984; Kohlhardt and Seifert, 1985; Valois and Sasyniuk, 1987; Roden et al., 1987; Bajaj et al., 1987).

Kohlhardt and Seifert (1985) investigated the interaction between the kinetically similar drugs quinidine and propafenone in vitro. The combination of these two agents produced a rate independent increase in the magnitude of both tonic and use-dependent $\dot{\mathrm{V}}_{\max }$ depression. The effects produced with this combination resembled effects expected from a rise in the concentration of either drug.

Pharmacological synergism was reported with the combination of quinidine plus mexiletine on $\dot{\mathrm{V}}_{\max }$ (Burke et al., 1986) and ventricular refractory period (Duff et al, 1986). These conclusions were based on the observation that the addition of a low ineffective concentrations of mexiletine increased the depression of $\dot{V}_{\max }$ or prolongation of 
ventricular refractory period produced by quinidine alone. However, these results are limited in that drug action was examined only at a fairly slow stimulation rate which did not take into account the cycle length dependencies of the individual agents (Burke et al.. 1986), nor that with the combination there is an increase in total drug concentration. Synergism did not occur at higher drug concentrations in both studies.

Competitive displacement interactions with sodium channel blockers have also been demonstrated with various drug combinations. The addition of lidocaine to bupivacaine (Clarkson and Hondeghem, 1985a) or glycylxylidide (GX) (Bennett et al., 1988) has been shown to reduce the magnitude of sodium channel block and therefore increase steady-state $\dot{\mathrm{V}}_{\max }$ or the sodium current. Competitive interactions have also been demonstrated through a decrease in the magnitude of the drug-induced slow component of $\dot{V}_{\max }$ recovery in the presence of the combination compared to effects with single agents. For example, the magnitude of the slow component of reactivation induced by quinidine alone was significantly diminished when lidocaine was also present (Clarkson and Hondeghem, 1985a; Sanchez-Chapula 1985). Similar results were observed with mixtures of mexiletine plus quinidine or ropitoin (Valenzuela and Sanchez-Chapula, 1989). All these interactions, however, required high drug concentrations in order that each dxug bind a large fraction of sodium channels and interfere with each other's binding. At lower concentrations, mixing two agents would result in more block than 
produced by either drug alone since the probability that two drugs interact simultaneously with the same receptor would be relatively smaller.

Effects with the combination of lidocaine and bupivacaine may be explained by the competitive displacement interactions described above. Bupivacaine binds avidly to inactivated sodium channels but has a relatively low affinity for resting and activated channels (Clarkson and Hondeghem, 1985b). Lidocaine binds to both activated and inactivated channels (Hondeghem and Katzung, 1984; Clarkson et al., 1988) and could therefore sequester a large fraction of channels before block by bupivacaine can become appreciable. Subsequently, faster recovery from block produced by lidocaine (Clarkson and Hondeghem, 1985a) in the presence of the combination would increase the sodium current during diastole compared to effects with bupivacaine alone. Similar events can explain effects with the combination lidocaine and GX. In addition, the interaction between lidocaine and $G X$ can be modulated by membrane voltage. GX-blocked channels recovered faster and more completely than lidocaine-block channels at normal membrane potentials, while the reverse was true at more negative membrane potentials (Bennett et al., 1988). Therefore, addition of GX to lidocaine can increase the sodium current only at normal potentials, while addition of lidocaine to $G X$ can increase the sodium current only at more hyperpolarized potentials.

Sanchez-Chapula (1985), but not Clarkson and Hondeghem (1985a), found an increased steady-state $\dot{\mathrm{V}}_{\max }$ in the presence of the combination of lidocaine plus quinidine compared to effects produced by quinidine 
alone. Quinidine binds avidly to activated channels (Weld at al., 1982; Kodama et a1., 1986 and 1987; Hondeghem and Matsubara, 1988) and dissociated very slowly. Since there would be little cycling of occupied channels between quinidine-bound and drug-free states at normal heart rates, it would be more difficult for lidocaine to displace quinidine than bupivacaine or GX. Nevertheless, both studies did find a decrease in the magnitude of the slow component of $\dot{V}_{\max }$ recovery due to quinidine with the combination suggesting that lidocaine interfered with $i t s$ binding. Competitive drug interactions and displacement support the concept of a common receptor site associated with sodium channel block by these agents.

\subsubsection{Action Potential Duration}

The effects of the combinations of quinidine plus tocainide (Valois and Sasyniuk, 1987) or mexiletine (Roden et al., 1987) on action potential duration have been investigated in vitro. Quinidine alone produced a prolongation of the action potential while both tocainide and mexiletine markedly shortened repolarization in Purkinje fibers. The combination of quinidine with either Ib agent produced changes in action potential duration reflecting the sum of the opposing acrions of the individual drugs. There was either a net change of zero or only a slight shortening of action potential duration. Similar results were observed with the combination of quinidine and mexiletine in vivo in canine myocardium (Costard-Jaeckle et al., 1989). Mexiletine atteriuated the prolongation of repolarization produced by quinidine. 
At higher drug concentrations, however, Burke et al. (1986) found that the combination of quinidine and mexiletine in vitro did not produce simple additive effects. In this study, both quinidine and mexiletine singly shortened action potential duration in canine Purkinje fibers. Mexiletine produced a greater shortening than quinidine, but the combination did not abbreviate repolarization beyond that observed with quinidine alone. Net effects on action potential duration may have resulted from changes in several membrane currents during repolarization. More insight into these results will require further investigation of the currents (including tissue specificity) and drug effects during repolarization as well as the frequency and concentration dependence of such interactions.

\subsection{Clinical Investigations}

The benefits of combining two Class I agents with different kinetics of interaction with the sodium channel have been demonstrated in clinical studies. In this setting, the combination of antiarrhythmic drugs have been used when single agent therapy was ineffective, only partially effective or poorly tolerated (due to adverse side effects). Duff et al. (1983b) showed that the combination of well-tolerated doses of the Class Ia drug quinidine with the Ib agent mexiletine markedly suppressed ventricular tachycardias compared to single agent therapy with either drug alone. Since administration of the two drugs in combination produced a greater depression of early extrasystoles, lower doses of the individual drugs were used which resulted in fewer side 
effects. Similar findings with this drug combination have been observed by Greenspan et al. (1985), Duff et al. (1987) and Whitford et al. (1988). The coadministration of other drug combinations of kinetically different agents have also produced enhanced antiarrhythmic responses. The combinations of mexiletine plus procainamide (Greenspan et al., 1985) or disopyramide (Kim et al., 1989), and tocainide plus quinidine (Kim et al., 1987; Barbey et al., 1988b) significantly increased suppression of premature ventricular complexes and/or ventricular tachycardias compared to effects produced with monotherapy.

The combinations of two kinetically slow agents have also been shown to produce enhanced antiarrhythmic responses. Coadministration of procainamide with quinidine (Kim et al., 1985), and propafenone with procainamide or quinidine (Klein et al., 1987) increased the suppression of premature ventricular complexes and/or ventricular tachycardias compared to effects with monotherapy. However, Duffy et al. (1983) did not find any additional benefits with the coadministration of procainamide with quinidine or disopyramide against ventricular tachycardias. The recovery time constants of $\dot{V}_{\max }$ depression with propafenone and quinidine in vitro are similar (Grant et al., 1982; Weld et al., 1982; Kohlhardt and Seifert, 1983), while that with procainamide is slightly shorter (Courtney, 1980; Ehring et al., 1988) and that with disopyramide is longer (Campbell, 1983a; Flemming and Sasyniuk, 1989; Gruber and Carmeliet, 1989). The recovery kinetics of all these agents, however, are so slow that there is minimal recovery of $\dot{V}_{\max }$ during clinical diastole. With these antiarrhythmic drugs, although enhanced 
antiarrhythmic efficacy may have resulted from effects similar to that of an increase in drug concentration, their combinations would not be useful in discriminating between premature and normal impulses.

Clinical studies of the combination of quinidine plus mexiletine (Duff et a1., 1983b) or tocainide (Barbey et a1., 1988b) on action potential duration produced similar effects to results obtained in vitro. Mexiletine or tocainide in combination with quinidine limited the $\mathrm{QT}_{\mathrm{c}}$ prolongation produced by quindine alone. With these combinations, the effectiveness of quinidine is probably not reduced following shortening of the action potential because quinidine is predominantly an open channel blocker (Weld et al., 1982; Kodana et al., 1986 and 1987; Hondeghem and Matsubara, 1988). In fact, shortening of the $\mathrm{QT}_{c}$ interval with the combination may even be beneficial against long QT syndrome arrhythmias with quinidine (Bauman et a1., 1984; Roden et a1., 1986a and 1986b). On the other hand, prolongation of $\mathrm{QT}_{\mathrm{c}}$ interval with the combination relative to effects with mexiletine alone may increase the effectiveness of mexiletine since it has a greater affinity for inactivated sodium channels (Kodama et al., 1986 and 1987).

Finally, the competitive displacement interactions observed between GX and lidocaine in vitro (Bennett et a1., 1988) may explain why some patients become refractory to lidocaine antiarrhythmic therapy after initial success (Lie et a1., 1974; Chopra et a1., 1971). In the study of Bennett et al. (1988), this phenomena was observed in two patients who initally responded to treatment with lidocaine for recurrent ventricular tachycardias. Failure of lidocaine therapy was accompanied 
by the appearance of $G X$ in the plasma while plasma lidocaine concentrations were similar throughout. The competitive interactions demonstrated in vitro with these compounds raise the possibility that similar interactions in vivo may be responsible for the loss of responsiveness to lidocaine.

\subsection{Interactions with Metabolites}

A special case of drug combinations in which interactions must be considered are those between antiarrhythmic drugs and their active metabolites. However, very few studies have investigated such interactions directly. The presence of a metabolite might beneficially increase the block of sodium channels and slowing of conduction produced by the parent drug. The metabolites of both quinidine and amiodarone have been shown to produce additive antiarrhythmic effects in combination with their parent drugs against experimentally-induced ventricular arrhythmias (Vozeh et al., 1987; Nattel et al., 1988). Conversely, the presence of a metabolite with faster kinetics of recovery from block might competitively antagonize the parent drug under appropriate conditions. Competitive displacement of lidocaine by its metabolite GX has been demonstrated in vitro (Bennett et al., 1988). 


\subsection{Proarrhythmic Antiarrhythmic Drug Interactions}

\subsubsection{Ventricular Tachycardia and Slow Conduction}

Although the aim of antiarrhythmic drug therapy is suppression or control of life-threatening cardiac arrhythmias, paradoxical provocation or aggravation of arrhythmias can be a side effect of these agents (Bigger and Sahar, 1987; Roden, 1990). One characteristic type of proarrhythmic response is clinically worsening ventricular tachycardia attended by widening of the QRS complex. Therapy with Class Ic antiarrhythmic agents such as flecainide and encainide have been most commonly implicated with such events (Roden, 1990). This subclass of sodium channel blockers have characteristic long time constants of recovery (Campbe11, 1983b) which do not allow relief of block even at long clinical diastolic intervals. Therefore, marked slowing of conduction at normal heart rates is a manifestion of therapy with these agents. Reentry caused by slow conduction with minimal prolongation of the refractory period may be the underlying mechanism. Recent data in a subset of patients have provided further evidence for the proarrhythmic potential of these drugs (Supression Trial (CAST) Investigators, 1989).

\subsubsection{Torsade de Pointes and Triggered Arrhythmias}

\subsubsection{Torsade de Pointes Arrhythmias in Patients}

A second characteristic proarrhythmic response to antiarrhythinic agents is torsade de pointes multiform ventricular tachycardias accompanied by prolongation of the QT interval (Bigger and Sahar, 1987;

Roden, 1990). The term torsade de pointes is used to describe 
polymorphic ventricular tachycardia in the setting of marked QT interval prolongation (long QT syndrome) (Tzivoni et a1., 1983). Torsade de pointes almost invariably occurs following a pause or abrupt deceleration in the ventricular rhythm and the first tachycardia complex is late coupled to the preceding normal complex, emerging from a large postpause $U$ wave (Jackman et al., 1988).

The etiology of torsade de pointes is frequently associated with the administration of action potential prolonging antiarrhythmic drugs amongst which are the Class Ia agents, sotalol and NAPA (Stratmann and Kennedy, 1987; Jackman et al., 1988; Roden, 1990). In particular, the Class Ia drug quinidine is most often cited as the culprit. Furthermore, with the Class Ia agents, proarrhythmic events usually occur within the normal range of therapeutic drug concentrations. Predisposing factors for torsade de pointes arrhythmias include electrolyte abnormalities (hypokalemia and hypomagnesemia) and bradycardia (Smith and Gallagher, 1980; Kay et al., 1983; Roden et al., 1986a and 1986b). Conversely, removing the drug, correcting the electrolyte abnormality or pacing is effective in preventing the recurrence of torsade de pointes.

\subsubsection{Early Afterdepolarizations and Triggered Activity In Vitro}

Similarities between events in vitro and in vivo have led to the hypothesis that the mechanisn for induction of torsade de pointes may be triggered activity due to early afterdepolarizations (Brachmann et al., 1983; Sasyniuk et al., 1989). Early afterdepolarizations are 
depolarizing afterpotentials which interupt or delay normal repolarization of the cardiac action potential and can induce triggered activity (Cranefield, 1975; Damiano and Rosen, 1984). A triggered action potential is a second nondriven upstroke induced by an early afterdepolarization.

The characteristics of drug-induced early afterdepolarizations and triggered activity in vitro have been recently reviewed (Wit and Rosen, 1986; Cranefield and Aronson, 1988; Sasyniuk et al., 1989). Consistent with clinical findings, triggered activity due to early afterdepolarizations: 1) requires marked drug-induced prolongation of action potential duration in association with bradycardia, 2) is facilitated by reduced external potassium concentrations and 3 ) is abolished or prevented by the various intervention that are effective clinically. Early afterdepolarizations have been induced in isolated cardiac tissue by numerous conditions or drugs that either increase inward depolarizing currents or reduce outward repolarizing currents to prolong action potential duration (Cranefield and Aronson, 1988). Antiarrhythmic agents associated with torsade de pointes arrhythmias in patients can induce early afterdepolarizations in vitro and include quinidine (Roden and Hoffman, 1985; Valois and Sasyniuk, 1987; Roden et a1., 1987; Nattel and Quantz, 1988; Davidenko et a1., 1989), sotalol (Lathrop and Varro, 1989) and NAPA (Dangman and Hoffman, 1981). Disopyramide has also been associated with torsade de pointes 
arrhythmias in patients (Stratmann and Kennedy, 1987; Jackman et al., 1988), however, its arrhythmogenic potential has not been previously investigated in vitro.

In addition, several issues still remain to be resolved before the precise role of early afterdepolarizations and triggered activity in drug-induced torsade de pointes can be established. Both the heart rate for induction and intrinsic frequency of sustained triggered activity in vitro are generally much slower than the physiological range of correlate events in the long QT syndrome in patients (Sasyniuk et a1., 1989). 


\section{Qbjectives}

The major metabolite of disopyramide in man, MND, occurs in significant plasma concentrations during disopyramide therapy (Karim, 1975). Electrophysiological studies of MND have demonstrated that it is an active compound in cardiac muscle. MND decreased the maximum atrial driving frequency both in vitro (Grant et al., 1978) and in vivo (Dubray et al., 1986) suggesting that it prolonged refractory periods. The parent compound, disopyramide, produces its antiarrhythmic effect by binding to a specific site within the sodium channel (Sheldon et al., 1987). MND may also have sodium channel blocking properties and depending on its kinetics of interaction may produce additive or antagonistic effects to disopyramide. Also, the effects of MND on action potential duration may be similar or opposite to disopyranide depending on its effects on other ion channels. Furthermore, the effects of the combination of disopyramide and MND when both are present simultaneously in the myocardium will be of clinical relevance and must be investigated directly.

Torsade de pointes arrhythmias in patients have been reported during disopyramide therapy (Stratmann and Kennedy, 1987; Jackman et al., 1988). Although disopyramide produces variable effects on action potential duration, it can prolong repolarization which is accentuated in the presence of external hypokalemia (Kus and Sasyniuk, 1978; Winslow et al., 1986). Similar effects have been observed with the Class Ia drug quinidine (Stratmann and Kennedy, 1987; Jackman et al., 1988). In 
addition, quinidine induces early afterdepolarizations and triggered activity in vitro which have been implicated in the initiation of torsade de pointes in vivo (Sasyniuk et al., 1989). Similar effects by disopyramide and quinidine suggest that disopyramide may also have such an arrhythmogenic potential in vitro.

We therefore assessed: 1) the effects of MND singly on $\dot{V}_{\max }$, action potential duration and effective refractory period of the propagated transmembrane action potential in canine ventricular tissue superfused in vitro; 2) the interaction between MND and disopyramide on these characteristics; 3 ) the ability of disopyramide to induce early afterdepolarizations and triggered activity in Purkinje fibers; and 4) the effects of MND on such triggered rhythms. 
Chapter 2

FREQUENCY AND VOLTAGE DEPENDENT EFFECTS OF

MONO-N-DEALKYLDISOPYRAMIDE, THE MAJOR METABOLITE OF DISOPYRAMIDE, IN CANINE VENTRICULAR TISSUE

(In press in the Journal of Pharmacology and Experimental Therapeutics.) 


\section{Abstract}

Mono-N-dealkyldisopyramide (MND), the major metabolite of disopyramide, reaches significant concentrations in patients; however, the contribution of MND to the antiarrhythmic or toxic effects of disopyramide is not known. We assessed the kinetics and magnitude of interaction of MND with the sodium channel in canine ventricular tissue superfused in vitro using $\dot{\mathrm{V}}_{\max }$ as an index of sodium channel block. At a basic cycle length of $1000 \mathrm{msec}$, MND (4-32 ug/ml) produced a concentration dependent depression of both $\dot{\mathrm{V}}_{\max }$ and amplitude of the action potential and accelerated all phases of repolarization in Purkinje fibers. To assess rate-dependent block, Purkinje fibers were stimulated with pulse trains at interstimulus intervals of 400 to 2000 insec. MND produced a concentration and rate dependent increase in the magnitude of rate-dependent block. There was also a concentration dependent increase in the kinetics of onset of block (decrease in rate constant). The rate constant increased with faster stimulation rates. Minimal tonic block occurred at clinically relevant concentrations. Recovery from rate-dependent block followed a single exponential time course with time constants of $5.23 \pm 0.90$ and $4.88 \pm 0.94 \mathrm{sec}$ for $\dot{V}_{\max }$ and activation time, respectively. There was no shift of the normalized $\dot{V}_{\text {max }}$-membrane potential relationship except at the highest concentration, $32 \mathrm{ug} / \mathrm{ml}$. 
At cycle lengths of 250 to $1000 \mathrm{msec}$ MND, $4 \mathrm{ug} / \mathrm{ml}$, shortened all phases of repolarization in Purkinje fibers, the greatest shortening occurring at the longest cycle length. Prolongation of effective refractory period occurred only at rapid heart rates. Both action potential duration and effective refractory period were prolonged in ventricular muscle which was independent of rate. Differential effects on action potential duration in Purkinje fibers and ventricular muscle decreased the disparity in durations between them.

The results suggest that MND, by depressing $\dot{V}_{\max }$ and conduction velocity and prolonging effective refractory period may have antiarrhythmic properties of its own. Therefore it may contribute to either the antiarrhythmic or toxic actions of disopyramide. Opposite effects to that of disopyramide on action potential duration in Purkinje fibers may be beneficial in preventing bradycardia dependent prolonged QT syndrome arrhythmias. 


\section{Introduction}

In man, disopyramide is metabolized primarily by hepatic $N$-dealkylation to MND and both compounds are excreted in the urine (Ranney et al., 1971; Karim et al., 1972; Karim, 1975). As much as 25 to $50 \%$ of an administered dose can be found in the urine as MND; ye:, its contribution to the antiarrhythmic and toxic effects of disopyramide is not known. Recent studies suggest that in patients with normal renal function on chronic oral therapy, MND reaches a concentration of approximately 30 \& of that of the parent compound (Aitio, 1981). Since the average protein binding of disopyramide is appraximately 80 while that of MND is only 22 to $35 \%$, the free drug fraction of both compounds would be similar in patients with normal renal function. In patients with depressed renal function, the free drug concentration of MND would be even higher. In patients on simultaneous therapy with microsomal enzyme inducing drugs the mean levels of MND are frequently higher than those of disopyramide (Aitio, 1981). Furthermore, there is pronounced interindividual variability with plasma MND:disopyramide ratios as high as 4 in patient populations (Bredesen et al., 1982).

Electrophysiological studies of MND have demonstrated that it is an active compound in cardiac muscle. The metabolite was effective in reversing experimentally-induced atrial fibrillation in dogs (Baines et al., 1976). In vitro, Grant et al. (1978) demonstrated that MND decreased the maximum driving frequency of guinea pig atria which 
suggested that MND prolongs refractory periods. Dubray et al. (1986) a1so demonstrated in vivo that levels of MND which are achieved during therapy diminished the maximal pacing frequency of canine atrial muscle. Disopyramide, like all Class I antiarrhythmic drugs, produces its antiarrhythmic effect by binding to a specific site within the sodium channel (Sheldon et al., 1987). MND may also have sodium channel blocking properties. Depending on its kinetics of interaction with the sodium channel, the electrophysiological actions of MND may be additive or antagonistic to that of the parent compound. Furthermore, the effects of MND on action potential duration may be similar or opposite to that of disopyramide depending on its effects on other ion channels.

Therefore, the present study was undertaken to assess the kinetics and magnitude of interaction of MND with the sodium channel using $\dot{V}_{\max }$ as an index of sodium channel block and to determine its effects on action potential duration and effective refractory period. Some of these results have been published previously in abstract form (Toy and Sasyniuk, 1988).

\section{Methods}

\subsection{Experimental preparation}

Mongrel dogs of either sex were anesthetized with sodiun pentobarbital $(30 \mathrm{mg} / \mathrm{kg})$ and their hearts were removed via a left thoracotomy. Both ventricles were thoroughly flushed with chilled, 
oxygenated Tyrode's solution. Purkinje fibers with small pieces of attached ventricular muscle were quickly excised and pinned to a sylgard block at the bottom of a lissue bath ( $4 \mathrm{ml}$ capacity). Fibers were continuously perfused with modified Tyrode's solution aerated with 95 \& $\mathrm{O}_{2}-5 \& \mathrm{CO}_{2}$ at a rate of $10 \pm 0.5 \mathrm{ml} / \mathrm{min}$. Our standard Tyrode's solution contained (in $\mathrm{mM}$ ): $\mathrm{NaCl}, 119.0 ; \mathrm{KCl}, 4.0 ; \mathrm{CaCl}_{2}, 1.8 ; \mathrm{MgCl}_{2}$, $0.5 ; \mathrm{NaHPO}_{4}, 0.9$; dextrose, 5.5; and $\mathrm{NaHCO}_{3}, 25$. $\mathrm{pH}$ of the solution was $7.33 \pm 0.03$. The temperature was maintained at $37.0 \pm 0.2^{\circ} \mathrm{C}$.

We used small, free-running intertrabecular Purkinje fiber bundles (length $<5 \mathrm{~mm}$ ) with attached ventricular muscle or ventricular papillary muscle preparations mainly from the right ventricle. These preparations displayed minimal diastolic depolarization and provided stable membrane potentials more negative than $-80 \mathrm{mV}$ during prolonged periods of quiescence. Preparations that displayed automaticity were not used.

The preparations were stimulated with rectangular pulses through bipolar tungsten electrodes etched in sodium nitrate and coated with Formvar. Electrical stimulation was provided by a Model RS-660 Timing Simulator/Word Generator controlled by a HP9816 computer in combination with a Digitimer stimulus isolation unit (model DS2).

Transmembrane potentials were recorded with glass microelectrodes filled with $3 \mathrm{M} \mathrm{KCl}$ and coupled to the input of a high-impedance, capacitance-neutralized amplifier (Model KS-700, WPI instruments). The 
output of the KS-700 was displayed on a Tektronix 5113 dual-beam storage oscilloscope and simultaneously displayed in digital form on a Data 6000 waveform analyzer (Data Precision, Inc.).

During control measurements and equilibration with drug, the preparations were stimulated at a basic cycle length of $1000 \mathrm{msec}$. Action potential variables were recorded on-line every $15 \mathrm{sec}$ until steady-state effects were observed.

\subsection{Protocols}

Drug effects on action potential parameters as a function of steady-state changes in stimulation frequency was examined by varying the basic cycle length from 250 to $1000 \mathrm{msec}$. Sufficient time ( $3 \mathrm{~min}$ or more) was allowed at each basic cycle length to permit changes in action potential configuration to reach steady-state.

To determine effective refractory period, test pulses were introduced after a stimulus train of 20 beats had produced steady-state changes in action potential duration. Test pulses of twice the diastolic threshold voltage, determined under control conditions, were initially introduced at the end of the action potential and then progressively earlier into phase 3 by steps of $10 \mathrm{msec}$ until a response was no longer elicited. The test pulse was then reintroduced from the last responding test interval to progressively earlier intervals by steps of $2 \mathrm{msec}$ until the response was no longer elicited. The 
effective refractory period was defined as the shortest $R_{1}-R_{2}$ interval in which the response to the test pulse propagated to a distal recording site.

To study the rate of development of $\dot{V}_{\max }$ depression with drive, the preparations were driven by 44 beat trains at interstimulus intervals of $400,600,1000$, and $2000 \mathrm{msec}$. Rest periods between trains of stimuli were long enough to ensure full recovery from rate-dependent block. Preparations were stimulated at a basic cycle length of $600 \mathrm{msec}$ prior to each rest period in order to maintain membrane potential at similar levels prior to each action potential train.

To determine recovery from $\dot{V}_{\max }$ depression, test pulses were introduced at varying diastolic intervals after a stimulus train had produced a steady-state level of $\dot{\mathrm{V}}_{\max }$ depression. The onset of diastole was defined as that time when repolarization had returned to the maximum diastolic potential. Test pulses were initially introduced during phase 3 of the action potential and then progressively later into diastole. The test intervals were initially increased in small increments and then progressively in larger steps with steps ranging from 50 to $5000 \mathrm{msec}$. Each recovery curve was comprised of a minimum of 30 points.

To study drug effect on the steady-state relationship between $\dot{V}_{\max }$ ' activation time and membrane potential, preparations were stimulated at cycle lengths of 1 to 5 sec under control conditions and 10 or $15 \mathrm{sec}$ with drug. Activation time was defined as the interval between the stimulus artifact and the maximum upstroke of the action potential. Purkinje fibers were exposed to progressively higher potassium 
concentrations ranging from 2.7 to $12 \mathrm{mM}$ until the preparations stopped responding. The preparations were then returned to a $2.7 \mathrm{mM}$ potassium Tyrode's solution. During alterations of potassium concentration $\dot{v}_{\max }$, activation time and membrane potential were recorded on-line every 5 sec.

$\dot{V}_{\max }$ was used as an indirect method to evaluate $I_{\mathrm{Na}}$. $\Lambda 1$ though $\dot{\mathrm{V}}_{\max }$ is a monotonic but not a linear index of $\mathrm{I}_{\mathrm{Na}}$ (Sheets et al., 1988; Fozzard et al., 1989), $\dot{\mathrm{V}}_{\max }$ does reflect net maximal inward current during the action potential and can provide a convenient, albeit nonquantitative index of changes in $\mathrm{I}_{\mathrm{Na}}$.

It was necessary to expose preparations to MND for at least $25 \mathrm{~min}$ before steady-state effects on action potential characteristics were obtained. In the majority of experiments it was not possible to maintain cell impalements long enough to study the entire concentration range in one ce11. Thus, onset of and recovery from block at different drug concentrations were studied in different experiments and the normalized data were pooled. Results from all other protocols under control and drug conditions were obtained from the same impalement.

\subsection{Drug}

MND used was generously supplied by Roussel Laboratories. The drug was added to Tyrode's solution made up from refrigerated stock solutions. Concentrations refer to that of the base. 


\subsection{Data analysis}

All action potential variables were determined using a Data 6000 waveform analyzer as previously described (Sasyniuk and Jhamandas, 1984). Action potential variables measured were: take-off potential; maximum diastolic potential; action potential amplitude; $\dot{\mathrm{V}}_{\max } ;$ and APD at the 50, 75, and $95 \%$ levels of repolarization (APD 50\%, APD 75\%, and $\triangle \mathrm{PD} 958$ respectively).

Where applicable, data are expressed as mean \pm S.D.. Paired Student's $t$ test was used to make statistical comparisons between control and drug effects on steady-state action potential characteristics and action potential duration. One- or two-way analysis of variance (anova) was used where appropriate to make comparisons between control and drug effects on the kinetics of onset and magnitude of rate-dependent block. $\quad p<0.05$ was considered significant. The time course of onset or recovery from block was defined with the use of a least squares error nonlinear exponential fitting program (Hewlett-Packard Statistical Library). The exponential onset or recovery from $\dot{V}_{\max }$ depression contained only one component. Least squares analysis of the data indicated that this component could be approximated by a single exponential function of the form $Y=\operatorname{Aexp}(-t / \tau)$ + B. No attempt was made to fit the data with mure complex functions. However, when appropriate, it was determined whether a double exponential function fit the data better than a single exponential. A 
double exponential was considered a better fit if the residual sum of squares for the double exponential was one-third or less than that for the single exponentia: (Clarkson and Hondeghein, 1985a).

\section{Results}

4.1 Concentration dependent effects on action potential characteristics in Purkinje fibers

Table 1 summarizes the concentration-response relationship of MND on action potential characteristics in Purkinje fibers stimulated at a basic cycle length of $1000 \mathrm{msec}$. MND did not alter the take-off potential but produced a concentration dependent depression of both $\dot{V}_{\text {max }}$ and action potential amplitude and shortened all phases of the action potential.

4.2 Effects of MND on action potential duration and effective refractory period during steady-state changes in basic cycle length

\subsubsection{Purkinje fibers}

Figure 1 summarizes the effects of $4 \mathrm{ug} / \mathrm{ml}$ MND on action potential duration when basic cycle length was decreased from 1000 to 250 insec. MND shortened all phases of repolarization at all cycle lengths. Shortening of action potential duration was greatest at the longest basic cycle length and most pronounced at the level of the plateau (APD 
TABLE 1. Concentration dependent effects of MND on action potential characteristics in canine Purkinje fibers

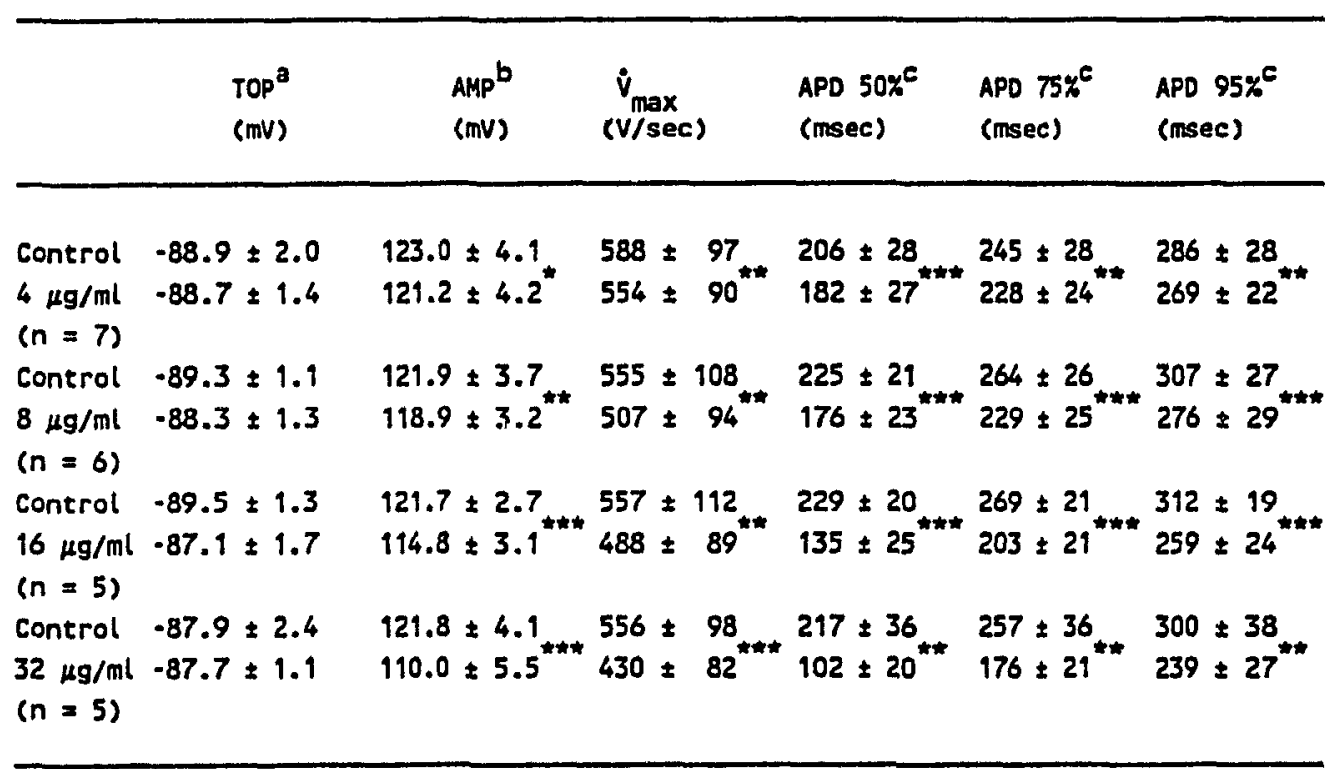

Values are expressed as mean \pm SO. Fibers were stimulated at a BCL of 1000 msec.

${ }^{\theta_{\text {TOP }}}=$ take-off potential; $b_{\text {/MP }}=$ amplitude; ${ }^{C_{A P D}}$ 50\%, APO $75 \%$, APD $95 \%=$ action potential duration at 50,75, and $95 \%$ levels of repolarization.

P<.05, P<.01 and P<.001. 
Figure 1 - Effects of $4 \mathrm{ug} / \mathrm{ml}$ MND on rate dependent shortening of action potential duration in Purkinje fibers and ventricular muscle. APD 50\%, $75 \%$ and $95 \%$ are plotted against steady-state cycle lengths in Purkinje fibers (top) and ventricular muscle (bottom) under control conditions (circles) and following $4 \mathrm{ug} / \mathrm{ml}$ MND (triangles). Data points represent mean \pm S.D. of 6 experiments in Purkinje fibers and 5 experiments in ventricular muscle. ${ }^{*}$ Significantly different from control, $\mathrm{P}<.05 ; * * \mathrm{P}<.01$. 

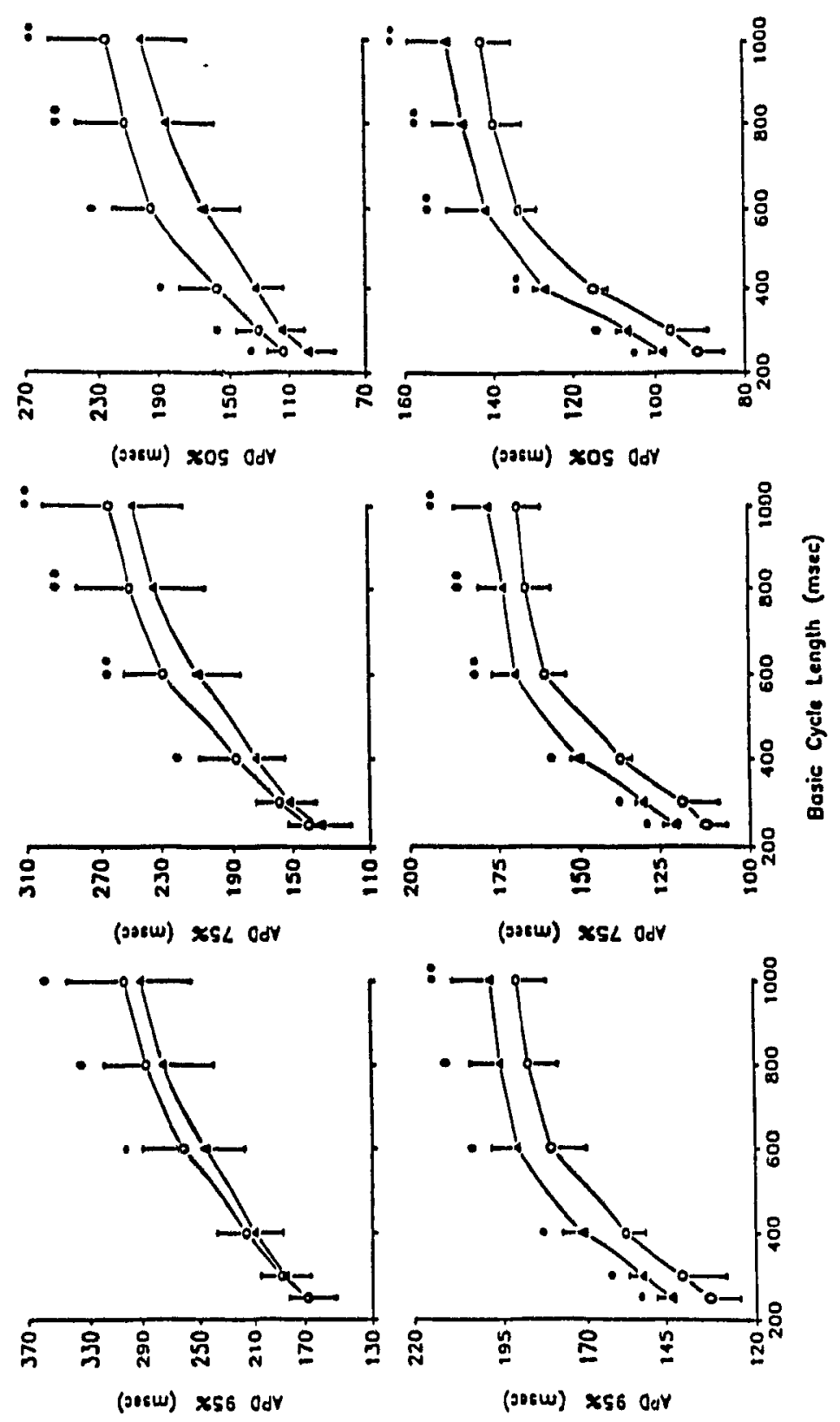
508). Despite shortening of action potential duration, effective refractory period was either unchanged or prolonged, particularly at shorter cycle lengths (Figure 2).

\subsubsection{Ventricular muscle}

MND produced opposite effects on repolarization in ventricular muscle. Action potential duration was significantly prolonged at all levels of repolarization and at all cycle lengths (Figure 1). This reduced the disparity in durations between muscle and Purkinje fibers (Figure 2). Unlike the effect in Purkinje fibers, absolute changes in action potential duration were similar at all cycle lengths. Effective refractory period was prolonged similarly at all cycle lengths which also reduced the disparity between muscle and Purkinje fibers even at normal rates (Figure 2 ).

4.3 Effects on the kinetics of onset and magnitude of rate-dependent $\dot{V}_{\max }$ depression

Figure 3 illustrates a typical example of the rate-dependent effects of MND. Rate-dependent effects on $\dot{V}_{\text {max }}$ were minimal under control conditions and may be attributed to a small decline in the take-off potential during the stimulus train. In the presence of MND, $\dot{V}_{\text {Inax }}$ decreased with each beat following an exponential decline to a steady-state. With the exception of a small depolarization prior to the first beat in the stimulus train, there were minimal changes in take-off potential throughout the train with $4 \mathrm{ug} / \mathrm{ml}$ of drug. lligher concentrations produced a slightly greater depolarizatio:t. 


\begin{abstract}
Figure 2 - Cycle-length dependent effects of MND on action potential duration and effective refractory period (ERP) in Purkinje fibers and ventricular muscle. The left panels shows a plot of APD 958 (open symbols) and effective refractory period (solid symbols) against steady-state basic cycle length in Purkinje fibers (top panel) and ventricular muscle (bottom panel) under control (circles) and following $4 \mathrm{ug} / \mathrm{ml}$ MND (triangles). The right panels illustrate the cycle length dependent reduction of disparity in APD $95 \%$ (top panel) and effective refractory period (bottom panel) between Purkinje fibers (diamonds) and ventricular muscle (squares) both under control conditions (open symbols) and following $4 \mathrm{ug} / \mathrm{ml}$ MND (solid symbols). Data points represent the means of 3 experiments,
\end{abstract}



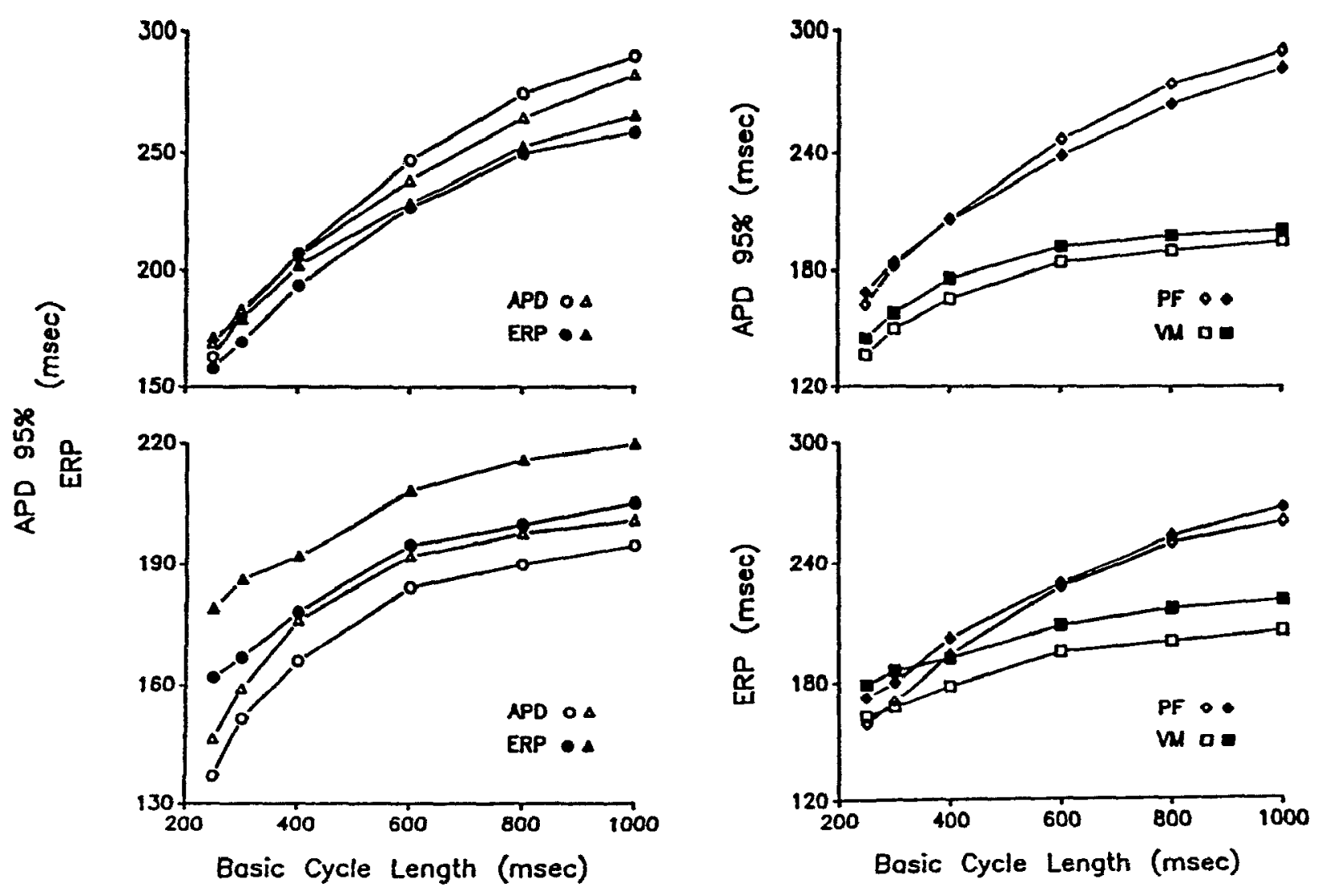
Figure 3 - Typical example of the concentration dependent effects of MND on the kinetics of onset and magnitude of rate-dependent block. $\dot{V}_{\max }$ (normalized to the $\dot{v}_{\max }$ of the first action potential of the stimulus train) and take-off potential (TOP) are plotted for each action potential during the stimulus train under control conditions (asterisks), and following 4 (triangles), 8 (squares), and 16 (diamonds) ug/ml of MND. Each stimulus train was preceded by a quiescent interval of $20 \mathrm{sec}$. Rate constants were 4.00 , 3.05 , and 2.76 beats and rate-dependent block was $6.8,11.6$, and 17.7 following 4,8 , and $16 \mathrm{ug} / \mathrm{ml}$ of MND, respectively. Take-off potential of the first action potential of the train was depolarized relative to the steady-state take-off potential. Steady-state take-off potential was more depolarized at higher concentrations. 

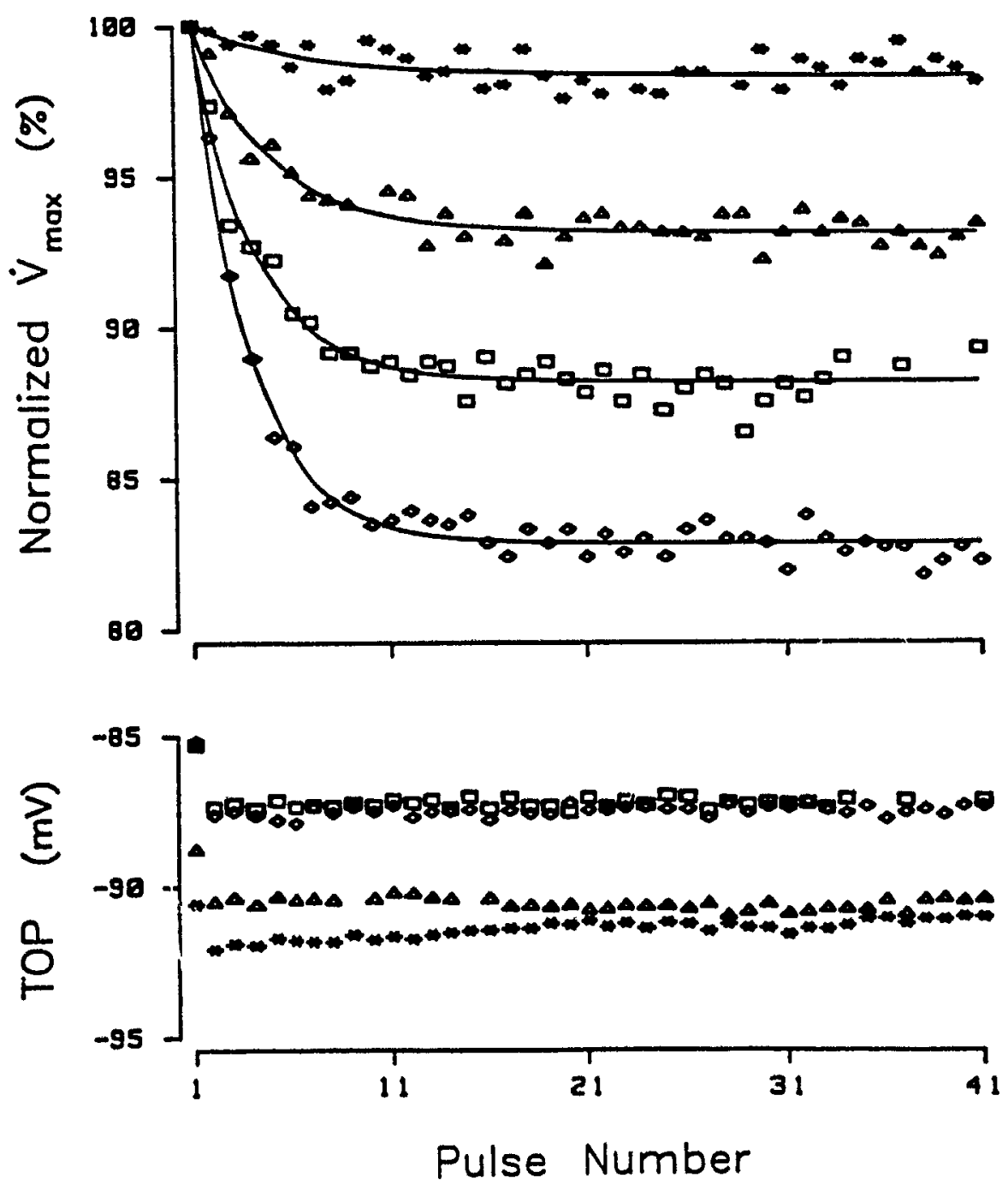
MND produced a concentration dependent decrease in the rate constant (faster kinetics) and an increase in the magnitude of rate-dependent $\dot{\mathrm{V}}_{\max }$ depression. The results are summarized in Figure 4. Tonic block, which represents block of sodium channels that is independent of rate, was minimal in the presence of $4-16 \mathrm{ug} / \mathrm{m} 1 \mathrm{MND}$. A significant increase in tonic block only occurred after $32 \mathrm{ug} / \mathrm{ml}$ of drug. Thus, total $\dot{\mathrm{v}}_{\max }$ depression was due to rate dependent effects at clinically relevant concentrations. MND produced a small but significant concentration dependent depolarization during the quiescent interval preceding onset of the stimulus train.

The effects of MND on rate-dependent block were also dependent on the interstimulus interval of the action potential train. Effects of interstimulus interval on the kinetics of onset and magnitude of rate-dependent block produced by MND are summarized in Table 2. The rate constant and magnitude of rate-dependent block were greatest at the shortest interstimulus interval.

\subsection{Characteristics of recovery from rate-dependent block \\ Figure 5 shows a typical example of the recovery of $\dot{V}_{\max }$ and} activation time from rate-dependent block in the presence of MND. Minimal recovery ( 58 ) occurred during the first two seconds of the diastolic interval. $\dot{\mathrm{V}}_{\max }$ recovered over a longer diastolic interval following a single exponential time course of $5.72 \mathrm{sec}$. The large depression of $\dot{\mathrm{V}}_{\max }$ early during diastole was consistently accompanied by a corresponding increase in activation time suggesting that depression 
Figure 4 - Concentration-dependent changes in rate constant (upper panel), depression of $\dot{\mathrm{V}}_{\max }$ (middle panel) and take-off potential (TOP; bottom panel) produced by MND. Data points represent mean \pm S.D. of 6 to 8 preparations. Interstimulus interval was $600 \mathrm{msec}$. Circles represent tonic block; squares, rate-dependent block and triangles, total block. Total block is the sum of tonic and rate-dependent block. There was a significant concentration dependent effect on all parameters (anova). 

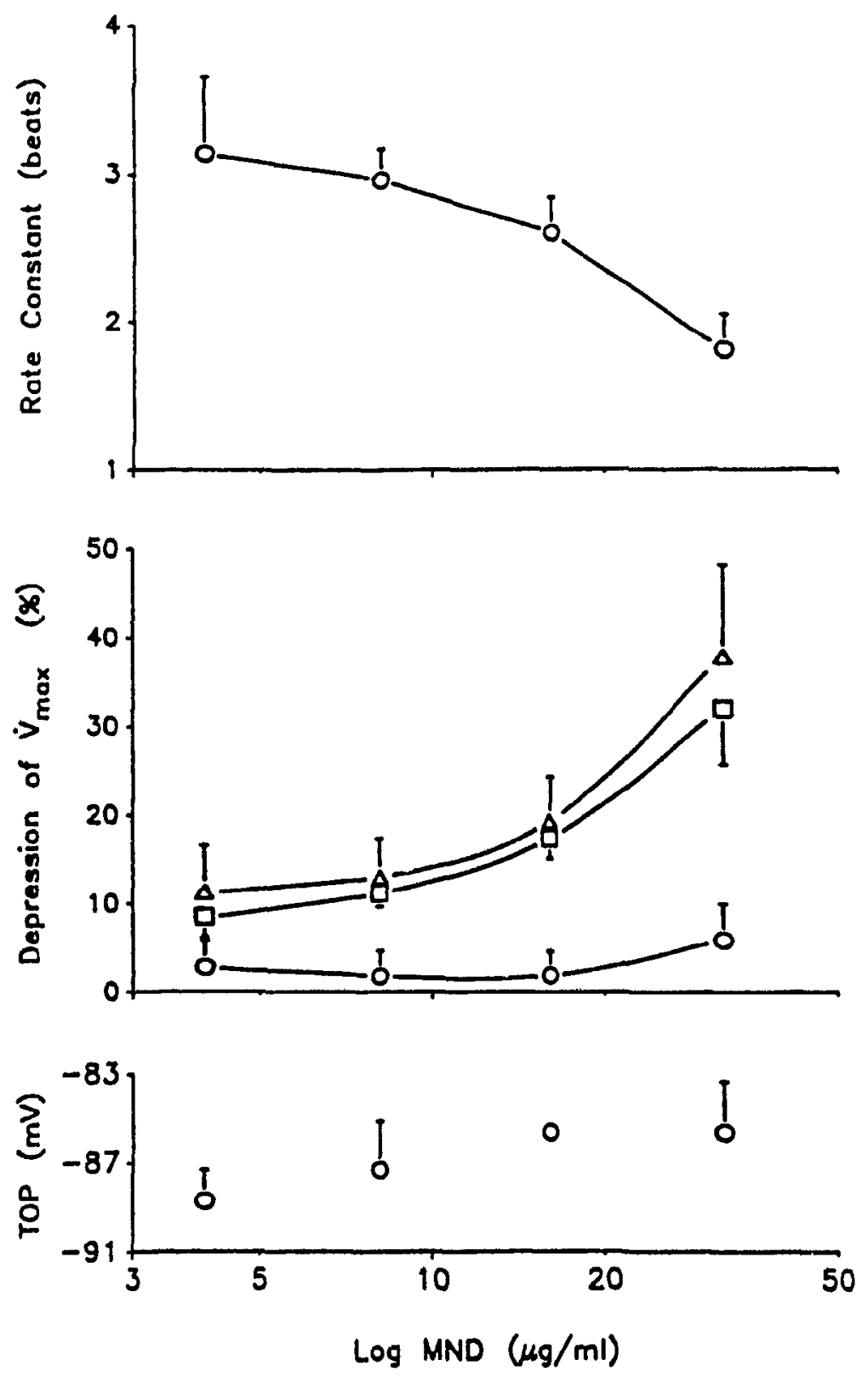
TABLE 2. Effects of interstimulus interval on the kinetics of onset and magnitude of rate-dependent $\dot{V}_{\max }$ depression produced by MND

\begin{tabular}{cccccc}
\hline \multicolumn{6}{c}{ EFFECTS ON RATE CONSTANT (beats) } \\
& & \multicolumn{6}{c}{ ISI (msec) } \\
\cline { 3 - 7 } $\begin{array}{c}\text { MND } \\
\text { (ug/m1) }\end{array}$ & $n$ & 400 & 600 & 1000 & 2000 \\
\hline 4 & 6 & $3.98 \pm 1.02$ & $3.14 \pm 0.52$ & $2.89 \pm 0.45$ & $2.05 \pm 0.61$ \\
8 & 6 & $3.48 \pm 0.44$ & $2.96 \pm 0.21$ & $2.85 \pm 0.65$ & $2.11 \pm 0.78$ \\
16 & 7 & $2.98 \pm 0.41$ & $2.60 \pm 0.24$ & $2.09 \pm 0.48$ & $2.10 \pm 0.77$ \\
32 & 8 & $1.83 \pm 0.51$ & $1.81 \pm 0.24$ & $1.60 \pm 0.26$ & $1.50 \pm 0.40$ \\
\hline
\end{tabular}

EFFECTS ON RDB ( 8 )

ISI (msec)

\begin{tabular}{cccccc}
\cline { 3 - 5 }$\left(\begin{array}{c}\text { MND } \\
(\mathrm{ug} / \mathrm{m} 1)\end{array}\right.$ & $\mathrm{n}$ & 400 & 600 & 1000 & 2000 \\
\hline 4 & 6 & $10.3 \pm 1.9$ & $8.5 \pm 2.3$ & $7.8 \pm 1.9$ & $5.6 \pm 1.9$ \\
8 & 6 & $12.2 \pm 1.1$ & $11.2 \pm 1.5$ & $8.8 \pm 1.4$ & $5.3 \pm 1.2$ \\
16 & 7 & $20.5 \pm 3.9$ & $17.4 \pm 2.3$ & $15.0 \pm 2.6$ & $11.0 \pm 2.0$ \\
32 & 8 & $37.2 \pm 5.1$ & $32.0 \pm 6.3$ & $29.2 \pm 3.5$ & $21.1 \pm 2.5$
\end{tabular}

Values are expressed as mean $\pm S . D$.

ISI $=$ interstimulus interval; $\mathrm{RDB}=$ rate-dependent block.

Onset of block was best fitted by a single exponential function.

Interaction between drug concentration and ISI were significant for both rate constant and RDB (two-way anova). 
Figure 5 - Typical example of the time course of recovery of $\dot{V}_{\max }$ and activation time with $16 \mathrm{ug} / \mathrm{ml}$ of MND. The right upper and middle panels show the first $2 \mathrm{sec}$ of recovery on an expanded scale. Early diastolic block, defined as the magnitude of $\dot{V}_{\max }$ depression or prolongation of activation time (act. time) at zero diastolic interval relative to full recovery, was 17.2 \& for $\dot{v}_{\max }$ and 19.6 for activation time. Changes in take-off potential (TOP) during the $30 \mathrm{sec}$ recovery interval are plotted in the bottom right panel. Take-off potential depolarized slightly from -88.06 to $-85.67 \mathrm{mV}$. 

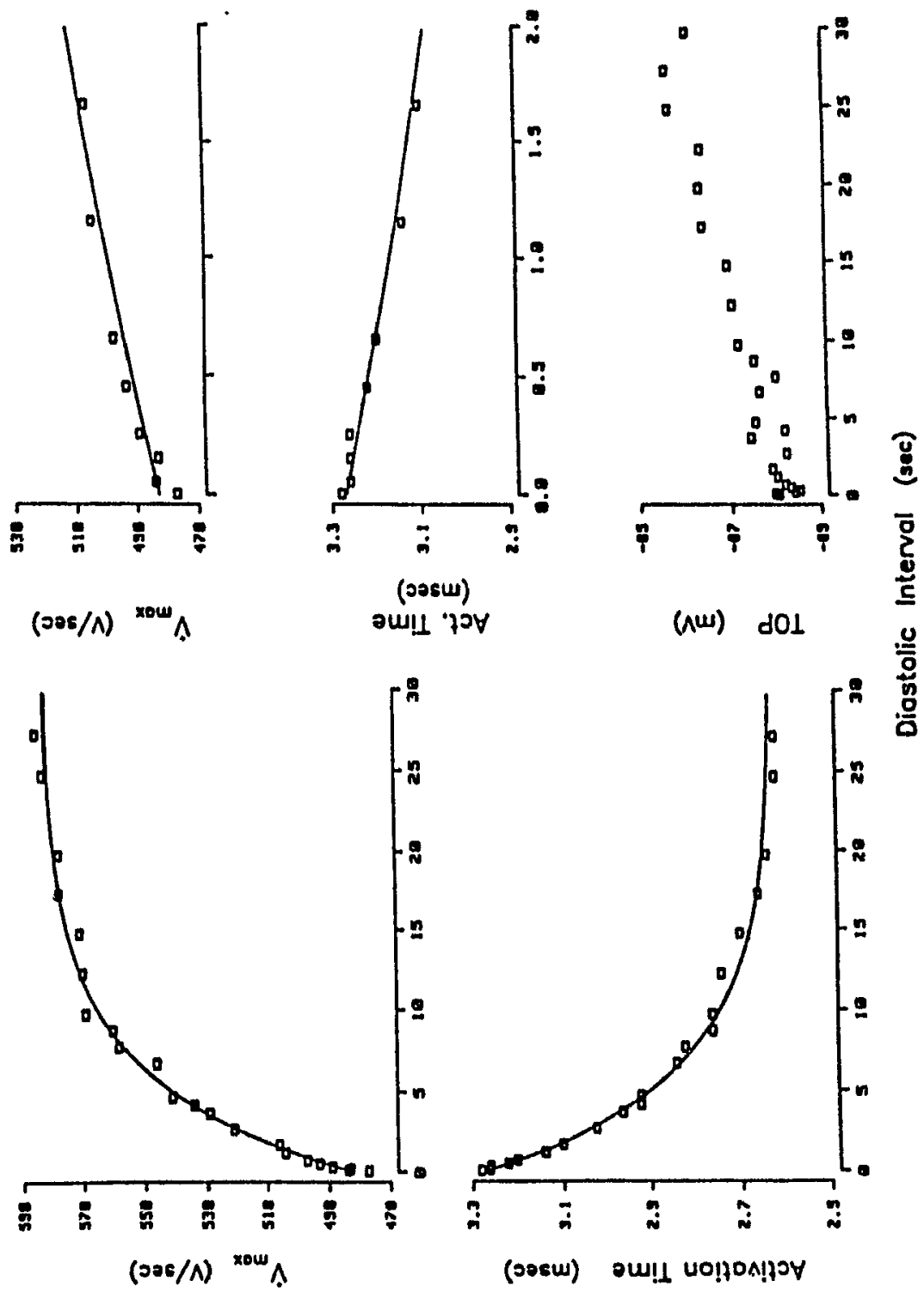
of $\dot{\mathrm{v}}_{\text {inax }}$ of early responses reflected a slowing of impulse conduction. Activation time recovered with a single exponential time constant of $5.83 \mathrm{sec}$. There were never more than 2 to 3 millivolts of depolarization during the $30 \mathrm{sec}$ interval. If there were more than a few millivolts of depolarization the results were not used.

A recovery period of $30 \mathrm{sec}$ was sufficient for $\dot{\mathrm{V}}_{\max }$ to recover completely in the presence of MND. We could not accurately determine recovery time constants under control because $\dot{V}_{\max }$ had already attained its maximum value when repolarization was complete. In 6 experiments, the recovery of $\dot{V}_{\max }$ and activation time in the presence of MND had time constants of $5.23 \pm 0.9$ and $4.88 \pm 0.94 \mathrm{sec}$, respectively. Thus, during the first two seconds of the diastolic interval, recovery from block averaged only $8.1 \pm 2.98$.

$\dot{V}_{\text {max }}$ recovery was independent of drug concentration. Figure 6 illustrates a typical example of the recovery of $\dot{V}_{\max }$ in the presence of 8,16 , and $32 \mathrm{ug} / \mathrm{ml} \mathrm{MND}$. Time constants for $\dot{\mathrm{V}}_{\max }$ recovery were similar although the initial level of block was greater with higher concentrations of drug.

\subsection{Voltage-dependent effects}

In a total of 6 experiments we assessed the effects of MND on the relationship between $\dot{\mathrm{V}}_{\max }$, activation time and membrane potential. It was not possible to study all concentrations in the same experiment. Thus, in 2 preparations we studied concentrations ranging from 4 to 16 ug/m1. In 3 experiments on 1 y $32 \mathrm{ug} / \mathrm{ml}$ was used. In the example 
Figure 6 - Concentration dependent effects on the magnitude and time course of recovery of $\dot{V}_{\max }$. The curves have been normalized to their respective $\dot{V}_{\text {max }}$ value at $30 \mathrm{sec}$. All curves were fitted by a single exponential function. Early diastolic block increased from 12.4 for $8 \mathrm{ug} / \mathrm{ml}$ (squares) to 22.0 and 35.3 \& for 1.6 (diamonds) and 32 (triangles) ug/ml of MND respectively. Time constants were $5.18,4.01$ and 4.83 sec for the three concentrations, respectively. The curves in the bottom panel show the first $2 \mathrm{sec}$ of the recovery interval. 

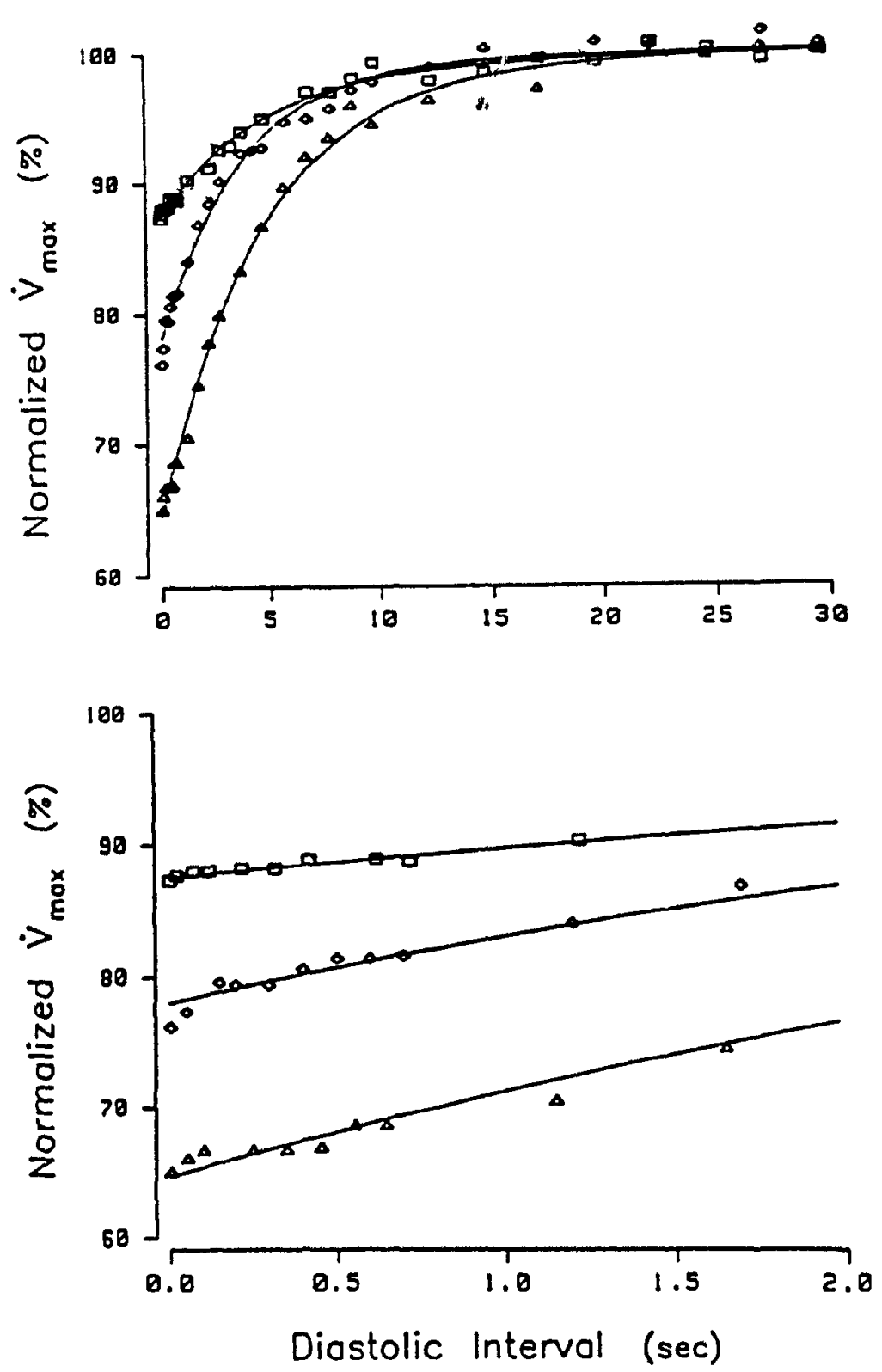
illustrated in Figure 7,8 to $32 \mathrm{ug} / \mathrm{ml}$ were used but only the effects of 16 and $32 \mathrm{ug} / \mathrm{ml}$ are shown. MND, 4 to $16 \mathrm{ug} / \mathrm{ml}$, did not produce a shift in the normalized $\dot{\mathrm{V}}_{\max }$-membrane potential curve. At the highest concentration, $32 \mathrm{ug} / \mathrm{ml}$, MND produced a 1 to $4 \mathrm{mV}$ shift of the curve at $E_{h}$ (membrane potential at which $\dot{V}_{\max }$ is reduced to half of its maximum value) to more negative potentials and decreased its maximun.

The shift due to $32 \mathrm{ug} / \mathrm{ml}$ may have a small rate-dependent component as complete recovery from rate-dependent block would not have occurred at a stimulation rate of $15 \mathrm{sec}$. Voltage dependent effects on activation time were similar. 
Figure 7 - Typical example of the effects of MND on the relitionship between $\dot{V}_{\max }$ and membrane potential. $\dot{V}_{\max }$ is plotted for control conditions (asterisks), following 16 (diamonds) and 32 (triangles) $\mathrm{ug} / \mathrm{ml}$ of $M N D$ in the same experiment. Stimulation rate was $15 \mathrm{sec}$ under drug and $1 \mathrm{sec}$ for control. 

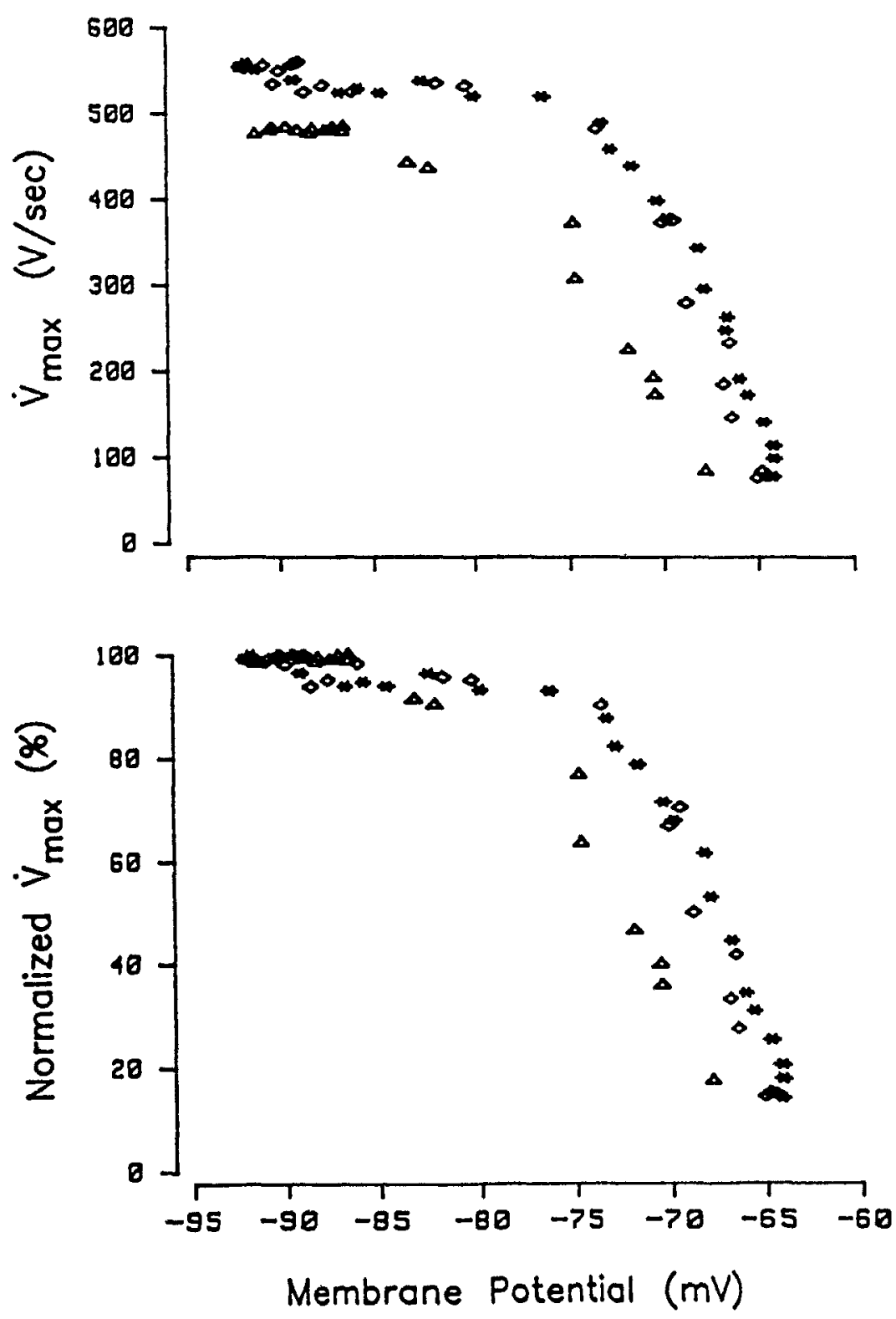


\section{Discussion}

Our results show that MND depresses $\dot{\mathrm{V}}_{\max }$ of the action potential suggesting that this compound blocks cardiac sodium channels.

Depression of $\dot{V}_{\max }$ was rate dependent and developed following a single exponential process, characteristic of many Class I antiarrhytimic agents (Campbe11, 1983b). Furthermore, $\dot{\mathrm{v}}_{\max }$ depression occurred at clinically relevant concentrations and stimulation rates. The lowest concentration of $\mathrm{MND}, 4 \mathrm{ug} / \mathrm{ml}$, was within the clinical range of concentrations measured in patients during chronic therapy with disopyramide (Aitio, 1981; Bredesen et al., 1982). Increasing both the concentration and stimulation rate increased the magnitude of $\dot{v}_{\max }$ depression. As an event dependent process, the kinetics of onset of block were faster at higher drug concentrations and slower stimulation rates. However, as a time dependent process the kinetics were faster at both higher concentrations and faster frequencies.

The relative potency of $M N D$ was less than that of the parent compound. The amount of rate-dependent block produced by MND was approximately one-half to two-thirds of that observed with disopyramide by Flemming and Sasyniuk (1989) under identical experimental conditions. In contrast to disopyramide which produced a significant amount of tonic block even at therapeutic concentrations (Flemming and Sasyniuk, 1989), MND produced no significant tonic block at concentrations less than 32 $u g / m 1$. Thus, with MND only rate-dependent block was significant at 
therapeutic concentrations. The onset of rate-dependent block was approximately three times faster than that seen previously with disopyramide.

Clinically useful Class I antiarrhythmic agents all delay recovery of the sodium channel from inactivation by direct interaction with a receptor site within the sodium channel (Hondeghem and Katzung, 1984). This delay in repriming kinetics was also observed with MND. The time course of recovery from rate-dependent block followed a single exponential process with a time constant of $5.23 \pm 0.90 \mathrm{sec}$. This single recovery process contrasts with the effects of the parent compound which has been reported to recover following at least 2 exponential processes (Kojima et al., 1982; Flemming and Sasyniuk, 1989). The first component had a time constant of hundreds of insec and increased with drug concentration. Such a component of recovery was not observed with MND. Recovery from block with MND was independent of drug concentration. The rate of recovery from block at normal diastolic potentials was slow enough so that block would not fully dissipate between beats throughout the clinical range of heart rates. The rate of recovery was approximately 3 times faster than that attributed to dissociation of disopyramide from the sodium channel by flemming and Sasyniuk (1989) and was more similar to that of the Class la drug quinidine (Grant et a1., 1982; Clarkson and Hondeghem, 1985a; Valois and Sasyniuk, 1987; Thompson et al., 1987) or the Class Ic drug propafenone (Kohlhardt and Seifert, 1983; Thompson et al., 1988; Rouet et al., 1989). 
Recovery of activation time (used as an estimate of effects on conduction) was similar to that of $\dot{\mathrm{V}}_{\max }$ and indicates that changes in $\dot{\mathrm{v}}_{\max }$ of the action potential reflect changes in conduction in the whole heart.

MND produced depolarization at higher concentrations. Drug-induced depolarization of membrane potential has been observed previously with many Class I agents. Significant concentration dependent depolarization has been observed with disopyramide (Flemming and Sasyniuk, 1989), quinidine (Weld et al., 1982) and NAPA (Dangman and Hoffman, 1981) in canine Purkinje fibers. In guinea-pig atrial and ventricular muscle Eibers, high concentrations of propafer.une produced a significant depolarization (Delgado et al., 1985). Although $\dot{\mathrm{V}}_{\max }$ studies were generally conducted at membrane potentials over the flat well polarized region of the $\dot{\mathrm{v}}_{\max }$-membrane potential curve, slight depolarization would have resulted in an overestimation of tonic block and an underestimation of rate-dependent block particularly at higher drug concentrations. More precise determination of drug effects on tonic and rate-dependent block may require voltage clamp experiments in order to minimize the effects of depolarization on $\dot{v}_{\max }$.

Shifts in the $\dot{\mathrm{V}}_{\max }$-membrane potential relationship to more negative potentials is characteristic of many sodium channel blocking agents (Hondeghem and Katzung, 1984). Such a shift was not observed with levels of MND that may be achieved during disopyramide therapy suggesting that additional block is not produced by such a mechanism at 
clinically relevant concentrations. Thus, effects of MND on sodium channels at clinically relevant concentrations reside mainly in the rate dependent depression of $\dot{\mathrm{v}}_{\max }$.

Several studies have shown that disopyramide blocks the sodium channel mainly during activation (Kodama et al., 1986 and 1987; Gruber and Carmeliet, 1989). The parent compound also fails to shift the $\dot{\mathrm{V}}_{\max }$-membrane potential relationship (Gruber and Carmeliet, 1989). Thus MND, like the parent compound, may also interact with the sodium channel during activation.

MND consistently shortens action potential duration in Purkinje fibers at clinically relevant heart rates and concentrations. This action is different from that of the parent compound which produces variable effects on action potential duration depending on drug concentration, stimulation rate and extracellular potassium concentration (Kus and Sasyniuk, 1975 and 1978; Fiemming and Sasyniuk, 1989). The effects of MND resembles more closely the disopyramide derivative, penticainide (Gautier et al., 1987) or the Class Ic agents flecainide (Yabek et al., 1987) and encainide (Elharrar and Zipes, 1982; which also shorten action potential duration in canine Purkinje fibers but prolong it in ventricular muscle.

Shortening of action potential duration by MND in Purkinje fibers probably results from block of the TTX-sensitive sodium "window" current involved in maintaining the action potential plateau (Attwell et al., 1979; Coraboeuf et al., 1979). This is also the mechanism by which 
penticainide (Gautier et al., 1987), flecainide (Smallwood et al., 1989) and encainide (Elharrar and Zipes, 1982) have been suggested to shorten action potential duration.

Lengthening of the action potential duration in ventricular muscle was uniform at all cycle lengths suggesting inhibition of the inward rectifying time-independent potassium current $\left(i_{k 1}\right)$. A parallel shift of the action potential duration-rate relationship in canine endocardium following 4-aminopyridine was attributed to inhibition of $i_{k 1}$ by Litovsky and Antzelevitch (1988). A similar rate independent prolongation of action potential duration was produced by quinidine in vivo in dog epicardium (Franz and Costard, 1988). In isolated canine ventricular myocytes quinidine decreased $i_{k 1}$ independently of frequency (Salata and Wasserstrom, 1988).

The inward rectifying outward current is responsible for a considerable fraction of the outward potassium current between $-40 \mathrm{mV}$ and the resting potential and reduction leads to the slowing of final (phase 3) repolarization (Van Bogaert and Snyders, 1982; Tseng et al., 1987). Since the TTX-sensitive "window" current plays a much smaller role in determining plateau durations in ventricular muscle than in Purkinje fibers (Corahueuf et al., 1979; Bhattacharyya and Vassalle, 1982), block of $i_{k 1}$ may exceed reduction of the TTX-sensitive "window" current thereby prolonging action potential duration. Prolongation of action potential duration was not reversible following washout of the 
drug for up to $90 \mathrm{~min}$ (Toy and Sasyniuk, unpublished observations). Similarly, block of $i_{k 1}$ was irreversible with quinidine (Hiraoka et al., 1986; Salata and Wasserstrom, 1988).

Prolongation of action potential duration in ventricular muscle has also been observed with the parent compound (Kus and Sasyniuk, 1975 and 1978; Kojima, 1981; Flemming and Sasyniuk, 1989) although rate dependent effects have not been investigated. Differential effects of MND may be beneficial in reducing disparity of action potential duration between Purkinje fibers and ventricular muscle and thus provide protection against re-entrant types of arrhythmias. The metabolite prolonged effective refractory period uniformly in ventricular muscle. However in Purkinje fibers effective refractory period was prolonged only at fast heart rates indicating that frequency-dependent block of sodium channels by MND probably contributed to an increase in effective refractory period. Prolongation of effective refractory period may account for the findings of Grant et a1. (1978) and Dubray et al. (1986) who reported decreases in the maximum pacing frequency in the presence of MND.

The present in vitro study of the major metabolite of disopyramide demonstrates that it has significant electrophysiological effects on $\dot{V}_{\max }$, action potential duration and effective refractory period. Further study will be required to evaluate these effects when MND is present in combination with the parent drug. Such investigation will 
provide information concerning the interaction of the two compounds and the potential clinical efficacy of their combined antiarrhythmic effects. 
Chapter 3

ELECTROPHYSIOLOGICAL INTERACTIONS BETWEEN DISOPYRAMIDE AND ITS MAJOR METABOLITE, MONO-N-DEALKY'IDISOPYRAMIDE, IN CANINE VENTRICULAR TISSUE

(Manuscript in preparation for publication.) 


\section{Abstract}

Mono-N-dealkyldisopyramide (MND), the major metabolite of disopyramide in man, has been shown to have Class I antiarrhythmic actions. To predict the potential clinical effects of its presence during disopyramide therapy, we investigated the interaction between disopyramide and MND with the sodium channel in canine ventricular tissue superfused in vitro. $\dot{\mathrm{V}}_{\max }$ was used as an indirect index of sodium channel block. Pulse trains at an interstimulus interval of 600 msec were used to assess the kinetics and magnitude of rate-dependent block in Purkinje fibers. With disopyramide (10 uM) alone, the rate constant and magnitude of rate-dependent block were $7.04 \pm 0.96$ beats and $11.1 \pm 2.08$; with MND (10 uM) the respective values were $4.39 \pm$ 1.58 beats and $6.3 \pm 1.1 \%$. The combination produced an additive increase in the magnitude of rate-dependent block $(15.1 \pm 3.98)$, while the rate constant $(4.56 \pm 1.94$ beats) was similar to that with MND alone. Tonic block was $6.3 \pm 3.6$ for disopyramide alone; $2.5 \pm 2.98$ for MND alone; and $9.1 \pm 6.0$ for the combination. Recovery from rate-dependent block with the combination followed a single exponential time course with a time constant of $9.10 \pm 2.17 \mathrm{sec}$.

Disopyramide produced a rate-dependent prolongation of the effective refractory period of 3 tightly coupled sequential extrasystoles but not the basic beat in Purkinje fibers. In ventricular 
muscle the effective refractory period of the basic beat in addition to the 3 extrasystoles were prolonged. Effects in both tissues were accentuated in the presence of the combination.

The combination produced an additive shortening of action potential duration at normal heart rates. However, disopyramide alone produced a reverse use-dependent prolongation of action potential duration following a long diastolic interval. In the presence of external hypokalemia, acidosis and bradycardia, disopyramide significantly increased the slope of the action potential duration-rate relationship which led to the induction of early afterdepolarizations and triggered activity in Purkinje fibers at cycle lengths of 2 sec or greater. MND shifted the incidence of triggered activity to longer cycle lengths. Addition of mexiletine ( $8-11 \mathrm{uM}$ ) or pacing at $1 \mathrm{~Hz}$ abolished triggered activity.

Additive interactions between disopyramide and MND suggest that MND may contribute to the clinical efficacy of disopyramide by enhancing $\dot{\mathrm{V}}_{\max }$ depression, thereby further slowing conduction, and prolonging refractory periods. Reverse use-dependent effects of disopyramide on action potential duration suggest it may be potentially proarrhythmic. The effects of MND may be beneficial against triggered arrhythmias by shifting the incidence of triggered activity to longer cycle lengths. 


\section{Introduction}

Interactions between antiarrhythmic drugs and their metabolites $m u=$ be carefully considered in the clinical efficacy of these agents. The Class Ia drug disopyramide is primarily metabolized in man by hepatic N-dealkylation to MND (Karim, 1975). Plasma concentrations of the metabolite generally reach approximately 30 of disopyramide levels during chronic oral therapy in patients, but may exceed this due to renal impairment or with interindividual variability (Aitio, 1981; Bredesen, 1982).

The primary electrophysiological effect of disopyramide in vitro is a depression of $\dot{V}_{\max }$ (Class $I$ effect), while prolongation of action potential duration ( $C$ lass III effect) has also been observed (Kojima, 1981; Campbel1, 1983b; Flemming and Sasynluk, 1989). MND also depressed $\dot{V}_{\max }$ in cardiac Purkinje fibers (Toy and Sasyniuk, 1990a). Its kinetics of interaction with the sodium channel are faster than with disopyramide. Unlike the parent compound, MND consistently shortened action potential duration in Purkinje fibers, but like the former prolonged it in ventricular muscle. At normal. heart rates, the combination of disopyramide and MND should increase depression of $\dot{v}_{\max }$ and prolongation of refractoriness. However, opposite effects on action potential duration by MND in Purkinje fibers may antagonize the Class II antiarrhythmic actions of disopyramide. 
Conversely, the Class III actions of disopyramide may also render it proarrhythmic. Torsade de pointes arrhythmias associated with prolongation of the $\mathrm{QT}_{\mathrm{c}}$ interval have been reported in patients during disopyramide therapy (Jackman et al., 1988). Studies with the Class Ia drug, quiridine, have implicated drug-induced early afterdepolarizations and triggered activity observed in vitro in the genesis of torsades de pointes (Roden et al., 1987; Davidenko et al., 1989; Sasyniuk et al., 1989). Similar effects of disopyramide and quinidine on action potential prolongation in vitro (Kus and Sasyniuk, 1978; Winslow et al., 1988 ) suggest that disopyramide may also induce early afterdepolaxizations and triggered activity. Abbreviation of action potential duration by MND in this situation, however, may oppose abnormal lenghtening of repolarization and be antiarrhythmic.

Therefore, the present study was undertaken to examine the interactions between disopyramide and MND with the sodium channel, using $\dot{V}_{\max }$ as an index of sodium channel block, and determine effects on effective refractory period and action potential duration. Effects on action potential duration were also investigated under conditions which facilitated induction of triggered activity. Some of these results have been published previously in abstract form (Toy and Sasyniuk, 1990b). 


\section{Methods}

\subsection{Experimental preparation}

Mongrel dogs of either sex were anesthetized with sodium pentobarbital $(30 \mathrm{mg} / \mathrm{kg})$ and their hearts were removed via a left thotacotomy. Both ventricles were thoroughly flushed with chilled, oxygenated Tyrode's solution. Purkinje fibers with small pieces of attached ventricular muscle were quickly excised and pinned to a sylgard block at the bottom of a tissue bath ( $4 \mathrm{ml}$ capacity). Fibers were continuously perfused with modified Tyrode's solution aerated with 95 \& $\mathrm{O}_{2}-5 \& \mathrm{CO}_{2}$ at a rate of $10 \pm 0.5 \mathrm{ml} / \mathrm{min}$. Our standard Tyrode's solution contained (in $\mathrm{mM}$ ): $\mathrm{NaCl}, 119.0 ; \mathrm{KCl}, 4.0 ; \mathrm{CaCl}_{2}, 1.8 ; \mathrm{MgCl}_{2}$, $0.5 ; \mathrm{NaHPO}_{4}, \mathrm{O} .9$; dextrose, 5.5; and $\mathrm{NaHCO}_{3}, 25$. $\mathrm{pH}$ of the solution was $7.33 \pm 0.03$. The temperature was maintained at $37.0 \pm 0.2^{\circ} \mathrm{C}$. To study drug-induced early afterdepolarizations and triggered activity the following changes were made with the superfusing Tyrode's solution (in mM): $\mathrm{KCl}, 2.7$; and $\mathrm{NallCO}_{3}, 12$. $\mathrm{pH}$ of the solution was reduced to 7.09 \pm 0.04 .

We used sma11, free-running intertrabecular Purkinje fiber bundles (length < 5 min) with attached ventricular muscle or ventricular papillary muscle preparations mainly from the right ventricle to study stcady-state and rate-dependent drug effects. Free running false tondons with small pieces of attached ventricular muscle predominantly from the left ventricular were used to study drug-induced early 
afterdepolarizations and triggered activity. Techniques for stimulating and recording have been described in detail previously (Valois and Sasyniuk, 1987; Toy and Sasyniuk, 1990a).

During control measurements and equilibration with drug, the preparations were stimulated at a basic cycle length of $1000 \mathrm{msec}$. Action potential variables were recorded on-line every 15 sec until steady-state effects were observed.

\subsection{Protocols}

To study the rate of development of $\dot{v}_{\max }$ depression with drive, the preparations were driven by 44 beat trains at an interstimulus interval of $600 \mathrm{msec}$. Rest periods between trains of stimuli were long enough to ensure full recovery from rate-dependent block.

To determine recovery from $\dot{v}_{\text {max }}$ depression, test pulses were introduced at varying diastolic intervals after a stimulus train had produced a steady-state level of $\dot{\mathrm{V}}_{\max }$ depression. The onset of diastole was defined as that time when repolarization had returned to the maximum diastolic potential. Test pulses were initially introduced during phase 3 of the action potential and then progressively later into diastole. The test intervals were initially increased in small increments and then progressively in larger steps with steps ranging from 50 to $10000 \mathrm{msec}$. Each recovery curve was comprised of a minimum of 30 points. The results were not used if there were more than 2 to $3 \mathrm{mV}$ of depolarization during the diastoic interval. 
To determine the effects on effective refractory period of the basic beat (SI) and sequential extrastimuli (S2-S4), test pulses of twice the diastolic threshold were introduced following steady-state changes in action potential parameters. Test pulses were initially introduced at the basic cycle length and then at progressively shorter intervals until they failed to elicit a response. The effective refractory period was defined as the shortest S1-S2 interval which elicited a propagated response. S2 was set at $10 \mathrm{msec}$ past the effective refractory period and $S 3$ was used to determined the effective refractory period of the response to 52 . Similarly, s3 was set at 10 msec past the effective refractory period and $\$ 4$ was used to determine the effective refractory period of the response to 33 . Preparations were stimulated at steady-state cycle lengths of 400 and $1000 \mathrm{msec}$.

All comparisons between control and drug conditions were made during the same impalement. $\dot{V}_{\max }$ was used as an indirect method to evaluate $I_{\mathrm{Na}}$. Although $\dot{\mathrm{V}}_{\max }$ is a monotonic but not a linear index of $\mathrm{I}_{\mathrm{Na}}$ (Sheets et al., 1988; Fozzard et al., 1989), $\dot{\mathrm{V}}_{\max }$ does reflect net maximal inward current during the action potential and can provide a convenient, albeit nonquantitative index of changes in $\mathrm{I}_{\mathrm{Na}}$.

To investigate the ability of disopyramide to induced early afterdepolarizations and triggered activity and to characterize its frequency dependence, preparations were perfused in the hypokalemic-acidotic Tyrode's solution described above. A low concentration of cesium chloride $(0.5-1 \mathrm{mM})$ was also added to the 
perfusate to reduce intrinsic automaticity by reducing the pacemaker current, If (Di Francesco, 1981). Early afterdepolarizations and triggered activity were induced by disopyramide in approximately 50 \& of preparations prior to addition of cesium (unpublished observations). Although both extreme acidosis or high concentrations of cesium alone have been used to induce triggered activity (Coraboeuf et al., 1980; Brachmann et al., 1983; Damiano and Rosen, 1984), the milder conditions of acidosis and lower concentrations of cesium we used do not induce triggered activity in Purkinje fibers stimulated at slow rates in the absence of drug (Valois and Sasyniuk, 1990, submitted). Purkinje fibers were exposed to a low therapeutic concentration of disopyramide (10 uM) for at least $1 \mathrm{hr}$ before data recording began.

The preparations were stimulated over a wide range of cycle lengths (1 - $6 \mathrm{sec})$. If early afterdepolarizations or triggered activity were observed, the pattern and range of cycle lengths over which they occurred were determined. At each frequency data was collected only after steady-state changes in action potential duration were achieved (minimum of 2 minutes). When triggered activity was sustuined and stable, a test drug (MND, mexiletine) was added to the disopyramide containing solution. Mexiletine was added during stimulation at slow rates. However, since effects with MND require at least $25 \mathrm{~min}$ to reach steady-state (Toy and Sasyniuk, 1990a), stimulation at slow rates was begun only after equilibration. 


\subsection{Drugs}

Disopyramide used was disopyramide phosphate for injection (Rythmodan). MND used was generously supplied by Roussel Laboratories. The concentration of disopyramide or MND used was 10 uM unless specified otherwise. Plasma concentrations of disopyramide in patients during chronic therapy range between $9-20 \mathrm{uM}$, while MND levels can reach up to 15 uM (Aitio, 1981; Bredesen, 1982; Brogden and Todd, 1987). Since the protein binding of disopyramide and MND in this concentration range vary from $50-80$ and $20-50$ \%, respectively (Aitio, 1981; Bredesen, 1982), concentrations used reflect therapeutic plasma levels of the free fraction of these drugs in patients. Mexiletine used was mexiletine hydrochloride generously supplied by Boehringer-Ingelheim. Drugs were added to Tyrode's solution made up from refrigerated stock solutions. Concentrations used refer to the concentration of the base.

\subsection{Data analysis}

Al1 action potential variables were deternined with a Data 6000 waveform analyzer as previously described (Sasyniuk and Jhamandas, 1984). Action potential variables measured werf: take-off potential; maximun diastolic priential; action potential amplitude; $\dot{V}_{\max } ;$ and APD at the 50, 75, and 958 levels of repolarization (APD 508, APD 758, and APD 958 respectively).

Where applicable, data are expressed as mean \pm S.D.. Paired Student's $t$ test was used to make statistical comparisons between control and drug effects on: steady-state action potential 
characteristics, tonic block and the slope of the action potential duration-rate relationship. One- or two-way analysis of variance and Newman-Keuls tests for multiple comparisons were used to compare drug effects on: rate-dependent block, recovery of $\dot{V}_{\text {max }}$ and effective refractory period. $\quad p<0.05$ was considered significant. Standard linear regression techniques were used to analyze the relationship between action potential duration and basic cycle length (Roden and llofeman, 1985). The time course of onset or recovery of $\dot{V}_{\text {max }}$ depression was defined with the use of a least square error nonlinear exponential fitting program (Hewlett-Packard Statistical Library). The time constants of onset or recovery of $\dot{V}_{\max }$ block contained only one component. Least squares analysis of the data indicated that this component could be approximated by a single exponential function of the form $Y=A \exp (-t / \tau)+B$. No attempt was made to fit the data with more complex functions. However, when appropriate, it was determined whether a double exponential function fit the data better than a single exponential. A double exponential was considered a better fit if the residual sum of squares for the double exponential was one-third or less than that for the single exponential (Clarkson and Hondeghem, 1985a).

\subsection{Definitions}

Early afterdepolarizations (EADs) and triggered activily were defined according to Cranefield (1975) and Damiano and Rosen (1984). An EAD was considered to be an afterpotential which interrupts or delays normal repolarization of the action potential. EADs and the triggered 
action potentials they induced were classified into two categories based on the membrane potential of the inflection point at which the repolarization process was interrupted. High-or low-membrane potential FADs were defined as depolarizing afterpotentials which delayed the terminal repolarization phase at membrane potentials more negative than $.45 \mathrm{mV}$ or less negative than $-30 \mathrm{mV}$, respectively. Low membrane potential EADs occurred too infrequently to permit analysis and will not be considered further. Thus, all references to EADs in this study refer to those at high membrane potentials.

These EADs either caused a delay of repolarization or gave rise to a second nondriven large amplitude upstroke. Characteristics of these triggered action potentials and their preceding diastolic intervals were measured off line on stored digitized traces. Activation voltage was defined as the membrane potential just prior to initiation of the depolarization phase of the triggered action potential. The coupling interval of the triggered response was defined as the time from the phase 0 upstroke of the driven action potential to phase 0 of the upstroke of the triggered action potential. For multilple triggered responses, the coupling intervals of the second and subsequent triggered action potentials were calculated from the upstroke of the preceding triggered response to the upstroke of the subsequent one. 


\section{Results}

\subsection{Effects at rapid stimulation rates}

\subsubsection{Effects on action potential characteristics in Purkinje fibers}

Table 1 summarizes the effects of disopyramide, MND and their combination on action potential characteristics in Purkinje fibers stimulated at a basic cycle length of $1000 \mathrm{msec}$. Disopyramide and MND administered singly did not alter the maximum diastolic potential but depressed $\dot{V}_{\max }$ and action potential amplitude, and shortened action potential duration. Addition of MND to disopyramide increased depression of $\dot{V}_{\max }$ and amplitude and shortening of all phases of repolarization. Similarly, addition of disopyramide to MND increased

depression of $\dot{V}_{\max }$ and amplitude and significantly shortened APD 50 and 758. Table 2 shows that the combination of disopyramide and MND produced effects consistent with the algebraic sum of the individual drug actions on all parameters with the exception of APD $95 \%$.

\subsubsection{Drug-induced tonic and rate-dependent block}

To investigate drug-induced depression of $\dot{V}_{\max }$ we used clinically relevant concentrations. Tonic block following a long rest period was produced by both disopyramide $(6.3 \pm 3.68 ; \mathfrak{n}=5)$ and MND $(2.5 \pm 2.98$; $\mathfrak{n}=4$ ) administered singly. The combination of disopyramide and MND consistently increased the magnitude of tonic block regardless of the order of drug administration, although results were not statistically 
TABLE 1. Effects of disopyramide, MND and their combination on action potential characteristics in canine Purkinje fibers

\begin{tabular}{|c|c|c|c|c|c|c|}
\hline & $\begin{array}{l}\text { MDP } \\
(\mathrm{mV})\end{array}$ & $\begin{array}{l}\text { AMP } \\
(\mathrm{mV})\end{array}$ & $\begin{array}{c}\dot{V}_{\max } \\
(\mathrm{V} / \mathrm{sec})\end{array}$ & $\begin{array}{l}\text { APD 50\% } \\
\text { (msec) }\end{array}$ & $\begin{array}{l}\text { APD } 75 \% \\
\text { (msec) }\end{array}$ & $\begin{array}{l}\text { APD } 95 \% \\
\text { (msec) }\end{array}$ \\
\hline $\begin{array}{l}\text { Control } \\
\text { Diso } 10 \text { uM } \\
\text { Combination } \\
(n=6)\end{array}$ & $\begin{array}{l}-91.0 \pm 2.8 \\
-90.5 \pm 3.7 \\
-89.9 \pm 3.3\end{array}$ & $\begin{array}{l}124.1 \pm 4.9 \\
120.6 \pm 5.0^{* *} \\
197.0 \pm 5.4^{c}\end{array}$ & $\begin{array}{l}565 \pm 65 \\
502 \pm 45^{\star \star} \\
470 \pm 52^{c}\end{array}$ & $\begin{array}{l}241 \pm 32 \\
206 \pm 39^{\text {}} \\
184 \pm 40^{c}\end{array}$ & $\begin{array}{l}278 \pm 38 \\
264 \pm 43^{*} \\
251 \pm 43^{c}\end{array}$ & $\begin{array}{l}316 \pm 40 \\
312 \pm 43 \\
306 \pm 43^{c}\end{array}$ \\
\hline $\begin{array}{l}\text { Control } \\
\text { MNO } 10 \text { uM } \\
\text { Combination } \\
(n=4)\end{array}$ & $\begin{array}{l}-93.9 \pm 2.1 \\
-92.3 \pm 2.5 \\
-92.7 \pm 1.1\end{array}$ & $\begin{array}{l}126.4 \pm 3.1 \\
123.7 \pm 2.6^{*} \\
120.6 \pm 1.8^{d}\end{array}$ & $\begin{array}{l}509 \pm 15 \\
495 \pm 32^{*} \\
447 \pm 43^{d}\end{array}$ & $\begin{array}{l}224 \pm 28 \\
197 \pm 7^{*} \\
143 \pm 15^{d}\end{array}$ & $\begin{array}{l}265 \pm 65 \\
250 \pm 17^{\star} \\
238 \pm 20^{d}\end{array}$ & $\begin{array}{l}304 \pm 26 \\
294 \pm 22 \\
296 \pm 22\end{array}$ \\
\hline
\end{tabular}

Values are expressed as mean $\pm S . D$. Fibers were stimulated at a BCL of $1000 \mathrm{msec}$.

MDP = maximum diastolic potential; AMP = amplitude; APD 50\%, APD $75 \%$, APD $95 \%=$ action

potential duration at 50,75 , and $95 \%$ levels of repolarization; ${ }^{a} D I S O=$ disopyramide; combination = disopyramide $10 \mathrm{UM}+$ MND $10 \mathrm{uM}$.

"significantly different from control, $p<0.05 ;{ }^{* *} p<0.01$.

csignificantly different from disopyramide alone $(p<0.05)$.

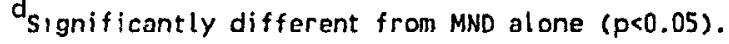


TABLE 2. Effects of the interaction between disopyramide and MND on action potential characteristics in canine Purkinje fibers

\& DEPRESSION

$\begin{array}{ccc}\text { Disopyramide } 10 \text { uM } & \text { MND } 10 \text { uM } & \text { Combinationa } \\ (n=6) & (n=4) & (n=10)\end{array}$

$\begin{array}{lrrr}\text { AMP } & 2.9 \pm 1.4 & 2.1 \pm 1.2 & 5.1 \pm 2.0 \\ \dot{\mathrm{V}}_{\max } & 10.9 \pm 4.5 & 3.7 \pm 3.3 & 15.0 \pm 5.2\end{array}$

\& SHORTENING

$\begin{array}{ccc}\begin{array}{c}\text { Disopyramide } \\ (n=6)\end{array} & \text { MND } 10 \text { uM } & \text { Combinationa } \\ & (n=4) & (n=10)\end{array}$

$\begin{array}{lrrr}\text { APD } 508 & 14.9 \pm 6.3 & 11.6 \pm 8.6 & 28.6 \pm 11.4 \\ \text { APD } 758 & 5.4 \pm 3.6 & 5.2 \pm 4.1 & 10.1 \pm 5.1 \\ \text { APD } 958 & 1.4 \pm 3.4 & 3.6 \pm 2.5 & 3.1 \pm 3.4\end{array}$

Values are expressed as mean \pm S.D.

AMP $=$ amplitude; APD 508, APD 758, APD 958 = action potential.

duration at 50,75 , and $95 \&$ levels of repolarization.

${ }^{a}$ Combination = disopyramide $10 \mathrm{uM}+$ MND $10 \mathrm{uM}$. 
significant. The increase in tonic block with the combination (".1 1 $6.0 \% ; n=9)$, nevertheless, was consistent with effects predicted by an additive interaction of the two drugs $\left(\begin{array}{ll}8.8 & 8\end{array}\right)$.

Both disopyramide and MND alone produced rate-dependent block at an Enterstimulus interval of $600 \mathrm{msec}$. The results are summarod in Table 3. The rate constant and magnitude of rate-dependent block in the presence of disopyramide was greater than with MND. The mainicude of rate-dependent block with the combination was equivalent to the sum of effects produced by both drugs while the rate constant was not significantly different from that with MND alone Figure 1 illustrates a typical example of tonic and rate-dependent block produced by disopyramide versus the combination of disopyramide and MND.

\subsubsection{Effects on action potential duration during abrupt decreases} in cycle length

Drug-induced changes of action potential duration reflect their effects on ion currents during action potential repolarization. Figure 2 shows a typical example of drug-induced changes in action potential duration during onset of a rapid pulse train following a long, rest perlod. Under control conditions and in the presence of drug, APD 95\% of the first action potential of the trains were prolonged Prolongation of APD $95 \%$ in the presence of disopyramide was tremendous compared to control conditions, suggesting block of potassiun chanmels in well polarized tissue. APD 508 of the first action potential and steady-steady APD 50 and 958 in the presence of disopyranide, however, 
TABLE 3 Effects of disopyramide, MND and their combination on the rate constant and magnitude of rate-dependent block

\begin{tabular}{llc} 
Drug & Rate constant (pulses) & RDB (8) \\
\hdashline $\begin{array}{l}\text { Disopyranide } 10 \mathrm{uM} \\
(\mathrm{n}=6)\end{array}$ & $7.04 \pm 0.96$ & $11.1 \pm 2.0$ \\
$\begin{array}{l}\text { MND } 10 \mathrm{uM} \\
(\mathrm{n}=4)\end{array}$ & $4.39 \pm 1.58^{*}$ & $6.3 \pm 1.1^{*}$ \\
$\begin{array}{l}\text { Combination } \\
(\mathrm{n}=10)\end{array}$ & $4.56 \pm 1.94^{*}$ & $15.1 \pm 3.9^{*+}$
\end{tabular}

Values are expressed as mean $\pm S . D$. Fibers were stimulated at an interstimulus interval of $600 \mathrm{msec} . \mathrm{RDB}=$ rate-dependent block.

"Combination $=$ disopyramide $10 \mathrm{uM}+$ MND $10 \mathrm{uM}$.

"Onset of block in the presence of the combination was best fitted by a single exponential

"Significantly different from disopyramide alone, $p<0.05$;

'significantly different from MND alone, $p<0.05$ (anova). 
Figure 1 - Typical example of the effects of disopyramide and the combination of disopyramide and MND on tonic and rate-dependent block in Purkinje fibers. $\dot{\mathrm{V}}_{\max }$ (top panel) and take-off potential (TOP; bottom panel) are plotted for each action potantial during, the stimulus train under control conditions (diamond), and following disopyramide 10 uM (square), and the combination of disopyramide 10 uM and MND 10 uM (triangle). Each stimulus train was preceded by a quiescent interval of $60 \mathrm{sec}$. Rate-dependent depression of $\dot{V}_{\text {max }}$ was minimal under control conditions and mal be attributed to a small decline in take-off potential during, the stimulus train. Rate constants were 6.44 and 4.47 pulses, tonte block was 5.2 and 8.6 \& and rate-dependent block was 7.6 and $9.2 \%$ following disopyramide and the combination of disopyramide and MND, respectively. The interstinulus interval was $600 \mathrm{msec}$ 

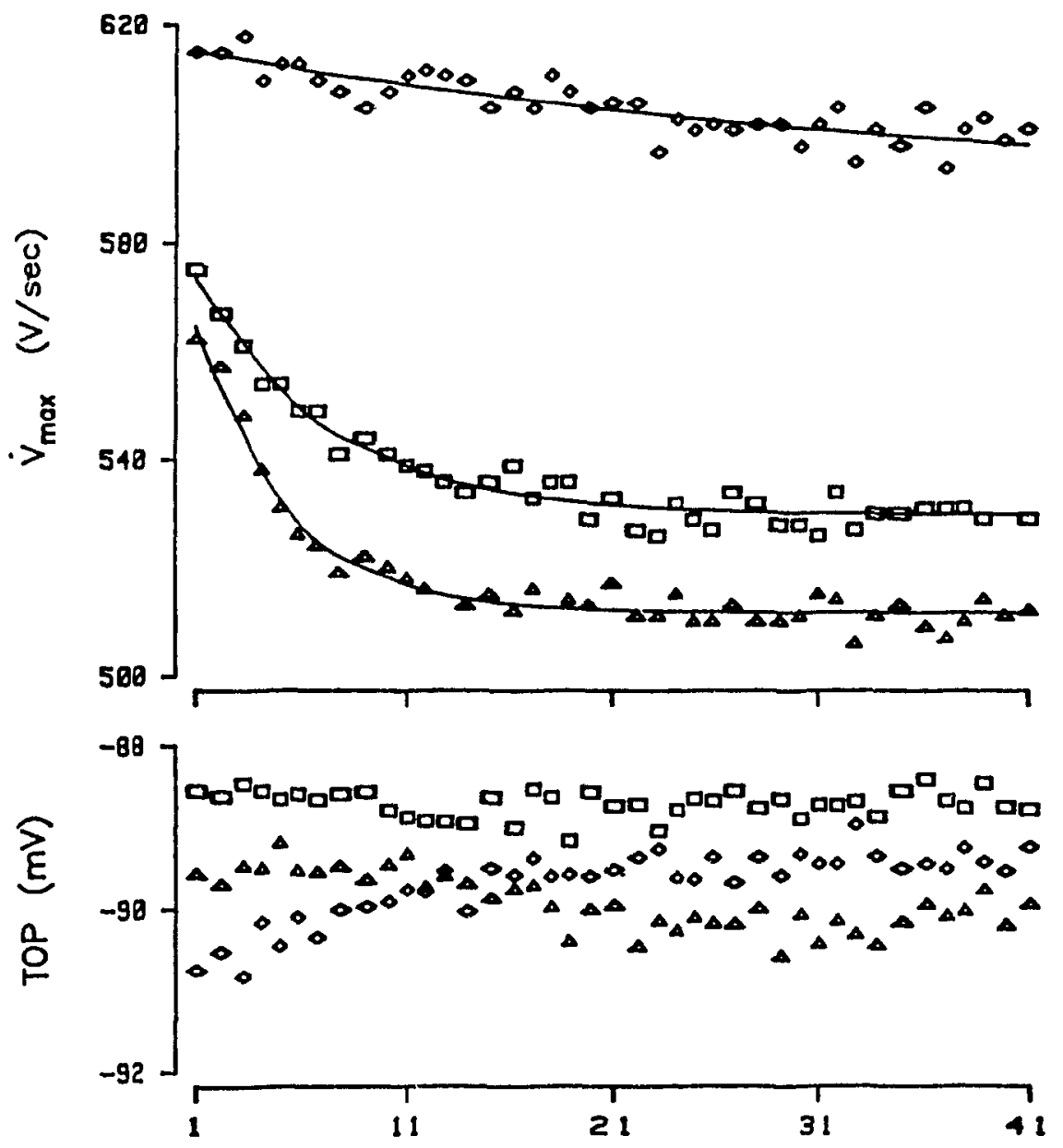

Pulse Number 
Figure 2 - Typical example of the effects of disopyramide and the combination of disopyranide and MND on rate dependent changres in action potential duration during onset of a stimulus tran in Purkinje fibers. APD 508 (top pane1) and APD 958 (bot tom panel) are plotted for each action potental during the ct imulus tran under control conditions (diamond), following disopylumble 10 uM (square), and the combination of disopyramide 10 uM and MNI) 10 UM (triangle). The stimulus train was preceded by a quiescent interval of $60 \mathrm{sec}$. The interstimulus interval was $690 \mathrm{mscc}$ 

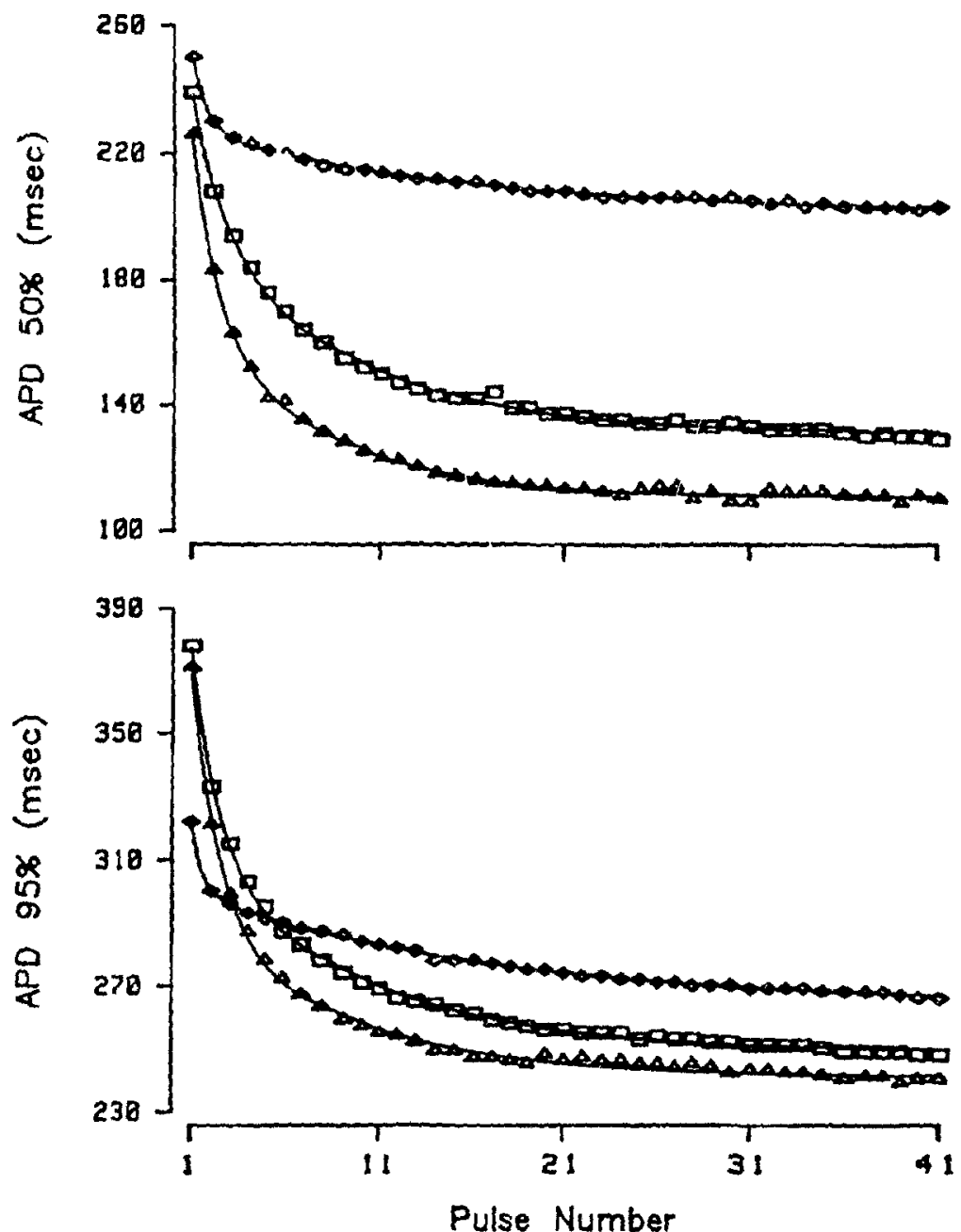
were abbrevated compared to control conditions The comblnation at disopyramide and MND increased the shortening produced by disopyrunide alone but did not alter APD 958 of the first action potential compured to disopyramide alone. Qualitatively similar results were observed in s other experiments.

41.4 Characteristics of recovery from rate-depondent block

The time course of $\dot{V}_{\max }$ recovery in the presence of the combination of disopyramide and MND was best approximated by a single exponential function with a time constant of $910 \pm 2.17 \mathrm{sec}(\mathrm{n}=4)$ The mugnitule of early diastolic block was $148 \pm 41$ \& Recovery tume comstant, under control conditions could not be deternined since $\dot{V}_{\text {mal }}$ has, all walv attaned its maximum value following action potential repolariat ion

Figure 3 summarizes the effects of disopyramide versus, the combination of disopyramide and MND on recovery of $\dot{V}_{\text {max }}$ over a clinically relevant diastolic interval. Disopyramide produced a significant depression of $\dot{V}_{\text {max }}$ at zero diastolic intorval which remalum throughout the $2 \mathrm{sec}$ interval. The combination of disopyrande and Hidl), 10 and 20 uM, produced a further depression of $\dot{V}_{\text {likis at aro diastola }}$ interval which also persisted throughout the 2 sec diastolic interval

\subsubsection{Effects on effective refractory period}

The ability of disopyramide versus the combuntion of disopyramide and IIND to protong the effective refractory period of basic batas vereac tightly coupled sequential extrastamuli is sumarized in Figure $t_{4}$ 


\begin{abstract}
Figure 3 - Effects of disopyramide and the combination of di copyraniae and MND on recovery of $\dot{v}_{\max }$ over a clinically rolevant diastolic interval $\dot{\mathrm{V}}_{\text {Inax }}$ is plotted over a distolic interval of 2 sec under control conditions (diamond), following di sopyramide 10 uM (square), and the combination of disopyramide $10 \mathrm{UM}$ and MND $10 \mathrm{UM}$ (triangle) or MND $20 \mathrm{uM}$ (sircle). Data points ropresont mean $\pm S D$ of 6 experiments in Purkinje fibers "significantly different from control, $\mathrm{p}<0.01$; tsignificantly diflerent from dasopyramide $10 \mathrm{uM}, \mathrm{p}<0.05, \phi_{\text {significantly }}$ differont from disopyramide 10 wh + MND 10 uM, $p<0.01$ (anova)
\end{abstract}




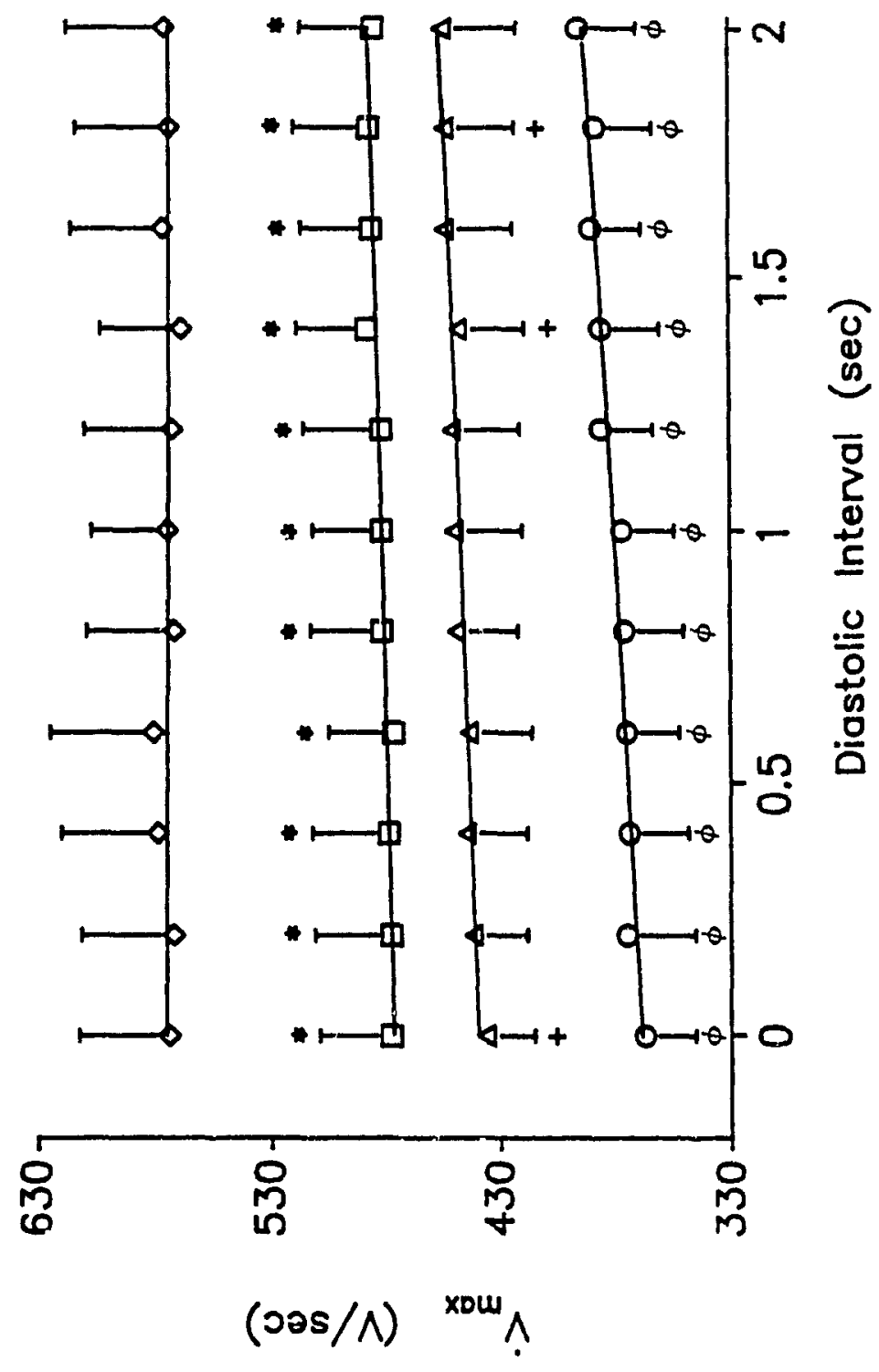


Figurc 4 - Effects of disopyramide and the combination of disopyramida and $M N D$ on the effective refractory period in Purtinje fibers versus ventricular muscle. Effective refractory perrod of the basic beat (SI) and 3 subsequential extrestimuli (S2, S3 and $S 4$ ) in Purkinje fibers (top panels) and ventricular muscle (bottom panels) are plotted under control conditions (diamond), following disopyramide $10 \mathrm{uM} \mathrm{(square)} \mathrm{and} \mathrm{the}$ combination of disopyramide 10 UM and MND 10 UM (triangle). Data points reprosent mean \pm S.D. of 6 and 5 experiments in Purkinje fibres and ventricular muscle, respectively. The cycle lengths were 1000 (left panels) and $400 \mathrm{msec}$ (right panels). "significantly different from control, $p<0.05, * * p<0.01 ;$ 'significantly different from disopyramide $10 \mathrm{uM}, \mathrm{p}<0.05$ (anova). 

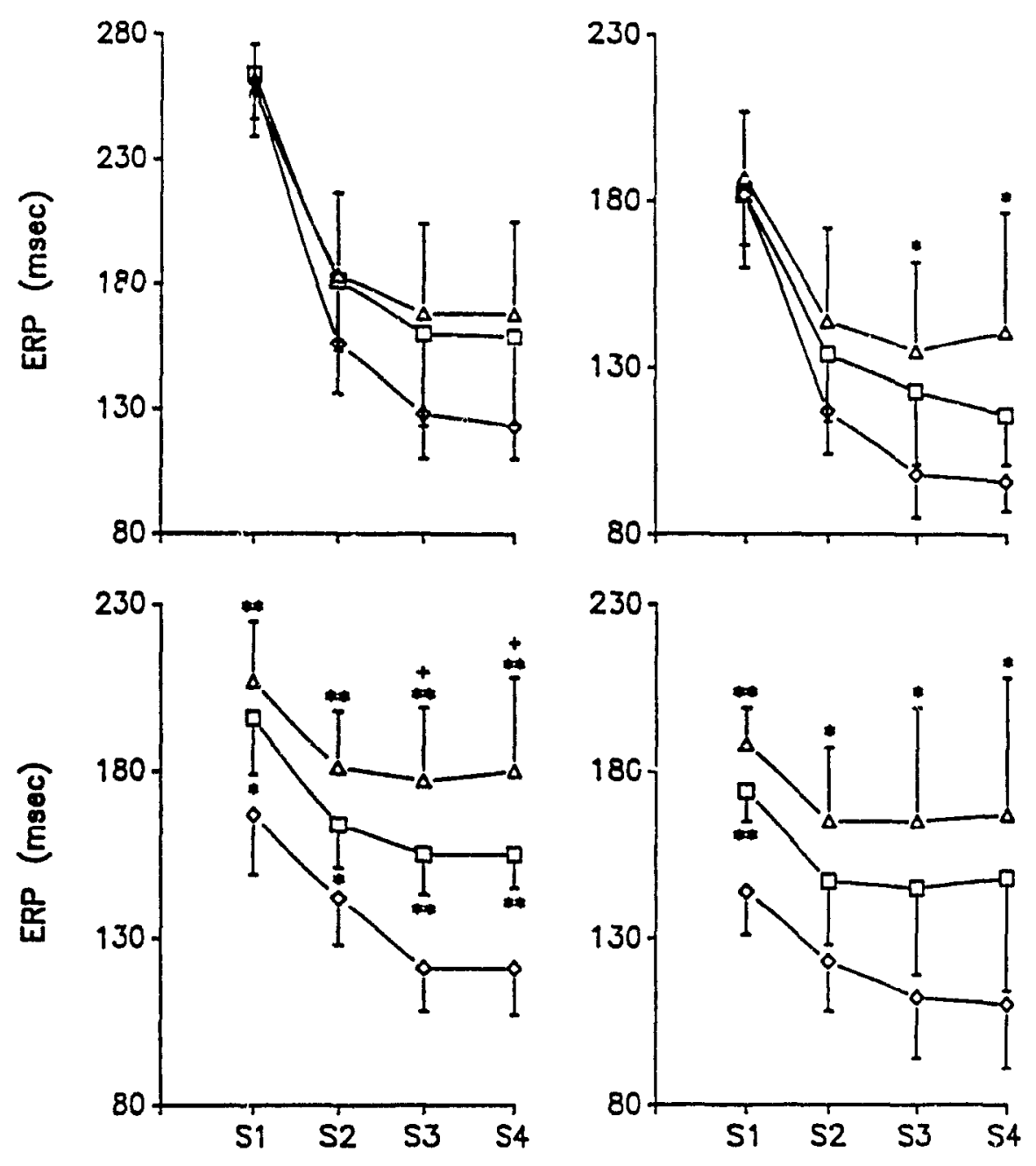
Disopyramide consistently but nonsignificantly increased the effective refractory period of the 3 sequential extrastimuli but not the basic beat in Purkinje fibers This effect was enhanced by the comoination of disopyramide and MND and was rate-dependent, there was a greater increase in effective refractory period with each subsequent extrastimulus.

Under control conditions, the effective refractory period shortened minimally in ventricular muscle compared to Purkinje fibers when the basic cycle length was decreased from 1000 to $400 \mathrm{msec}$. Disopyramide consistently increased the effective refractory period of both the basic beat and the 3 sequential extrastimuli. This effect was further enhanced by the combination of disopyramide and MND.

\subsection{Effects at slow stimulation rates}

\subsubsection{Action Potential Duration in the Absence of Triggered Activity}

We investigated the ability of disopyramide to induce triggered activity in a total of 17 preparations. In 4 preparations, we were able to define the relationship between action potential duration and stimulation frequency. Figure 5 summarizes the effects of disopyramide (10 UM) on the steady-state action potential duration-rate relationship at cycle lengths from 1 to $5 \mathrm{sec}$. There was a rate-related increase in action potential duration under control conditions which was linear in the $\log$ cycle length versus action potential duration plot $(r=.992)$. 
Figure 5 - Effects of disopyramide on the action potential duration-rate relationship in Purkinje fibers. Action potential duration is plotted over the range of cycle lengths of 1000 to 5000 msec under control conditions (circle), and followng disopyramide 10 uM in the presence of hypokalemia, acidosis and cesium $05 \mathrm{mM}$ (square) The slope was 0147 and 0.400 under control conditions and following disopyramide, respectively Data points represent mean \pm S.D. of 4 experiments. Error bars located within symbols were not plotted. Action potential duration is also plotted for 2 experiments in which disopyrumide, under identical conditions, Induced EADs and triggorod activity (triangle). Deviation of the action potential duration-rate relation from linearity was due to the appearance of EAls Action potential duration was not plotted for stimulatod boats accompanied by triggered action potentials. 


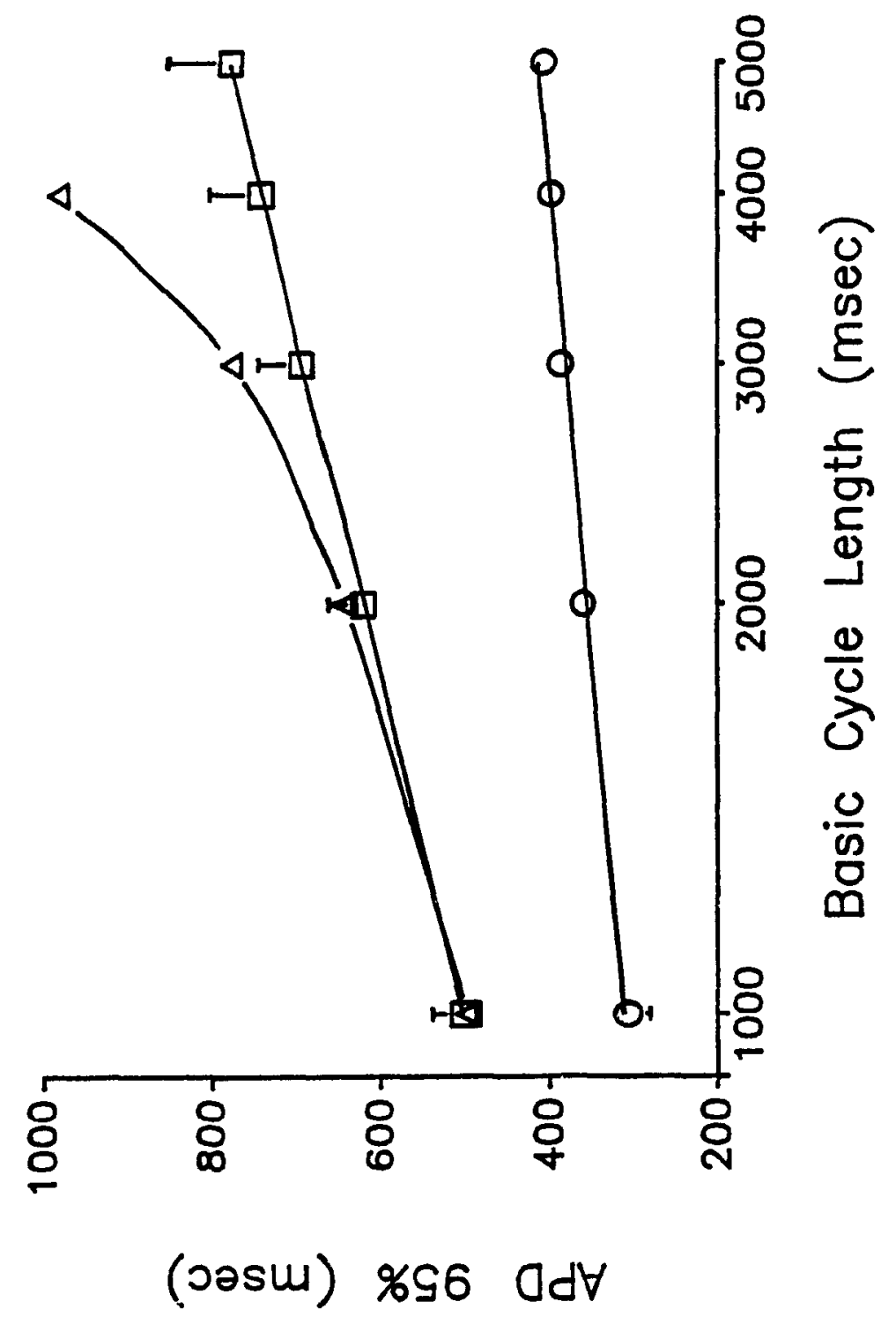


Disopyramide in a hypokalemic-acidotic Tyrode's solution producad a reverse use-dependent prolongation of action potential duration and increased the slope of the relationship $(p<0.05)$ This relationship could not be determined for the hypokalemic-acidotic Tyrode's solution in the absence of drug due to automaticity. When disopyramide did induce EADs and triggered activity, the action potential duration-rate relationship deviated from linearity at longer cycle lengths (Figure 5).

42.2 Early Afterdepolarizations (EADs) and Triggered Activity

In 13 preparations superfused with the hypokalemic-acidotic Tyrode's solution, disopyramide (10 uM) induced EADs and triggered activity during bradycardia. This activity attended by marked prolongation of repolarization generally appeared $60-90 \mathrm{~min}$ after adminis ration of disopyramide. In any given preparation, there was a characteristic relationship between the steady-state pattern of aclivily and basic cycle length. Figure 6a shows a typical example. EADs delayed repolarization of each action potential at a basic cycle length of $2 \mathrm{sec}$ and became more prominent at $3 \mathrm{sec}$. At $4 \mathrm{sec}$, a triggerod action potential followed the EAD of every third action potential. As the stimulation rate was further slowed, there was an increase in the incidence of triggered action potentials. At a cycle length of 5 sec, 2 of every 3 action potentials were followed by a triggered action potential. Finally, at $6 \mathrm{sec}$, every action potential was followed by a triggered response. 
Figure 6 - (a) Typical example of the effects of cycle length on EADs and triggered activity induced by disopyramide $10 \mathrm{uM}$ in the presence of hypokalemia, acidosis and cesium $0.5 \mathrm{mM}$ in Purkinje fibers. Transmembrane action potentials at cycle lengths ranging from 1 to $6 \mathrm{sec}$ are plotted. (b) Transmembrane action potentials at cycle lengths of 4 to $6 \mathrm{sec}$ are superimposed. 
(a)

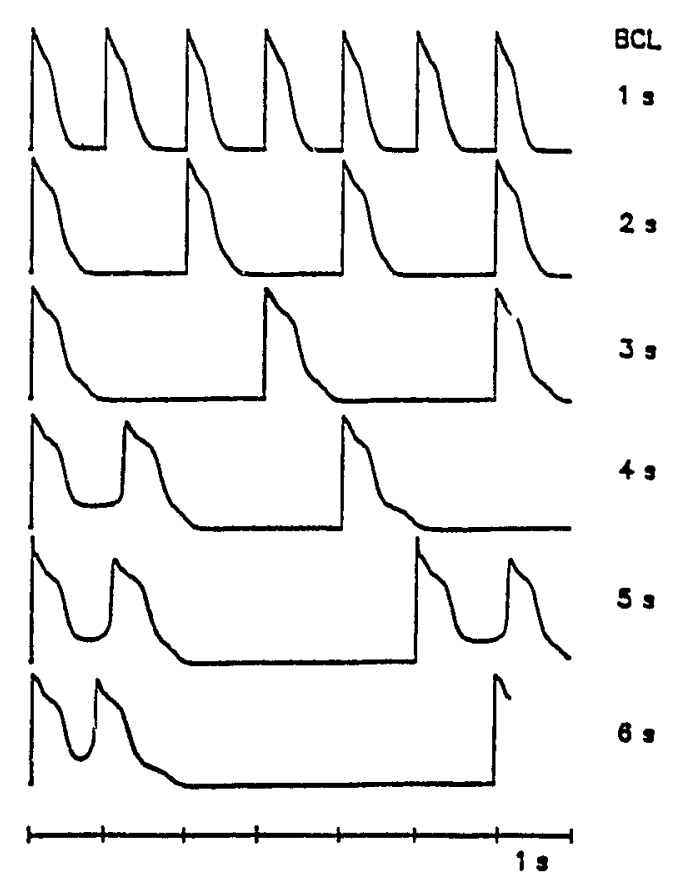

(b)

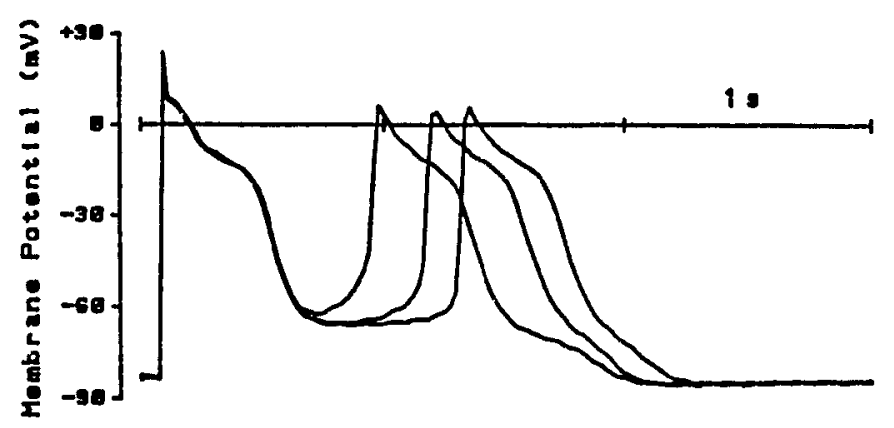


In all preparations, there was a similar progression from action potential prolongation to the appearance and increase in the size of EADs to induction and increase in the number of action potentials followed by triggered responses. Although the shortest cycle length at which triggered activity first occurred varied in different fibers, it was clearly bradycardia-dependent. Of the 11 Purkinje fibers studied, only 1 showed triggered activity at a cycle length of $2 \mathrm{sec}, 2$ at $3 \mathrm{sec}$, 11 at $4 \mathrm{sec}$ and all 13 at $5 \mathrm{sec}$.

In each preparation, consistent changes in triggered action potential characteristics were observed with changes in cycle length. slower stimulation rates shortened the coupling interval and decreased the activation voltage to more positive potentials (Figure 6b). Multiple triggered action potentials were observed only in a few fibers. In these examples, multiple responses occurred at longer cycle lengths than required for single responses. Each subsequent upstroke occurred at a more negative activation voltage until the last upstroke was followed by full repolarization. All triggered activity developed in the potential range in which the fast sodium current could be partially activated and thus exhibited fast upstrokes and prominent overshoots.

Disopyramide-induced EADs and triggered activity were never observed to occur in ventricular muscle. Triggered activity occurring in Purkinje fibers propagated to muscle to produce prolonged but otherwise normal action potentials. Figure 7 shows a typical example. 
Figure 7 - Typical example of the differential effects by disopyramide in the presence of hypokalemia, acidosis and cesium $0.5 \mathrm{mM}$ on induction of triggered activity in Purkinje fibers versus ventricular muscle. Transmembrane action potentials from a false tendon and a distal muscle cell from the left ventricle at a spontaneous cycle length of $5.5 \mathrm{sec}$ are plotted and superimposed. 


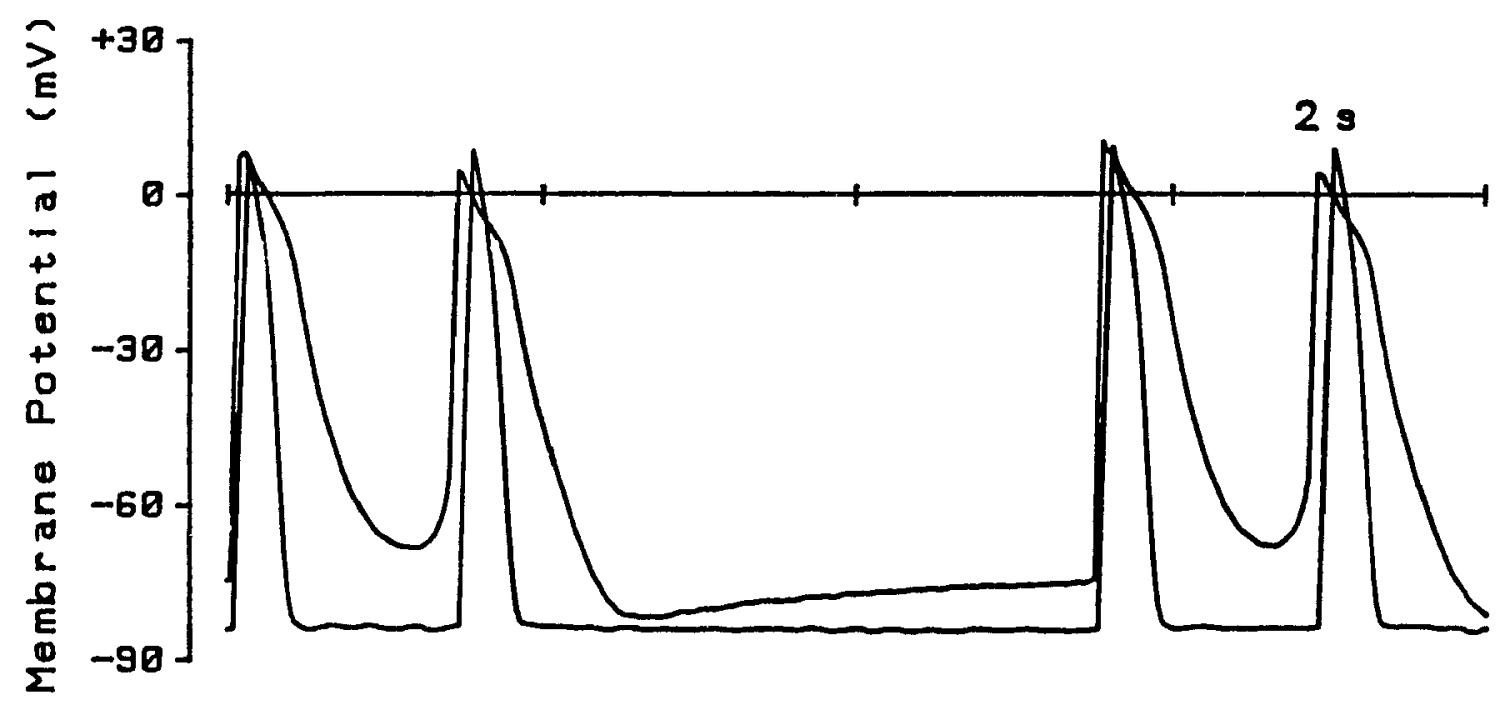




\subsection{Prevention and Abolition of Triggered Actw1ty}

\section{$42.3 .1 M N D$}

In 2 of 4 preparations with sustained and stable triggered activity, addition of MND (10 uM) to the superfusate shitced the incidence of triggered activity to longer cycle lengths Figure 8 shows one example. Disopyramide induced prominent EADs at a cycle longth of 3 sec and triggered action potentials at 4 and 5 sec Superfusion with the combination of disopyramide and MND prevented EADs and triggered activity at cycle lengths of 3 and $4 \mathrm{sec}$, respectively Although triggered activity was still induced at $5 \mathrm{sec}$, triggered action potentials occurred relatively later during repolarization and at mor negative membrane potentials. Also, triggered responses did not follow every action potential as before. Washout of MND revorsol these effects. In the other 2 experiments, MND had no effects on the cycle length dependence of triggered activity.

\subsubsection{Mexiletine}

In 4 preparations, therapeutic concentrations of mexiletine $(8-11$ uM) was added to the superfusate. In all experiments, mexiletine abolished triggered activity and eliminated EADs within minutes, of administration. Following exposure to mexiletine, there was a prolongation of the coupling interval and an incroase in the activation voltage (more negative) of the triggered action potential until it was abolished (Figure 9a). Subsequently, there was a progressive decrease in the magnitude and duration of EADs thereby shortening action potential duration (Figure 9b). Thus, abolition of triggered action 
Figure 8 - Example of the effects of MND on EADs and triggered activity induced by disopyramide in Purkinje fibers Transmembrane action potentials at cycle lengths ranging from 1 to 5 sec are plotted following disopyramide $10 \mathrm{uM}$ (left panels), the combination of disopyramide 10 uM plus MND 10 uM (middle panels), and disopyramide 10 uM after washout of MND (right panels) in the presence of liypokalemia, acidosis and cesium $0.5 \mathrm{mM}$ 

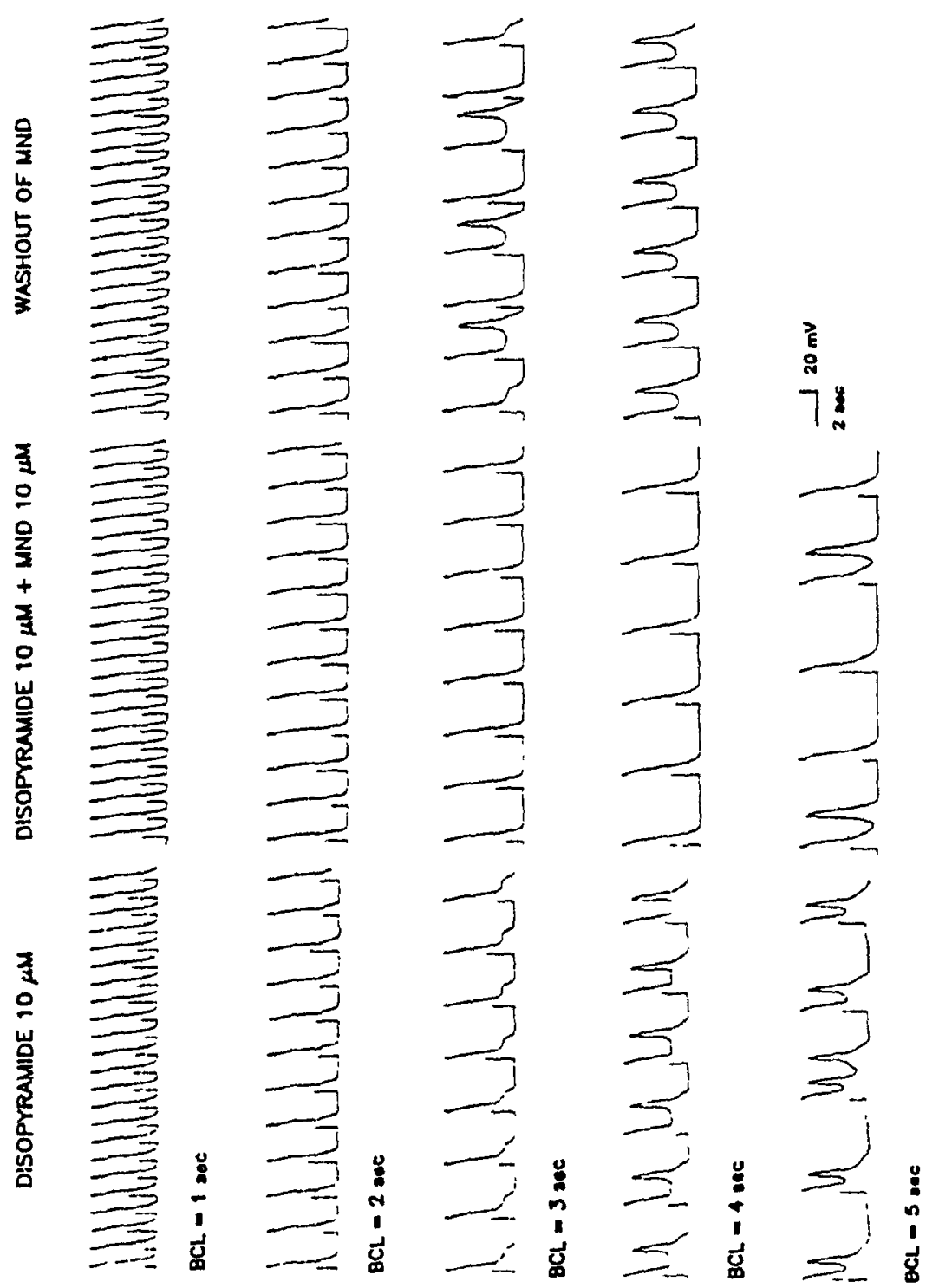
Figure 9 - Typical examples of the effects of mexiletine on EADs and triggered activity induced by disopyramide $10 \mathrm{uM}$ in the presence of hypokalemia, acidosis and cesium $0.5 \mathrm{mM}$ in Purkinje fibers. (a) Transmembrane action potentials showing the abolition of triggered action petentials following addition of mexiletine 8 uM at a cycle length of $4 \mathrm{sec}$ are plotted and superimposed. (b) From a different preparation, transmembrane action potentials recorded from both the septal (S) and papillary muscle (PM) insertion regions of the false tendon are plotted following steady-state changes in the presence of disopyramide 10 uM (top panels), the combination of disopyramide 10 wil plus mexiletine 11 uM (middle panels), and disopyramide $10 \mathrm{uM}$ after washout of mexiletine (bottom panels). 
(a)

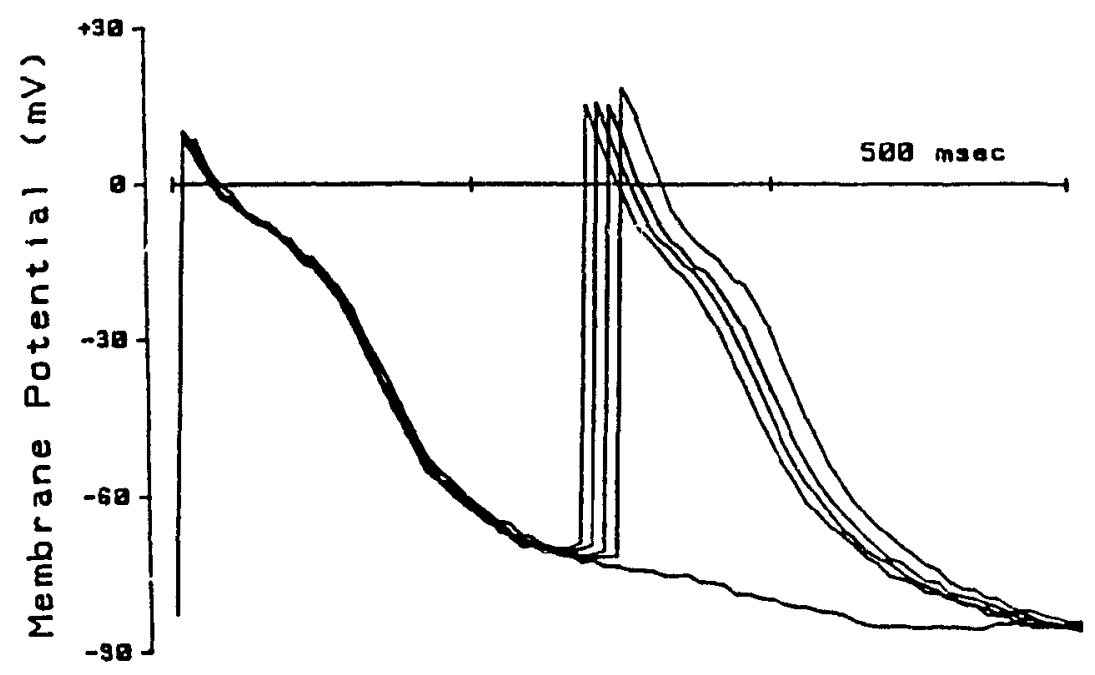

(b)
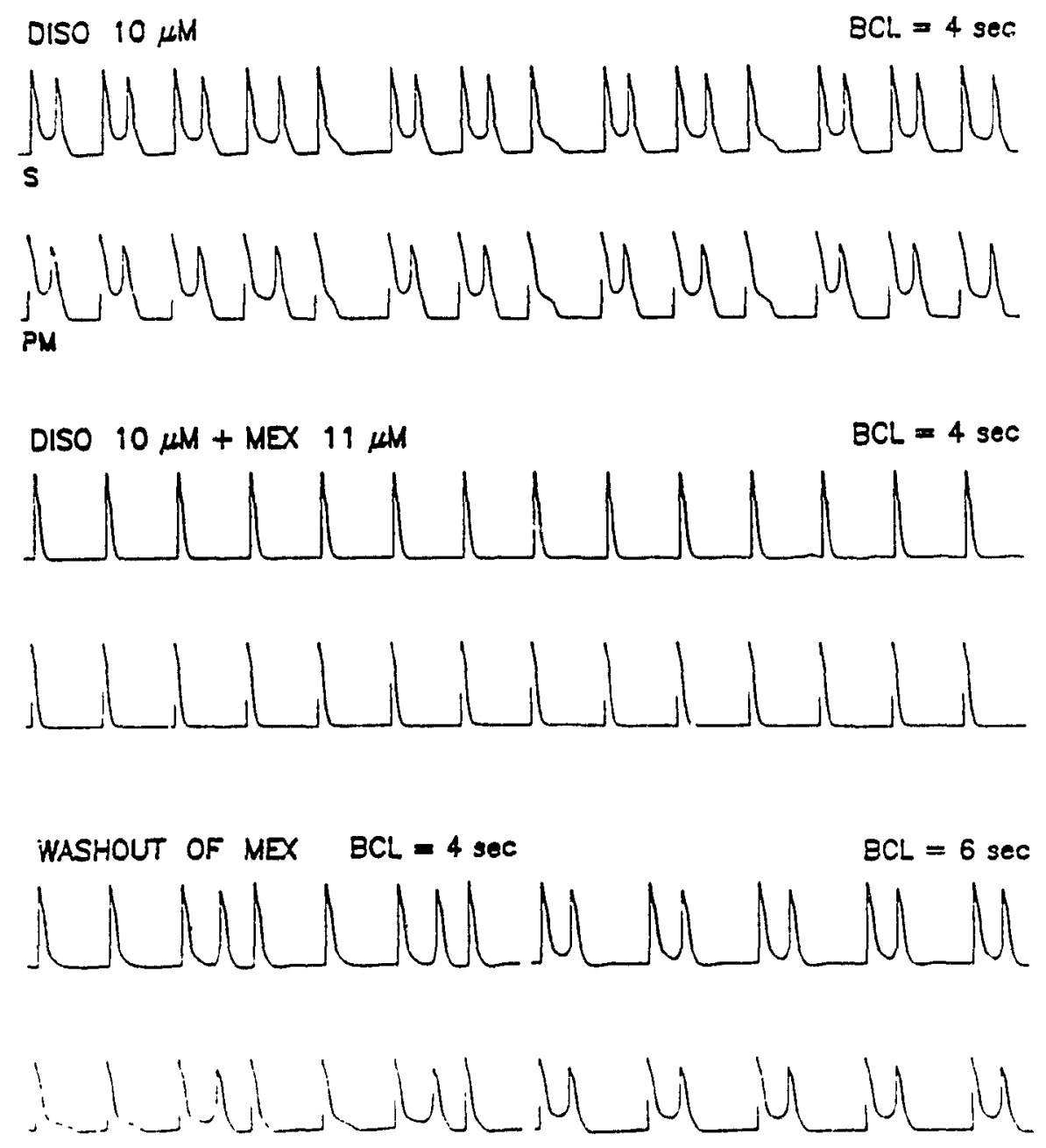
potentials occurred prior to shortenting of action potential duration. Romoval of mexiletine from the superfusate led to the reappearance of EAise, and triggered action potentials.

42,3 Pathe

In all Purkinje fibers, EADs and triggered activity occurring durng, bradycardia was immediately abolished by an abrupt increase in the driving rate to $1 \mathrm{~Hz}$. This effect was accor ranied by shortening of action potontial duration

'Discussion

Our results show that the interaction between disopyramide and MND at clinically relevant concentrations and heart rates produced additive affer on the magnitude of tonic and rate-dependent $\dot{v}_{\text {max }}$ depression. Thu combination produced net effects on shortening of the plateau phase of the actom potential which were also additive. These effects are most lilely related to block of sodium channels by both drugs. Additive effects were not observed on phase 3 repolarization presumably due to the effects of disopyramide in blocking potassium channels.

Both disopyramide and MND produces a depression of $\dot{V}_{\max }$ which reovers minimally over the clinical range of diastolic intervals. Both Wugs also produced a prolongation of effective refractory periods. The iflocts of the combination resemble that expected from an increase in dirug concentration of either drug. Additive increases in the magnitude of tonic and rate-dependent block have been previously seen with the 
combination of quinidine and propafenone due to similar kinetics of onset and recovery for both drugs (Kohlhardt and Seifert, 198j). MND has a recovery time constant which is approximately three time faster than disopyramide (Flemming and Sasyniuk, 1989; Toy and Sasyniuk, 1990a), however, at heart rates of $1 \mathrm{~Hz}$ or faster recovery from $\dot{v}_{\text {max }}$ depression with both drugs is slow enough to appear indistinquishable.

The recovery kinetics of rate-dependent block produced by the combination of disopyramide and MND was best described by a single exponential process with a time constant intermediate to values for each drug singly: smaller than disopyramide alone (Campbel1, 1983a; Flemming and Sasyniuk, 1989; Gruber and Carmeliet, 1989; Hiraoka et al., 1989) and greater than MND alone (Toy and Sasyniuk, 1990a). The rate constants of onset and magnitude of rate-dependent block with the individual drugs were within the range of values previously observed (Flemming and Sasyniuk, 1989; Toy and Sasyniuk, 1990a). Onset kinetics with the combination treatment was also characterized as a single exponential but was similar to the faster kinetics (smaller rate constant) with MND alone. This may be accounted for by a higher total concentration of drug in the presence of the combination. Both disopyramide and MND have been shown to produce a concentration-dependent increase in the kinetics of onset (Flemming and Sasyniuk, 1989; Toy and Sasyniuk, 1990a).

Monoexponential kinetics have been observed with the combination of quinidine and propafenone (Kohlhardt and Seifert, 1985), while two components described the exponential onset or recovery produced by the 
combinations of propafenone plus lidocaine or prajmalium (Kohlhardt and Seifert, 1985) or mexiletine (Valenzuela et al., 1989), and quinidine plus tocainide (Valois and Sasyiuk, 1987) or mexiletine (Roden et al., 1987). Biexponential kinetics with combinations of drugs result with one component being attributable to each drug and have veen distinquished only when the difference between the two components were approximately one order of magnitude or greater. Single exponential processes with the combination of disopyramide and MND are most likely observed because the components of each drug cannot be resolved with our protocol and are not due to any physiological changes in onset or recovery processes of $\dot{\mathrm{v}}_{\max }$ depression.

The effective refractory period is a function of both action potential duration and rate-dependent block of rapid sodium channels. The effects of the latter component is consequentially related to the kinetics of onset for a particular drug (Campbe11, 1983b). In Purkinje fibers, shortening of action potential duration by both disopyramide and MND may have offset any increase in effective refractory period of the basic beat produced by block of sodium channels. However, since both disopyramide and MND have relatively slow onset kinetics and require several beats to produce significant effects, prolongation of refractoriness with each subsequent extrasystoles may be due to a rate related increase in the block of sodium channels. Similar effects by disopyramide on effective refractory period have been shown previously by Flemming and Sasyniuk (1989) in Purkinje fibers. 
Unlike in Purkinje fibers, both disopyramide and MND prolonged action potential duration in ventricular muscle (Kojima, 1981; Campbe11, 1983b; Toy and Sasyniuk, 1990a), and in the present study prolonged the effective refractory period of the basic beat. Although block of sodium channels may have contributf to increases in the effective refractory period, rate-independent prolongation of the effective refractory period of the extrasystoles suggest that the predominant effect was due to prolongation of action potential duration.

At therapeutic concentrations and normal heart rates, both shortening and prolongation of action potential duration (APD 95\%) was observed with disopyramide in Purkinje fibers. Variable effects on action potential duration have been previously noted and are likely due to concommitant effects by disopyramide on several membrane conductances during repolarization (Coraboeuf et al., 1988; Flemming and Sasyniuk, 1989). Disopyramide depresses both the TTX-sensitive sodium "window" and slow calcium currents which help to sustain the platea's of the action potential, as well as outward potassium currents involved in repolarization (Coraboeuf et al., 1988; Hiraoka et al., 1989). Although disopyramide predominantly shortened action potential duration in the present study, prolongation of action potential duration was also observed. MND abbreviated repolarization regardless of the effects of disopyramide. However, despite statistically significant effects, the overall changes in action potential duration with either drug or their combination were minor $(\leq 10 \mathrm{msec})$ at clinically relevant heart rates. 
In contrast, after a long rest interval, disopyramide consistently produced a pronounced prolongation of action potential duration. These observations reaffirm results obtained previously by flemming and Sasyniuk (1989) with disopyramide. Furthermore, the most striking finding in our study was that in the presence of bradycardia, hypokalemia and acidosis, prolongation of action potential duration led to the development of EADs and triggered activity in Purkinje fibers. To our knowledge, this is the first report of triggered activity induced by disopyramide in vitro. A preliminary report has been previously presented (Sasyniuk et al., 1989). Triggered activity has been induced in Purkinje fibers by many antiarrhythmic drugs which prolong repolarization such as quinidine (Roden and Hoffman, 1985; Valois and Sasyniuk, 1987), NAPA (Dangman and Hoffman, 1981) and sotalol (Lathrop and Varro, 1990). Experimental investigations suggest that prolonged QT syndrome arrhythmias such as torsade de pointes in vivo may originate from drug-induced EADs and triggered activity in cardiac Purkinje fibers (Brachmann et al., 1983; Sasyniuk et al., 1989). Therapeutic doses of disopyramide have been associated with the occurrence of these arrhythmias in patients (Casedevant and Sabaut, 1975; Tzivoni et al., 1981; Schweitzer and Mark, 1982; Riccioni et al., 1983).

Abrupt increases in cycle length and hypokalemia are common clinical features of antia rhythmic drug-induced torsade de pointes (Jackman et al., 1988). Therefore, studies of the electrophysiological effects of antiarrhythmic drugs under these conditions are relevant. In 
addition, we used mild acidosis and bradycardia to set up an enviromment in vitro in which disopyramide would readily evoke triggered activity for systematic observation. Valois and Sasyniuk (199n, submitted) have investigated the role of acidosis on the characteristics of triggered activity. They found that acidosis prolongs action potential duration and slows the spontaneous cycle length which permits characterization of triggered activity during bradycardia.

The generation of triggered activity with disopyramlde may occur by a mechanism similar to that with the Class Ia drug quinidine. Both drugs induce triggered activity at low therapeutic doses associated with torsade de pointes arrhythmias in vivo (Valois and Sasyniuk, 1987; Stratmann and Kennedy, 1987). Quinidine blocks the time-dependent outward potassium current $\left(i_{K}\right)$ at negative resting mombrane potentials (Roden et al., 1988). This effect combined with further reductions in outward repolarizing current due to low rates and hypokalemia (Gadsby, 1980; Falk and Cohen, 1984; Scamps and Carmeliet, 1989) may be sufficient to allow normal inward currents during repolarization to precipitate triggered activity (Davidenko et al., 1989). In addition, block of sodium channels by quinidine may be attenuated at slower rates (Roden and Hoffman, 1985). Disopyramide has also been shown to reduce $i_{K}$ in Purkinje fibers (Coraboeuf et al., 1988). Although the time- and voltage-dependent reduction of this current by disopyramide remains to be elucidated, a pronounced resting block of these channels may account for reverse use-dependent effects on action potential duration and contribute to induction of triggered activity at slow stimulation rates 
As in previous experimental models (Sasyniuk et al., 1989), a marked prolongation of action potential duration in association with bradycardia was required for the induction of triggered activity with disopyramide. Once induced, there was a greater incidence of triggered action potentials at longer cycle lengths which occurred at shorter coupling intervals and more positive membrane potentials. These characteristics are similar to effects observed with the high membrane potential EADs and triggered activity induced by cesium (Damiano and Rosen, 1984), and indicate that there is an increase in the net inward current during repolarization with longer cycle lengths.

Addition of the Class Ib drug mexiletine readily eliminated triggered action potentials. Roden et al. (1987) attributed the abolition of qunidine-induced triggered activity by mexiletine to shortening of action potential duration and $\backslash$ or blocking of the inward current generating triggered activity. Our results show that mexiletine is also effective in abolishing triggered activity induced by disopyramide and suggest that there is first a reduction of excitability so that EADs are unable to produce triggered action potentials. This is then followed by a shortening of action potential duration and climination of EADs.

MND was effective in prolonging the cycle length at which triggered activity first appeared. In contrast to shortening of action potential duration at normal heart rates, in 2 experiments MND prolonged repolarization during bradycardia under the conditions used to induce triggered activity with disopyramide (unpublished observations). 
Prolongation with MND was much smaller than with disopyramide and did not induce triggered activity. Therefore, its effects on disopyramide-induced triggered activity was most likely mediated by a reduction of an inward current involved in the generation of the triggered impulse. MND may possibly reduce the TTX-sensitive sodium "window" current (Attwell et al., 1979; Coraboeuf et al., 1979), which would account for shortening of action potential duration at normal heart rates. However, reduction of this current was not sufficient to prevent triggered activity at longer cycle lengths at which the net inward current would be greater. Also, since MND has been suggested to block activated sodium channels (Toy and Sasyniuk, 1990a), its effectiveness to reduce sodium currents may be attenuated due to voltage-dependent as well as time-dependent recovery at longer cycle lengths.

Nevertheless, this is the first time that a metabolite has been shown to reduce such arrhythmogenic effects of an antiarrhythmic drug. The metabolites of quinidine may enhance its arrhythmogenic potential since several metabolites can also produce EADs (Thompson et al., 1987). In the case of procainamide, only the metabolite NAPA has been shown to induce triggered activity (Dangman and Hoffman, 1981).

In summary, the combination of disopyramide and MND produced additive effects on $\dot{\mathrm{v}}_{\max }$ and action potential duration at clinically relevant concentrations and heart rates. Our results suggest that MND may contribute to the clinical efficacy of disopyramide by enhancing $\dot{\mathrm{V}}_{\max }$ depression, thereby further slowing conduction, and prolongation of 
refractoriness. However, disopyramide displays reverse use-dependent effects on action potential duration in Purkinje fibers which under predisposing electrolyte conditions and bradycardia induced EADs and triggered activity. Reverse use-dependent effects on action potential duration may reduces the class III antiarrhythmic actions of disopyramide during tachycardias as well as rendering it proarrhythmic at slow heart rates. The effects of MND, however, suggest that it may be beneficial against triggered arrhythmias. 
Chapter 4

General Summary and Conclusions 
General Summary and Conclusions

Metabolites can play a role in the clinical efficacy or toxicity of antiarrhythic drug therapy (Roden et al., 1980; Barbey et al., 1988a). With the exception of decreasing the maximum pacing frequency and raversing experimentally-induced fibrillation in atrial muscle (Baines et al., 1976; Grant et al., 1978; Dubray et al., 1986), little is known concerning the electrophysiological actions of MND, the major metabolite of disopyranide in man.

We have shown that MND depresses $\dot{V}_{\max }$ of the action potential in a concentration and rate dependent manner in canine Purkinje fibers suggesting that it blocks cardiac sodium channels. At clinically relevant concentrations, depression of $\dot{\mathrm{V}}_{\max }$ resides mainly from rate dependent actions with minimal voltage dependent effects. The kinetics of onset and recovery with MND are faster than with disopyramide. However, the potency of rate-dependent $\dot{V}_{\max }$ depression by MND ranges from only one-half to two-thirds compared to disopyramide. MND shortens action potential duration in Purkinje fibers, but lengthens repolarization and refractory periods in ventricular muscle. Differential effects on action potential duration in Purkinje fibers versus ventricular muscle decreases the disparity in durations between the' The prolongation of refractory periods in muscle may explain the decrease in maximal pacing frequency in atrial muscle observed previously with MND (Grant et al., 1978; Dubray et a1., 1986). 
The combination of disopyramide and MND produces an additive depression of $\dot{V}_{\max }$ at clinically relevant concentrations. Additive interactions are produced by the combination on tonic and rate-dependent $\dot{\mathrm{V}}_{\max }$ depression at normal to fast heart rates. In our study, both compounds shortened action potential duration at normal stimulation rates, and in the presence of the combination a net additive shortening of action potential plateau was also observed. Disopyramide produces a rate dependent prolongation of the effective refractory period of three sequential extrasystoles but not the basic beat in Purkinje fibers. In ventricular muscle, disopyramide produces an increase in effective refractory period of the basic beat in addition to the three extrasystoles. Effects in both tissues are accentuated in the presence of the combination. Our results demonstrate in vitro that the electrophysiological actions of MND enhance and contribute to those produced by disopyramide in the presence of the combination.

Only additive interactions are observed with the combination of disopyramide and MND at clinically relevant concentrations and heart rates. Kohlhardt and Seifert (1985) found additive effects when they investigated the combination of quinidine and propafenone. In their study, additive tonic and rate-dependent block with the combination occurred because the two drugs had similar onset and recovery kinetics for rate-dependent block. Therefore, additive effects at normal heart rates in our study with the combination of disopyramide and MND are not surprising since both compounds produce a depression of $\dot{V}_{\max }$ which 
recovers minimally over the clinical range of heart rates. The effects of the combination resembles that of an increase in the concentration of either drug.

Therapeutic synergy as described by Hondeghem and Katzung (1980) has been shown with combinations of Class Ia and Ib agents such as quinidine plus tocainide (Valois and Sasyniuk, 1987) or mexiletine (Roden et al., 1987). Due to different kinetics of unblocking, these combinations allow more effective depression of premature beats than either drug alone, but at normal heart rates depression produced by the faster Ib drug is reduced during diastole. This type of interaction, however, is not possible with the combination of disopyramide and MND (at least at clinically relevant heart rates). Despite different kinetics of unblocking, these drugs recover so slowly that recovery from rate-dependent block for both is minimal during clinical diastole.

Antagonistic interactions resulting from competitive displacement such as with the combination of lidocaine and its metabolite (Bennett et al., 1988) is also not possible. Although competitıve displacement can occur between disopyramide and MND, there would not be a subsequent reduction in the magnitude of depression of $\dot{\mathrm{V}}_{\max }$ because both drugs recover very slowly. In addition, antagonistic interactions require that each drug bind to a large fraction of sodium channels so that they may interfere with each other. At clinically relevant concentrations, however, the probability that two drug molecules interact simultaneously with the same receptor would be relatively small. 
Finally, since disopyramide has a greater affinity for activated channels (Kodama et a1., 1986 and 1987; Gruber and Carmeliet. 1989), shortening of action potential duration by MND would probably not affect depression of $\dot{\mathrm{V}}_{\max }$ produced by the parent drug.

The accumulation of significant plasma levels of MND during disopyramide th rapy suggest that it may play a role in both the antiarrhythmic and toxic effects ascribed to disopyramide. Arlditive depression of $\dot{\mathrm{V}}_{\max }$ would occur both during normal rhythms and during a rapid tachycardia with greater depression occurring during the tachycardia. This would result in greater depression of conduction velocity both during a normal heart rate and during rapid tachycardia. Additive effects would also be observed on refractory periods. These actions should be beneficial in the abolition and prevention of reentrant ventricular arrhythmias. In fact, the mechanism of termination of reentrant excitation by disopyramide in one model was correlated with the depression of conduction (Spinelli and Hoffman, 1989). Furthermore, studies with the new antiarrhythmic agent penticainide (a disopyramide derivative) which produces electrophysiological effects similar to MND in canine ventricular tissue (Gautier et a1., 1987), show that drugs with this pharmacodynamic profile are effective against chronic ventricular arrhythmias in patients (Priori et a1., 1987).

However, toxicity may occur if there is excessive depression of conduction. At clinically relevant stimulation rates, recovery of $\dot{\mathrm{v}}_{\max }$ depression is minimal for both disopyramide and MND. An increase in 
drug concentration can readily lead to marked slowing of conduction or conduction block. Too much depression of conduction velocity or unidirectional block could lead to or potentiate reentry and hence drug toxicity as is typically seen with Class Ic antiarrhythmic agents such as encainide or flecainide (Roden et al., 1990). Development of sustained ventricular arrhythmias have been observed previously during troatment with disopyramide (Kudenchuk et al, 1990).

As a result of reverse use-dependence, the potential Class III properties of disopyramide may be least effective during tachycardias while maximum prolongation of action potential duration would occur during bradycardia or after a long diastolic interval. Hondeghem and Snyders (1990) have suggested that reverse use-dependence may even render drugs proarrhythmic, especially after long diastolic intervals. Disopyramide has been associated with the production of prolonged QT syndrome arrhythmias such as torsade de pointes following therapeutic doses (Casedevant and Sabaut, 1975; Tzivoni et al., 1981; Schweitzer and Mark, 1982; Riccioni et al., 1983).

Although therapeutic concentrations of disopyramide shortened action potential duration at normal heart rates, we found that it produced a pronounced prolongation of repolarization following a very long diastolic interval and thus exhibits reverse use-dependent effects. Abnormal impulse generation in the form of early afterdepolarizations and triggered activity occurs following marked prolongation of action potential duration with disopyramide in the presence of slow heart rates, hypokalemia and acidosis. Pacing at normal heart rates or 
addition of a therapeutic concen"ration of mexiletine abolishes carly afterdepolarizations and triggered activity. Our study shows that triggered activity can be induced by disopyramide $1 n$ vitro and provides a possible mechanism for the genesis of torsade de pointes arthythmias with disopyramide in vivo.

The metabolite, however, might reduce this arrhythnogenic potent 1 al of the parent drug. Addition of a clincially relevant concentration of MND altered the incidence of disopyamide-induced early afterdepolarizations and triggred activity to longer cycle lenglis. A similar effect in vivo may be beneficial in altering the conditions such that initiation of prolonged QT syndrome arrhythnias such as torsacle de pointes becomes more difficult. This may explain why the incidence of torsade de pointes is less with disopyramide than it is with, for example, quinidine (Stratmann and Kennedy, 1987) In contrast, only potential arrhythmogenic effects have been observed previously with the metabolites of other antiarrhythmic drugs which produce triggered activity in vitro (Dangman and Hoffman, 1981; Thompson et a1, 1987)

Future studies will be required to confirm our in vitro finding in in vivo models. The arrhythogenic potential of cisopyrallide must be tested in vivo under the same conditions which precipitate long OT syndrome arrhythmias such as torsade de pointes in patients This may provide further evidence for the involvement of triggered activity in torsade de pointes and may potentially lead to development of an in vivo model of torsade de pointes using an antiarrhythic drug. To date, two in vivo models have been available for the study of torsade de pointes 
and involve the use of cesium (Brachmann et al., 1983) or anthopleurin-A (El-Sherif et a1., 1988). The beneficial effects of MND against drug-induced triggered rhythms must also be confirmed using such in vivo mode1s Furthermore, the discrepancy between the rate of arrhythmias in vitro versus events in vivo must be resolved before torsade de pointes arrhythnias can be attributed to triggered activity. The effects of factors such as sympathetic stimulation in vivo (Ben-David and Zipes, 1988 ) on the initiation and incidence of triggered activity or torsade de pointes must be considered. The answers to these questions will provide further insight into the mechanisms responsible for the antiarthythmic and arrhythogenic potential of disopyramide and the role of MND during therapy. 
Chapter 5

References 


\section{References}

Altio, M.L.: Plasma concentrations and protein binding of disopyramide and mono-N-dealkyldisopyramide during chronic oral disopyramide therapy. Br J. C1in. Pharmacol. 11:369-376, 1981.

Amlie, J.P., Nesje, O.A., Frislid, K., Lunde, P.K.M., Landmark, K.: Serum levels and electrophysiological effects of $\mathrm{N}$-acetylprocainamide as compared with procainamide in the dog heart in situ. Acta. Pharmacol. et. Toxicol. 42:280-286, 1978.

Atlinson Jr., A.J., Lertora, J J.L., Kushner, W, Chao, G.C., Nevin, M.J Efficacy and safety of $\mathrm{N}$-acetylprocainamide in long-term treatment of ventricular arrhythmias. Clin. Pharmacol. Ther. $33: 565-576,1983$.

Attwell, D, Cohen, I., Eisner, D., Ohba, M., Ojeda, C.: The steady state TTX-sensitive ("window") sodium current in cardiac Purkinje flbres. Pfluegers Arch. 379:137-142, 1979.

Bagwel1, E.E., Walle, T., Drayer, D.E., Reidenberg, M.M., Pruett, J.K.: Correlation of the electrophysiological and antiarrhythmic properties of the $\mathrm{N}$-acetyl metabolite of procainamide with plasma and tissue drug concentrations in the dog. J. Pharmacol. Exp. Ther. 197:38-48, 1976.

Baines, M.W., Davies, J.E., Kellett, D.N., Munt, P.L.: Some pharmacological effects of disopyramide and a metabolite. J. Int. Med. Ros 4(supp1 1) $5-7,1976$.

Bajaj, A.K., Kopelman, H.A., Wikswo, J.P., Cassidy, F., Woosley, R.L., Rodon, D.M.: Frequency- and orientation-dependent effects of mexiletine and quinidine on conduction in the intact dog heart. Circ. $75.1065-1073,1987$. 
Barbey, J.T., Thompson, K.A., Echt, D.S., Woosley, R.L., Roden, D.M.: Antiarrhythmic activity, electrocardiographic effects and pharmacokinetics of the encainide metabolites 0 -desmethyl encainide and 3-methoxy-o-demethyl encainide in man. Circ. 77:380-391, 1988a

Barbey, J.T., Thompson, K.A., Echt, D.S., Woosley, R.L., Roden, D.M.. Tocainide plus quinidine for treatment of ventricular arrhythmas Am. J. Cardio1. 61:570-573, 1988b.

Bauman, J.L., Bauernfeind, R.A., Hoff, J.V., Strasberg, B., Swiryn, S., Rosen, K.M.: Torsade de pointes due to quinidine: observations in 31 patients. Am. Heart J. 107·425-430, 1984.

Ben-David, J., Zipes, D.P.: Differential response to right and left ansae subclaviae stimulation of early afterdepolarizations and ventricuiar tachycardia induced by cesium in dogs. Circ. 78:1241-1250, 1988.

Bennett, P.B., Woosley, R.L., Hondeghem, L.M. Competition betweon lidocaine and one of its metabolites, glycylxylidide, for cardicic sodium channels. Circ. 78.692-700, 1988.

Bhattacharyya, M.L., Vassalle, 14.: Effects of tetrodotoxin on electrical and mechanical activity of cardiac Purkinje fibers J Electrocardio1. 15:351-360, 1982.

Bigger Jr., T.J., Sahar, D.I.: Clinical types of proarrhythic response to antiarrhythmic drugs. An. J. Cardiol. 59:2E-91:, 1987.

Boucher, M., Dubray, C., Paire, M., Duchene-Marullaz, P.: Comparativo effects of procainamide and its $\mathrm{N}$-acetylated metabolite in conscious dogs with atrioventricular block: plasma concentration-response relationship. J. Cardiovasc. Pharmacol. 10:562-567, 1987. 
Brachmann, J., Scherlag, B.J., Rosenshtraukh, L.V., Lazzara, R.: Bradycardia-dependent triggered activity: relevance to drug-induced multiform ventricular tachycardia. Circ. 68:846-856, 1983.

Bredesen, J.E., Pike, E., Lunde, P.K.M.: Plasma binding of disopyramide and mono-N-dealkyldisopyramide. Br. J. Clin. Pharmacol. 14:673-676, 1982.

Brogden, R.N., Todd, P.A.: Disopyramide, a reappraisal of its pharmacodynamic and pharmacokinetic properties and therapeutic use in cardiac arrhythmias. Drugs 34:151-187, 1987.

Burke, G.H., Loukides, J.E., Berman, N.D.: Effects of simultaneous administration of mexiletine and quinidine on the electrophysiologic parameters of canine Purkinje fibers. J. Cardiovasc. Pharmacol. $8: 1138-1143,1986$.

Burney, R.G., DiFazio, C.A., Peach, M.J., Petrie, K.A., Silvester, M.J.: Anti-arrhythmic effects of lidocaine metabolites. Am. Heart $\mathrm{J}$. $88 \cdot 765-769,1974$.

Campbel1, T.J.' Resting and rate-dependent depression of maximum rate of depolarization $\left(\dot{V}_{\max }\right)$ in guinea pig ventricular action potentials by mexiletine, disopyramide, and encainide. J. Cardiovasc. Pharmacol. $5: 291-296,1983 a$.

Campbe11, T.J.: Kinetics of onset of rate-dependent effects of class I antiarhythic drugs are important in determining their effects on refractorinoss in guinea-pig ventricle, and provide a theoretical basis for their subclassification. Cardiovasc. Res. 17:344-352, 1983b. 
Carey, E.L., Duff, H.J., Roden, D.M., Primn, R.K., Oates, J.A., Woosley, R.L.: Relative electrocardiographic and antiarthythmic effects of encainide and its metabolites. Circ. 64 (suppl IV):IV-264, 1981.

Casedevant, B., Sabaut, D.: Syncopes par torsades de pointes en rapport avec la prise de disopyramide. Nouv. Presse Med. 4:2339, 1975.

Chopra, M.P., Thadani, U., Portal, R.W., Aber, C.P.: Lignocaine therapy for ventricular ectopic activity after acute myocardial infarction: a double-blind trial. Br. Med. J. 3:668-670, 1971

Clarkson, C.W., Follmer, C.H., Ten Eick, R.E., Hondeghein, L.M., Yoh, J.Z.: Evidence for two components of sodium channel block by lidocainc in isolated cardiac myocytes. Circ. Res. 63:869-878, 1988.

Clarkson, C.W., Hondeghem, L M : Evidence for a specific receptor site for lidocaine, quinidine and bupivicaine associated with cardiac sodium channels in guinea pig ventricular myocardium. Circ. Res 56.496-506, 1985a.

Clarkson, C.W., Hondeghem, L.M.: Mechanisın for bupivacaine depression of cardiac conduction: fast block of sodium channels during, the action potential with slow recovery fromblock during diastole Anesthesiology $62: 396-405,1985 b$.

Conard, G.J, Ober, R.E.: Metabolism of flecainide. Am J. Cardiol. $53: 41 B-51 B, 1984$.

Coraboeuf, E., Deroubaix, E., Coulombe, A.: Effects of telrodotoxin on action potentials of the conducting system in the dog heart Am J. Physiol. 236:H561-H567, 1979. 
Coraboeuf, E., Deroubaix, E, Coulombe, A.: Acidosis-induced abnormal repolarization and repetitive activity in isolated dog Purkinje fibers. J. Physio1. (Paris) 76:97-106, 1980.

Coraboeuf, E., Deroubaix, E., Coulombe, A.: Comparative effects of three class I antiarrhythic drugs on plateau and racemaker currents of sheep cardiac Purkinje fibers. Cardiovasc. Res. 22:375-384, 1988.

Costard-Jaeckle, A., Liem, L.B., Franz, M.R.: Frequency-dependent effect of quinidine, mexiletine, and their combination on postrepolarization refractoriness in vivo. J. Cardiovasc. Pharmacol. $14: 810-817,1989$.

Courtney, K.R.: Interval-dependent effects of small antiarrhythmic drugs on excitability of guinea-pig myocardium. J. Mol. Ce11. Cardiol. $12 \cdot 1273-1286,1980$.

Courtney, K.R.: Quantitative structure/activity relations based on use-dependent block and repriming kinetics in myocardium. J. Mol. Cell. Cardio1. 19:319-330, 1987.

Cranefield, P.F.: The conduction of the cardiac impulse. Futura Press, Mt. Kisco, N.Y., 1975.

Crancfield, P.F., Aronson, R.S.: Cardiac arrhythmias: the role of triggered activity and other mechanisms. Futura Press, Mt. Kisco, N.Y., 1988.

Damiano, B.P., Rosen, M.R.: Effects of pacing on triggered activity induced by early depolarizations. Circ. 69:1013-1025, 1984. 
Dangman, K.H., Hoffman, B.F.: In vivo and in vitro antiarrhythmic and arrhythmogenic effects of $\mathrm{N}$-acetyl procainamide. J. Pharmacol. Exp. Ther. $217.851-862,1981$.

Davidenko, J.M., Cohen, L., Goodrow, R., Antzelevitch, C : Quinidine-induced action potential prolongation, carly afterde olarizations, and triggered activity in canine Purkinje fibers: effects of stimulation rate, potassium, and magnesium. Circ $79: 674-686,1989$.

Davy, J.-M., Dorian, P., Kantelip, J.-P., Harrison, D.C., Kates, R.E.. Qualitative and quantitative comparison of the cardiac affects of encainide and its three major metabolites in the dog J. Pharmacol. Exp. Ther. 237:907-911, 1986.

Delgado, C., Tamargo, J., Tejerina, T.: Electrophysiological effects of propafenone in untreated and propafenone-pretreated guinea-pig atrial and ventricular muscle fibers. Br. J. Pharmac. 86.765-775, 1985

Delgado, C., Tamargo, J., Tejerina, T., Valenzuela, C : Effects of 5-hydroxy-propafenone in guinea-pig atrial fibres. Br. J Pharmacol. $90: 575-582,1987$.

Di Francesco, D.: A new interpretatior of the pacemaker current in calf Purkinje fibres. J. Physiol. 314:359-376, 1981.

Drayer, D.E., Lowentha1, D.T., Restivo, K.M., Schwartz, A, Cook, C. E, Reidenberg, M M.: Steady-state serum levels of quinidine and act 1 ve metabolites in cardiac patients with varying degrees of renal function Clin. Pharmacol. Ther. 24:31-39, 1978. 
Drayer, D.E., Lowentha1, D.T., Woosley, R.L., Nies, A.S., Schwartz, A., Reidenberg, M.M.: Cumulation of N-acetylprocainamide, an active metabolite of procainamide, in patients with impaired renal function. C1 in. Pharmacol. Ther 22:63-69, 1977.

Drayer, D.E., Reidenberg, M.M., Sevy, R.W.: N-acetylprocainamide: an active metabolite of procainamide. Proc. Soc. Exp. Biol. Med. $146: 358-363,1974$.

Dresel, P.E.: Effects of encainide and its two major metabolites on cardiac conduction. J. Pharmacol, Exp. Ther. 228:180-186, 1984.

Dubray, C, Boucher, M, Paire, M., Pinatel, H., Duchene-Marullaz, P.: Comparative effects of disopyramide and its mono-N-dealkylated metabolite in conscious dogs with chronic atrioventricular block: plasma concentration-response relationships. J. Cardiovasc. Pharmacol. 8.1229-1234, 1986.

Durf, $11 \mathrm{~J}$ Mexiletine-quinidine combination: enhanced antiarrhythmic and clectrophysiologic activity in the dog. J. Pharmacol. Exp.Therap. $249: 617-622,1989$.

Duff, H.J., Dawson, A.K., Roden, D.M., Oates, J.A., Smith, R.F., Woosley, R.L.: Electrophysiological actions of 0 -demethyl encainide: an active metabolite. Circ. 68:385-391, 1983a.

Duff, H.J., Kolodgie, F.D., Roden, D.M., Woosley, R.L.: Flectropharmocologic synergism with mexiletine and quinidine. J. Cardiovase Pharmacol. 8:840-846, 1986. 
Duff, H.J., Mitchel1, L.B., Manyari D., Wyse, D.G.: Mexiletine-quinidine combination: electrophysiologic correlates of a favorable antiarrhythmic interaction in humans. J. Am. Coll. Cardiol 10:1149-1156, 1987 .

Duff, H.J., Roden, D.M., Primm, R.K., Oates, J.A, Woosley, R.L. Mexiletine in the treatment of resistant ventricular arthythmias. enhancement of efficacy and reduction of dose-related side effects by combination with quinidine. Circ. 67:1124-1128, 1983b.

Duffy, C.E., Swiryn, S., Bauernfeind, R.A., Strasberg, B., Palileo, B., Rosen, K.M.: Inducible sustained ventricular tachycardia refractory to individual class I drugs: effects of adding a second class I drug An Heart J. 106:450-458, 1983 .

Dukes, I., Vaughan Williams, E.: The inultiple modes of action of propafenone. Eur. J. Cardiol. 5:115-125, 1984.

Ehring, G.R., Moyer, J.W., Hondeghem, L.M.: Quantitative structure activity studies of antiarrhythmic properties in a series of lidocaine and procainamide derivatives. J. Pharmacol. Exp. Ther. 244:479-492, 1988 .

Elharrar, V., Zipes, D.P.: Effects of encainide and metabolites, (MJ14030 and MJ9444) on canine cardiac Purkinje and ventricular fibers J. Pharmacol. Exp. Ther. 220:440-447, 1982 .

El-Sherif, N., Zeiler, R.H., Craelius, W., Gough, W.B., llenkin, R. . QTU prolongation and polymorphous ventricular tachyartiythmias due $c o$ bradycardia dependent early afterdepolarizations Circ. Res. $63: 286-305,1988$. 
Elson J., Strong, J.M., Lee W.-K., Atkinson Jr., A.J.: Antiarrhythmic potency of N-acetylprocainamide. Clin. Pharmacol. Ther. 17:134-140, 1975.

Falk, R.T., Cohen, I.S.: Membrane current following activity in canine cardiac Purkinje fibers. J. Gen. Physiol. 83:771-799, 1984.

Fleming, M.A , Sasyniuk, B.I.: Frequency and voltage dependent effects of disopyramide in canine Purkinje fibers. Can J. Physiol. Pharm. $67: 710-721,1989$.

Fozzard, H.A., Hanck, D.A., Sheets, M.F.: The relationship between $\dot{V}_{\max }$ and $\mathrm{I}_{\mathrm{Na}}$ in cardiac Purkinje cells and their interpretation from single $\mathrm{Na}^{+}$channel analysis. In Molecular and Cellular Mechanisms of Antiarrhythmic Agents, ed. by L. Hondeghem, pp. 1-17. Futura Press, Mt. Kisco, N.Y., 1989.

Francen, P.F., Vereecke, J.S., Carmeliet, E.E.: Effects of combinations of lidocaine and quinidine on the maximum rate of rise of cardiac action potentials. Circ. 70:SII-273, 1984.

Franz, M.R., Costard, A.: Frequency-dependent effects of quinidine on the relationship between action potential duration and refractoriness in the canine heart in situ. Circ. 77.1177-1184, 1988.

Freedman, M D., Gal, .., Freed, C.R.: Decreased toxicity and equipotent antiarthythmic potency of monoethylglycine xylidide compared to lidocaine. C1in. Res. 30:87 A, 1982.

Gadsby, D.C.: Activation of electrogenic $\mathrm{Na}^{+} / \mathrm{K}^{+}$exchange by extracellular $\mathrm{K}^{+}$in canine cardiac Purkinje fibers. Proc. Natl. Acad. Sci. USA 77:4035-4039, 1980 
Gautier, P, Guiraudou, F, Pezziardi, F., Bertrand, J-P., Gagnol. J.-P. Electrophysiological studies of penticainide ( $\mathrm{CM} 785 /$ ), a new antiarrhythmic agent, in mammalian myocardiun. J. Cardiovasc. Pharmaco1. 9:601-610, 1987.

Grant, A.M., Marsha11, R.J., Ankier, S.I.: Some effects of disopyramide and its $\mathrm{N}$-dealkylated metabolite on isolated nerve and cardiac musclo Eur. J. Pharmacol. 49:389-394, 1978.

Grant, A.O, Trantham, J.L., Brown, K.K., Strauss, H.C.: pll-dependent effects of quinidine on the kinetics of $\mathrm{dV} / \mathrm{dt}_{\max }$ in guined pig, ventricular myocardium. Circ. Res. 50:210-217, 1982.

Greenspan, A M., Spielman, S.R., Webb, C.R., Sokoloff, N.M, Rae, A.P., Horowitz, L.N.: Efficacy of combination therapy with mexiletine and a type Ia agent for inducible ventricular cachyarhythmias secondary to coronary artery disease. Am. J. Cardiol 56:277-284, 1.985

Gruber, R., Carmeliet, E.: The activation gate of the sodium channel controls blockade and deblockade by disopyramide in rabbit Purkinje fibers. Br. J. Pharmacol. 97:41-50, 1989.

Guehler, J., Gornick, C.C., Tobler, H.G., Almquist, A, Schmid, J R, Benson Jr., D.W., Benditt, D.G. Electrophysiologic effucts of flecainide acetate and its najor metabolites in the canine hart An J Cardiol. 55:807-812, 1985 .

Hiraoka, M.. Kuga, K., Kawano, S., Sunami, A., Fan, Z. Now observations on the mechanisms of antiarrhythmic actions of disopyranide on cardiac membranes. Am. J. Cardiol. 64:15J-19J, 1989. 
lliraoka, M., Sawada, K., Kawano, S.: Effects of quinidine on plateau currents in guinea-pig ventricular myocytes. J. Mol. Cell. Cardiol. $18: 1097-1106,1986$.

Hondeghem, L.M.: Antiarrhythmic agents: modulated receptor applications. Circ. 75:514-520, 1987.

Hondeghem, L.M., Katzung, B.G.: Test of a model of antiarrhythic drug action. Effects of quinidine and lidocaine on myocardial conduction. Circ $61: 1217-1224,1980$.

llondeghem, LM., Katzung, B.G. Antiarrhythmic agents: The modulated receptor mechanisms of action of sodium and calcium channel blocking drugs. Ann. Rev. Pharmacol. Toxicol. 24:387-423, 1984.

Hondeghem, L.M., Matsubara, T.: Quinidine blocks cardiac sodium channels during opening and slow inactivation in guinea-pig papillary muscle $\mathrm{Br} J$ Pharmacol. 93:311-318, 1988.

llondeghem, L.M., Snyders, D.J.: Class III antiarrhythmic agents have a lot of potential but a long way to go: Reduced effectiveness and dangers of reverse use dependence. Circ. 81:686-690, 1990.

Jackman, WM., Friday, K.J., Anderson, J.L., Aliot, F.M., Clark, M., Lazzara, R.: The long QT syndromes: a critical review, new clinical observations and a unifying hypothesis. Prog. Cardiovasc. Dis. $31 \cdot 115 \cdot 172,1988$.

Jaillon, P., Winkle, R.A.: Electrophysiologic comparative study of procainamide and $\mathrm{N}$-acetylprocainamide in anesthetized dogs: concentration-response relationships. Circ. 60:1385-1394, 1979. 
Karim, A.: The pharmacokinetics of norpace. Angiology 26 (suppl. 1) $: 85-98,1975$.

Karim, A., Ranney, .E., Kraychy, S.: Species differences in the biotransformation of a new antiarrhythmic agent: disopyramide phosphate. J. Pharm. Sci. 61:888-893, 1972.

Kates, R.E.: Metabolites of cardiac antiarrhythic drugs their clinical role. Ann. N.Y. Acad. Sci. 432:75-89, 1984.

Kates, R.E. Metabolites of antiarrhythic drugs are they clinically important? Rat. Drug Ther. 20:1-5, 1986.

Kates, R.E., Harrison, D.C., Winkle, R.A.: Metabolite cunulation during long-term oral encainide administration. Clin. Pharmacol. Ther. $31: 427-432,1982$.

Kates, R.E., Yee, Y.G, Winkle, R.A: Metabolite cumulation during, chronic propafenone dosing in arrhythmia. Clin. Pharmacol Ther. $37: 610-614,1985$.

Kay, G.N., Plumb, V.J , Arciniegas, J.G., Henthorn, R W., Walclo, A.l. Torsade de pointes: the long-short initiating sequence and other clinical features: observations in 32 patients. J Am. Coll Carliol. $2: 806-817,1983$.

Kerr, M.J., Allen, J.D., Harron, D.W.G., Shanks, R.G. The effects of encainide and its major metabolites, o-demothyl encanide and 3-methoxy-0-demethyl encainide, on experimental cardiac arrliythnias in dogs. J. Cardiovasc. Pharmacol. 7:449-457, 1985. 
Kim, S G., Mercando, A.D., Fisher, J.D.: Combination of tocainide and quinidine for better toleran e and additive effects in patients with coronary artery disease. J. Am. Coll. Cardiol. 9:1369-1374, 1987.

Kin, S.G., Mercando, A.D., Tam, S., Fisher, J.D.: Combination of disopyl mide and mexiletine for better tolerance and additive effects for treatment of ventricular arrhythmias. J. Am. Coll. Cardiol. $13.659-664,1989$.

Kim, S.G, Seiden, S.W., Matos, J.A., Waspe, L.E., Fisher, J.D.: Combination of procainamide and quinidine for better tolerance and dditive effects for ventricular arrhythmias. Am. J. Cardiol. 56:84-88, 1985

Klein, R.C., Huang, S.K., Marcus, F.I., Horwitz, L., Fenster, P.E., Rushforth, R.N., Kirsten, E.B.: Enhanced antiarrhythmic efficacy of propafenone when used in combination with procainaimide or quinidine. An. Heart J. 114:551-558, 1987.

Kochama, 1., Toyama, J., Yamada, K.: Open and inactivated sodium shannel block by class-I antiarrhythic drugs. Jpn. Heart J 27:83-89 (suppl.), 1986.

Kodima, I., Toyama, J., Takanaka, C., Yamada, K.: Block of activated and inactivated sodium channels by class-I antiarrhythmic drugs studies by using the maximum upstroke velocity $\left(\dot{\mathrm{V}}_{\max }\right)$ of action potential in guinea-pig cardiac muscle. J. Mol. Ce11. Cardiol 19:367-377, 1987.

kohllwrll, $M$, Seifert, $C_{.}$: Tonic and phasic $I_{\mathrm{Na}}$ blockade by antiarhythmics: different properties of drug binding to fast sodium channels as judged from $\dot{V}_{\max }$ studies with propafenone and derivatives in mammalian ventricular myocardium. Pfluegers Arch. 396:199-209, 1983. 
Koh1hardt, M., Seifert, C.: Properties of $\dot{\mathrm{V}}_{\max }$ block of $\mathrm{I}_{\mathrm{Na}}$-modiated action potentials during combined application of antiarthythic drugs in cardiac muscle. Naunyn-Schmiedeberg's Arch. Pharmacol 330.235-244, 1985.

Kojima, M.: Effects of disopyramide on transmembrane action potentials in guinea pig papillary muscle. Eur. J. Pharmacol. 69:11-24, 1981

Kojima, M., Ban, T., Sada, A.: Effects of disopyramide on the maximum rate of rise of action potential $\left(\dot{V}_{\max }\right)$ in guinea pig papillary muscle Jap. J. Pharmaco1. 32:91-102, 1982.

Kudenchuk, P.J., Kron, J., Walance, C., McAnulty, J.H.. Spontaneous sustained ventricular tachyarrhythmias during treatment with type Ia antiarrhythmic agents. Am. J. Cardiol. 65:446-452, 1990.

Kus, T., Sasyniuk, B.I.: Electrophysiological actions of disopyramide phosphate on canine ventricular muscle and Purkinje fibers. Circ. Res $37: 844-854,1975$.

Kus, T., Sasyniuk, B.I.: The electrophysiological effects of disopyramide phosphate on canine ventricular muscle and Purkinje fibers in normal and low potassium. Can. J. Physiol. Pharmacol. 56:139-149, 1978 .

Lathrop, D.A., Varro, A.: Modulation of the effects of sotalol on Purkinje strand electromechanical characteristics Can. J Physiol Pharmaco1. 67:1463-1467, 1989.

Latini, R., Marchi, S., Riva, E., Cavalli, A, Cazzaniga, M.G; , Maggioni, A.P., Volpi, A.: Distribution of propafenone and its active metabolite, 5-hydroxypropafenone, in human tissues An Heart $J$. $113: 843-844,1987$. 
Ledda, F., Mantelli, L., Manzini, S., Amerini, S., Mugelli, A.: Electrophysiological and antiarrhythmic properties of propafenone in isolated cardiac preparations. J. Cardiovasc. Pharmacol. 3:1162-1173, 1981.

Lie, K.I., Wellens, H.J., van Capelle, F.J., Durrer, D.: Lidocaine in the prevention of primary ventricular fibrillation. N. Engl. J. Med. 291:1324-1326, 1974 .

Litovsky, S.H., Antzelevitch, C.: Transient outward current prominent in canine ventricular epicardium but not endocardium. Circ. Res. $62 \cdot 116-126,1988$

Malfatto, G., Zaza, A., Forster, M., Sodowich, B., Danilo Jr., P., Rosen, MR.: Electrophysiologic, inotropic and antiarrhythmic effects of propafenone, 5-hydroxypropafenone and $\mathrm{N}$-depropylpropafenone. $\mathrm{J}$. Pharmacol. Exp. Ther. 246:419-426, 1988.

Minchin, R F., Ilett, K.F., Paterson, J.W.. Antiarrhythmic potency of procainamide and $\mathrm{N}$-acetylprocainamide in rabbits. Eur. J. Pharmacol. $47 \cdot 51-56,1978$.

Narang, P.K., Crouthamel, W.G., Carliner, N.H., Fisher, M.L.: Lidocaine and its active metabolites. Clin. Pharmacol. Ther. 24:654-662, 1978.

Nattel, S., Davies, M., Quantz, M.: The antiarrhythmic efficacy of amiodarone and desethylamiodarone, alone and in combination, in dogs with acute myocardial infaction. Circ. 77:200-201, 1988.

Nattel, S., Quantz, M.A.: Pharmacological response of quinidine induced carly afterdepolarizations in canine cardiac Purkinje fibres: insights into underlying ionic mechanisms. Cardiovasc. Res. 22:808-817, 1988. 
Oti-Amoako, K., Vozeh, S., Ha, H.-R., Follath, F: The relative potency of major metabolites and enantiomers of propafenone in an experimental reperfusion arrhythmia model. J. Cardiovasc. Pharnacol. 15·75-81, 1990

Pallandi, R.T., Campbell, T.J.: Selective depression of conduction of premature action potentials in canine Purkinje fibers by class lb antiarhythmic drugs: comparison with Ia and Ic drugs. Cardiovase Ross $22: 171-178,1988$.

Pentikainen, P.J., Koivula, I.H, Hiltunen, H.A.: Effects of rifampicin treatment on the kinetics of mexiletine. Eur. J. Clin. Pharmacol $23: 261-266,1982$.

Philipsborn, G., Gries, J , Hofmann, H.P, Kreiskott, H, Kretzschmal, R., Muller C.D., Raschack, M., Teschendorf, H J. Pharmacolog,ical studies on propafenone and its main metabolite 5-hydroxypropafonone Arznein.-Forsch. $34 \cdot 1499-1497,1984$

Priori, S.G., Bonazzi, 0., Facchini, M., Varisco, T., Schwartz, P J Antiarrhythic efficacy of penticainide and comparison with disopyramide, flecainide, propafenone and mexiletine by acute oral drug, testing Am J. Cardiol. 60-1068-1072, 1987.

Ranney, R.E., Dean, R.R., Karim, A, Radzialowsk1, F.M . Disopyramtcle phosphate: pharmacokinetic and pharmacologic relationships of a now antiarrhythmic agent. Arch. Int. Pharmacodyn. 191.162-188, 1971

Reynolds, R D., Kamath, B.L.: N-acetylprocainamide and 1schemin-induced ventricular fibrillation in the dog Eur. J. Pharmacol s9 115-119, 1979 . 
Riccioni, N, Castiglioni, M., Bartolomei, C.: Disopyramide-induced QT prolongation and ventricular tachyarrhythmias. Am. Heart J. $105: 870-871,1983$.

Roden, D.M.: Clinical features of arrhythmia aggravation by antiarhythmic drugs and their implications for basic mechanisms. Drug D.v. Res. 19:153-172, 1990 .

Rodeu, D.M., Bennett, P.B., Snyders, D.J., Balser, J.R., Hondeghem, L.M. Quinidine delays $I_{K}$ activation in guinea pig ventricular inyocytes Circ. Res. 62·1055-1058, 1988.

Roden, D.M., Duff, H.J., Altenbern, D., Woosley, R.L.: Antiarrhythmic activity of the 0 -demethyl metabolite of encainide. J. Pharmacol. Exp. Ther 221:552-557, 1982.

Roden, DM., Hoffman, B.F.: Action potential prolongation and induction of abnormal automaticity by low quinidine concentrations in canine Purkinje fibers relationship to potassium and cycle length. Circ. Res. 56:857-867, 1985 .

Roden, D.M, Iansmith, H.S., Woosley, R.L.: Frequency-dependent interactions of mexiletine and quinidine on depolarization and repolartzation in canine Purkinje fibers. J. Pharmacol. Exp. Ther $243 \cdot 1218 \cdot 1224,1987$.

Roden, D.M., Reele, S.B., Higgins, S.B., Wilkinson, G.R., Smith, R.F., Oates, J.A., Woosley, R.L.: Antiarrhythmic efficacy, pharmacokinetics and safety of $\mathrm{N}$-acetylprocainamide in human subjects: comparison with procainanide An. J. Cardiol. 46:463-468, 1980. 
Roden, D.M., Thompson, K.A., Hoffman, B.F., Woosley, R.L : Clinical features and basic mechanisms of quinidine-induced arrhythmias. J Am. Col1. Cardiol. 8:73A-78A, 1986a.

Roden, D.M., Woosley, R.L., Primm, R K.. Incidence and clutic.1 features of the quinidine-associated long QT syndrome implications for patient care. Am. Heart J. 111:1088-1093, 1986b.

Ronfeld, R.A., Wolshin, E.M., Block, A.J.: On the kinetics and dynamies of tocainide and its metabolites. Clin. Pharmacol Ther. 31:384-392, 1982 .

Rouet, R., Libersa, C C , Broly, F., Caron, JF, Adandntidis, $M M$, Honore, E., Wajnan, A, Dupuis, B.A.: Comparative electrophysiolopical effects of propafenone, 5-hydroxy-propafenone, and $\mathrm{N}$-depropylpropafonone on guinea pig ventricular muscle fibers. J. Cardiovasc. Pharmacol $14: 577-584,1989$.

Salata, J.J, Wasserstrom, J.A: Effects of quinidine on action potentials and ionic currents in isolated caning ventroular myocylas Circ Res 62.324-337, 1988.

Sanchez-Chapula, J.: Electrophysiological interactions between quinidine-lidocaine and quinidine-phenytoin in guinea-pig papillary muscle. Naunyn-Schmiedeberg's Arch. Pharmacol 331:369-375, 1985

Sasyniuk, B.I., Jhamandas, V.: Mechanisms of reverhal of toxac effects of atnitryptyline on cardiac purkinje fibers by sodum bicatbonate. I Pharmacol. Esp Ther. 231.387-394, 1984.

Sasyniuk, B.I., Valois, M., Toy, W. Recent advances in our understanding of the basis mechanism in drug induced torsades de pointe arrhythmias. Am. J. Cardiol 64:29J-32J, 1989. 
Scamps, F, Carmeliet, E.: Delayed $\mathrm{K}^{+}$current and external $\mathrm{K}^{+}$in single cardiac Purkinje cells. Am. J. Physiol. 257:C1086-C1092, 1989.

Schweitzer, P., Mark, H.: Torsade de pointes caused by disopyramide and lypokalemia M Sinai J. Med. 49:110-114, 1982.

Sheets, M F., Hanck, D.A., Fozzard, H.A.: Nonlinear relation between $\dot{\mathrm{V}}_{\mathrm{maX}}$ and $\mathrm{I}_{\mathrm{Na}}$ in canine cardiac Purkinje cells. Circ. Res. 63:386-398, 1988 .

Sheldon, R.S., Cannon, N.J., Duff, H.J.: A receptor for type I antiarrhythic drugs associated with rat cardiac sodium channels. Circ. Res. 61.492-497, 1987.

Siddoway, L.A., Roden, D.M., Woosley, R.L.: Clinical pharmacology of propafenone: pharmacokinetics, metabolism and concentration-response relations. An J. Cardio1. 54:9D-12D, 1984.

Singh, B.N., Feld, G, Nademanee, K.: Arrhythmia control by selective longthening of cardiac repolarization role of $\mathrm{N}$-acetylprocainamide, active metabolite of procainamide. Angiology 39:930-938, 1988.

Smallwood, J K., Robertson, D.W., Steinberg, M.I.' Electrophysiological offects of flecainide enantiomers in canine Purkinje fibres. Naunyn-Schniedeberg's Arch. Pharmacol. 339:625-629, 1989.

Smith, ER., Duce, B.R: The acute antiarrhythmic and toxic effects in mice and dogs of 2-cthylanino-2',6'-acetoxylidine (L-86), a metabolite of lidocalne J Pharmacol Exp. Ther. 179:580-585, 1971.

Smith, WM., Gallagher, J.J.: "Les torsades de pointes": an unusual ventricular arthythmia. Ann. Int. Med. 93:578-584, 1980. 
Spinelli, W., Hoffrnan, B.F.: Mechanisms of termination of reentrant atrial arrhythmias by Class I and Class III antiarrhythmic agents. Firc. Res. 65:1565-1579, 1989.

Stratmann, H.G., Kennedy, H.L.: Torsades de pointes associated with drugs and toxins: recognition and management. Am. Heart $J$. $113: 1470-1482,1987$.

Strong, J.M., Mayfield, D.E., Atkinson Jr., A.J., Burris, B.C., Raymon, F., Webster Jr., L.T.: Pharmacological activity, metabolism, and pharmacokinetics of glycinexylidide. Clin. Pharmacol. Ther. 17:184-194, 1975.

Suppression Trial (CAST) Investigators: Preliminary report: effect of encainide and flecainide on mortality in a randomized trial of arrhythmia suppression after myocardial infarction. N. Engl. J. Med. $321: 406-412,1989$.

Thompson, K.A., Blair, I.A., Woosley, R.L., Roden, D.M.: Comparative in vitro electrophysiology of quinidine, its major metabolites and dihydroquinidine. J. Pharmaco1. Exp. Ther. 241:84-90, 1987.

Thompson, K.A., Iansmith, D.H.S., Siddoway, L.A., Woosley, R.L., Roden, D.M.: Potent electrophysiologic effects of the major metabolites of propafenone in canine Purkinje fibers. J. Pharmacol. Exp. Ther. 244:950-955, 1988.

Toy, W., Sasyniuk, B.I.: Electrophysiological actions of mono-N-dealkyldisopyramide. Pharmacologist 30:A36 (abstr), 1988.

Toy, W., Sasyniuk, B.I.: Frequency and voltage dependent effects of mono-N-dealkyldisopyramide, the major metabolite of disopyramide, in canine ventricular tissue. J. Pharmacol. Exp. Ther., 1990a, in press. 
Toy, W., Sasyniuk, B.I.: Electrophysiological actions between disopyramide and its major metabolite, mono-N-dealkyldisopyramide, in canine ventricular tissue. Eur. J. Pharmacol. 83:1238 (abstr), 1990b.

Tseng, G., Robinson, R.B., Hoffman, B.F.: Passive properties and membran currents of canine ventricular myocytes. J. Gen. Physiol. $90: 671-701,1987$.

Tzivoni, D., Keren, A., Stern, S.: Torsades de pointes versus polymorphous ventricular tachycardia. Am. J. Cardiol. 52:639-640, 1983.

Tzivoni, D., Keren, A., Stern, S., Gottlied, S.: Disopyramide-induced torsade de pointes. Arch. Intern. Med. 141:946-947, 1981.

Valenzuela, C., Delpon, E., Tamargo, J.: Electrophysiologic interactions between mexiletine and propafenone in guinea pig papillary muscles. J. Cardiovasc. Pharmacol. 14:351-357, 1989.

Valenzuela, C., Sanchez-Chapula, J.: Electrophysiological interactions between mexiletine-quinidine and mexiletine-ropitoin in guinea pig papillary muscle. J. Cardiovasc. Pharmacol. 14:783-789, 1989.

Valois, M., Sasyniuk, B.I.: Modification of the frequency-and voltage-dependent effects of quinidine when administered in combination with tocainide in canine Purkinje fibers. Circ. 76:427-441, 1987.

Valois, M., Sasyniuk, B.I.: Chalacteristics of quinidine-induced triggered activity; and its modulation by type Ib antiarrhythmic drugs. 1990, submitted for publication.

Van Bogaert, P.P., Snyders, D.J.: Effects of 4-aminopyridine on inward rectifying and pacemaker currents of cardiac Purkinje fibers. Pflugers Arch. $394: 230-238,1982$. 
Vozeh, S., Oti-Amoako, K., Uematsu, T., Follath, F.: Antiarrhythimic activity of two quinidine metabolites in experimental reperfusion arrhythmia: relative potency and pharmacodynamic interaction with the parent drug. J. Pharmacol. Exp. Ther. 243:297-301, 1987.

Weld, F.M., Coromilas, J., Rottman, J.N., Bigger Jr., J.T.: Mechanisms of quinidine-induced depression of maximum upstroke velocity in ovine cardiac Purkinje fibers. Circ. Res. 50:369-376, 1982.

Whitford, E.G., McGovern, B., Schoenfeld, M.H., Garan, H., Newell, J.B., McElroy, M., Ruskin, J.N.: Long-term efficacy of mexiletine alone and in combination with class Ia antiarrhythmic drugs for refractory ventricular arrhythmias. Am. Heart J. 115:360-366, 1988.

Winslow, E., Campbe11, J.K., Marshal1, R.J.: Comparative electrophysiological effects of disopyramide and bepridil on rabbit atrial, papillary, and Purkinje tissue: modification by reduced extracellular potassium. J. Cardiovasc. Pharmacol. 8:1208-1216, 1986.

Wit, A.L., Rosen, M.R.: Afterdepolarizations and triggered activity. In The Heart and Cardiovascular System, ed. by H.A. Fozzard, E. Haber, R.B. Jennings, A.M. Katz, H.E. Morgan, Pp. 1449-1490. Raven Press, N.Y., 1986.

Yabek, S.M., Kato, R., Ikeda, N., Singh, B.N.: Effects of flecainide on the cellular electrophysiology of neonatal and adult cardiac fibers. Am. Heart J. 113:70-76, 1987. 